Portland State University

PDXScholar

\title{
On the Drought Recovery and Resiliency: How Terrestrial and Riverine Ecosystems Recover from Agricultural and Hydrological Droughts
}

Behzad Ahmadi

Portland State University

Follow this and additional works at: https://pdxscholar.library.pdx.edu/open_access_etds

Part of the Civil and Environmental Engineering Commons Let us know how access to this document benefits you.

Recommended Citation

Ahmadi, Behzad, "On the Drought Recovery and Resiliency: How Terrestrial and Riverine Ecosystems Recover from Agricultural and Hydrological Droughts" (2019). Dissertations and Theses. Paper 4834. https://doi.org/10.15760/etd.6710

This Dissertation is brought to you for free and open access. It has been accepted for inclusion in Dissertations and Theses by an authorized administrator of PDXScholar. Please contact us if we can make this document more accessible: pdxscholar@pdx.edu. 
On the Drought Recovery and Resiliency - How Terrestrial and Riverine Ecosystems Recover from Agricultural and Hydrological Droughts

by

Behzad Ahmadi

A dissertation submitted in partial fulfillment of the requirements for the degree of

Doctor of Philosophy

in

Civil and Environmental Engineering

Dissertation Committee:

Hamid Moradkhani, Chair

Scott Wells

Annette Dietz

Andres Holz

Portland State University

2019 


\begin{abstract}
Climate extremes, in particular droughts are significant driving forces towards riverine and terrestrial ecosystems disturbance. Drought impacts on stream ecosystems include losses that can either be direct (e.g. destruction of habitat for aquatic species) or indirect (e.g. deterioration of water quality, soil quality, and increased chance of wildfires). This study investigate hydrological and agricultural droughts and their recovery durations. For the riverine ecosystems, this study combines hydrologic drought and water quality changes during droughts and represents a multi-stage framework to detect and characterize hydrological droughts, while considering water quality parameters. Hydrological droughts are categorized into three stages of growth, persistence, retreat, and water quality variables (i.e., water temperature, dissolved oxygen concentration, and turbidity) are utilized to further investigate drought recovery. The framework is applied to 400 streamflow gauges across the Contiguous United States (CONUS) over the study period of 1950-2016. The framework is assessed and validated based on three drought events declared by the state of California in 2002, 2008, and for the 2012 US drought, which affected most of the nation. Results reveal the duration, frequency, and severity of historical droughts in various regions, additionally, duration of each stage of drought (i.e., growth, persistence, and retreat) is also assessed and the spatial patterns are diagnosed across the CONUS. Varied drought recovery durations are perceived for different water quality variables, and in general, it takes about two more months for water quality variables to recover from a drought, following the hydrological drought termination. For the terrestrial ecosystem, this study evaluated drought impacts on gross primary productivity (GPP), evapotranspiration (ET), and water use efficiency (WUE = GPP/ET)
\end{abstract}


of different terrestrial ecosystems over the CONUS, as well as the drought-recovery during the period of 2000 to 2014. The response of WUE to drought showed large differences in various regions and biomes. WUE for arid ecosystems typically showed a positive response (increase) to drought, whereas WUE for humid ecosystems showed both positive and negative response to drought. The results revealed that WUE is correlated with drought severity, and for more severe droughts, WUE changes more significantly. Furthermore, terrestrial drought recovery shows a positive correlation with drought severity and in regions that experienced more severe drought episodes, ecosystem requires longer period to recover. 


\section{Acknowledgements}

I would like to express my sincere gratitude to my advisor, Dr. Hamid Moradkhani for his support and patience throughout the years of my study at Portland State University. I am honored to have had the opportunity to be a student in his classes and a member of his research team for the past few years. I would like to also thank my dissertation committee members, Drs. Scott Wells, Annette Dietz, and Andres Holz for their willingness to serve on my committee and for their valuable comments and feedbacks on my research. Their comments and suggestions helped me significantly improve the quality and clarity of my research.

I should also thank all the post-doctoral associates and graduate students that I had the pleasure to work with in the Water Resources and Remote Sensing Lab, including Drs. Ali Ahmadalipour, Masoud Irannezhad, and Mahkameh Zarekarizi. Our collaborations expanded my knowledge and abilities, and provided me strong leadership and communication skills.

I am also thankful of the kind staff of the Department of Civil and Environmental Engineering, including Dr. Chris Monsere, Megan Falcone, Kiley Melicker, and Ariel Lewis, who were always great resources and helped me navigate my work in the department. Moreover, I must express my gratitude to the lovely staff of the International Student Life team at PSU, especially Jill Townley and Yoko Honda, who helped me adapt my life and overcome any cultural shocks.

Finally, I must express my deepest gratitude and appreciation to Sarah E. Dys (my wife) and family for their continuous and unconditional love, care, and support. Their 
encouragement motivated me to strive to achieve my dreams, and I could have not completed this work without their support and patience. 


\section{Table of Contents}

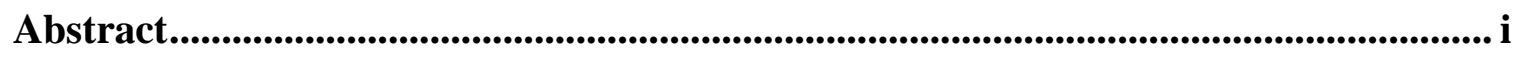

Acknowledgements ........................................................................................................ iii

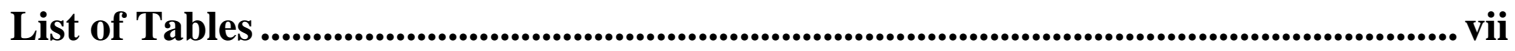

List of Figures.................................................................................................................... viii

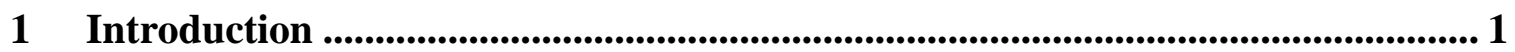

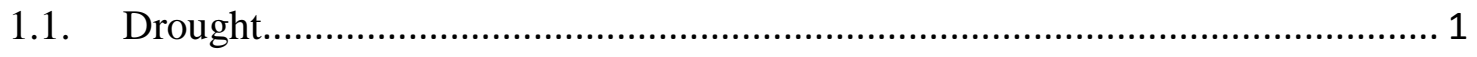

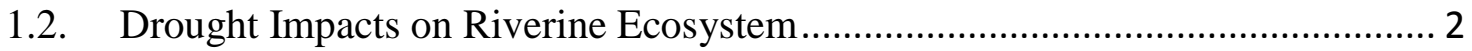

1.3. Drought Impacts on Terrestrial Ecosystems ............................................ 3

1.4. Objectives of Dissertation .................................................................... 5

2 Hydrological Droughts Considering Water Quality ................................................. 6

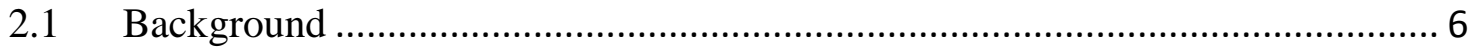

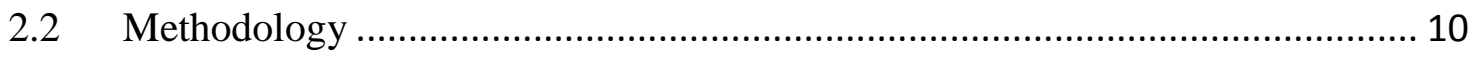

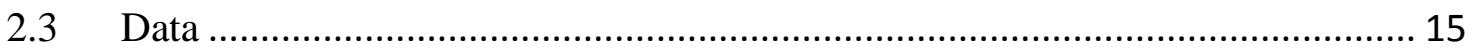

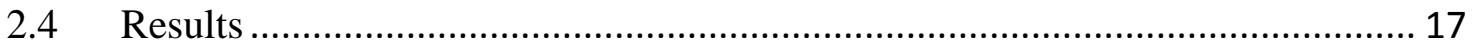

2.4.1 Verification of the hydrological drought detection framework: California

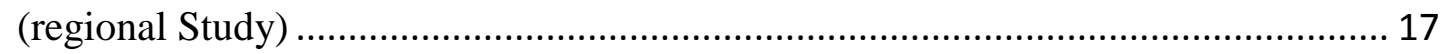

2.4.2 Verification of the hydrological drought detection framework: The 2012 US drought 24

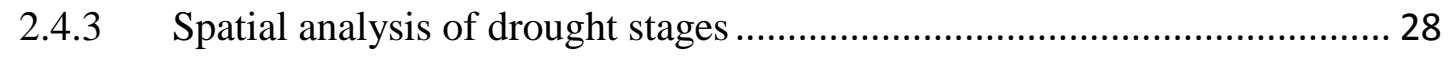

2.4.4 Drought impacts on water temperature ................................................ 32

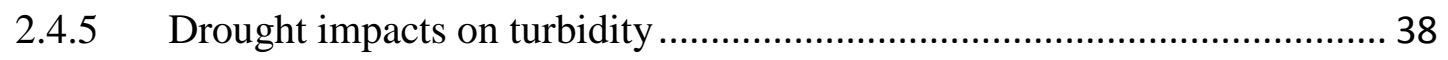

2.4.6 Drought impacts on dissolved oxygen ................................................. 39

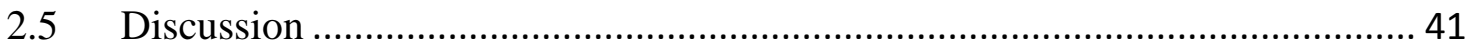




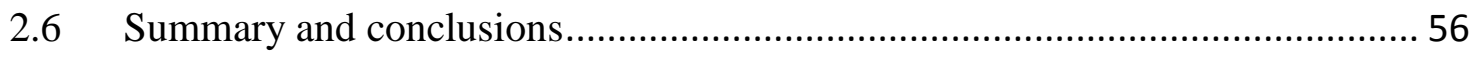

3 Agricultural droughts and terrestrial ecosystems recovery .............................. 58

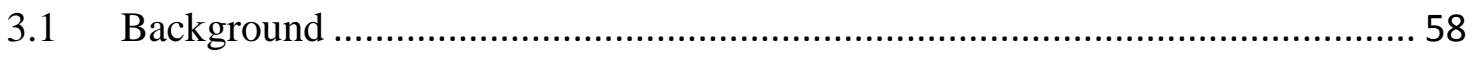

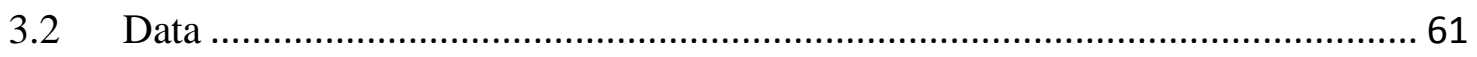

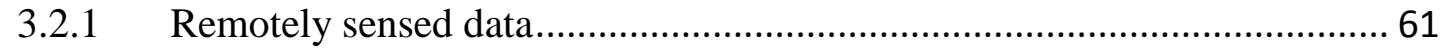

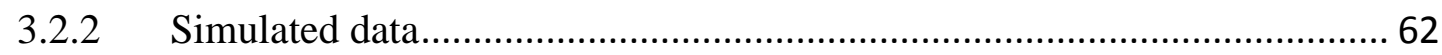

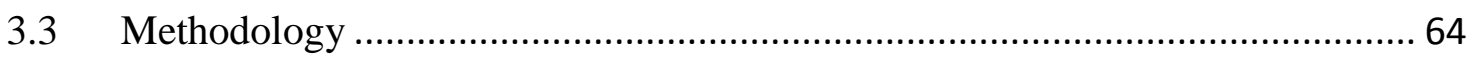

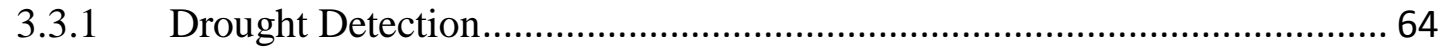

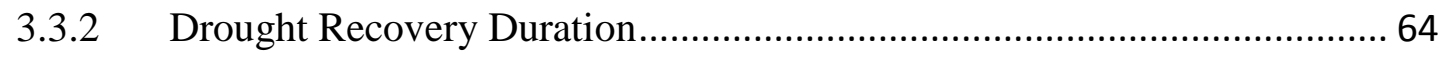

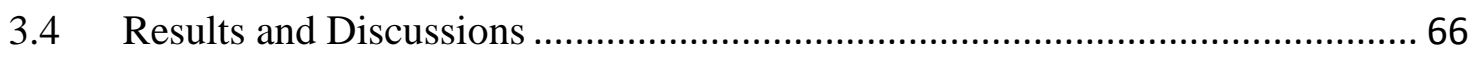

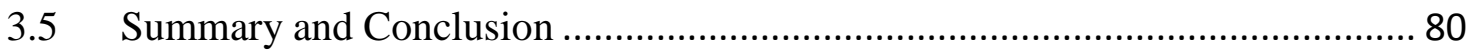

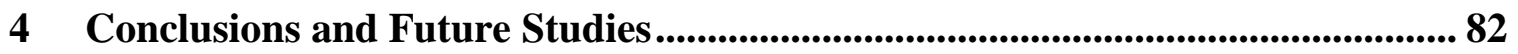

References.............................................................................................................................. 85 


\section{List of Tables}

Table 2-1 Minimum, median, and maximum deviation of water temperature, dissolved oxygen, and water turbidity during drought for each river basin.

Table 2-2 Minimum p-value for t-test and Kruskal-Wallis test water temperature, dissolved oxygen, and water turbidity during drought for each river basin.

Table 2-3 The lowest correlation coefficients between air and water temperature, and its

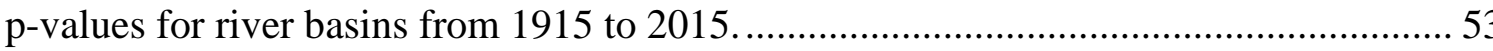

Table 2-4 the maximum p-values for t-test and Kruskal-Wallis tests between the mean and median of observed air temperature and normal condition during drought for each river basin.

Table 3-1 Summary of the data used in this study

Table 3-2 USDM drought categories employed in this study to categorize drought intensity 


\section{List of Figures}

Figure 2-1 The flowchart of drought analysis given water quantity and quality parameters. having determined streamflow threshold, drought stages are detected for each drought episode. The key water quality parameter thresholds are used to determine water quality recovery duration. 11

Figure 2-2 A conceptual diagram of drought growth, persistence, retreat, and recovery stages. In this study, persistence is when the flow remains below threshold for 30 days or more; moving backward/forward from persistence begin/end, drought onset/termination is when there is 15 or less days with flow below the threshold level in a $\mathrm{T}$-day window ( $\mathrm{T}$ $=60$ days for this study). The gray shaded area shows streamflow deficit.

Figure 2-3 Study area, river basin boundaries, and location of the selected streamflow/water quality stations. All the stations record streamflow observations, and the water quality variables are specified using three colors.

Figure 2-4 Chronology of drought stages and spatial distribution of drought recovery seasonality over California; a) 2002 hydrological drought, b) 2008 hydrological drought.

Figure 2-5 Chronology of drought stages during 1950-2010 for: a) northern California, b) southern California.

Figure 2-6 Chronology of drought stages for the 2012 drought over the affected US states. 
Figure 2-7 Spatial distribution of water temperature, dissolved oxygen and turbidity deviations from thresholds over the 2012 drought episode

Figure 2-8 Spatial distribution of number of drought (top) and average drought duration in days (bottom) during the historical period of 1950-2016.

Figure 2-9 Mean duration (in days) of a) drought growth; b) persistence; and c) recovery in the historical period of 1950-2016. 31

Figure 2-10 Drought impacts on water temperature, dissolved oxygen, and turbidity during three hydrological drought episodes occurred in South Carolina in 2009 (first row), Kansas in 2014 (middle row), and Oregon in 2012 (bottom row). The red bar shows drought duration (onset to termination) and the green bar indicates the required time for water quality to recover. 34

Figure 2-11 Spatial distribution of average time needed for; a) water temperature, b) dissolved oxygen, and c) turbidity to recover from drought after the hydrological drought termination (i.e. after the streamflow has reached normal conditions)

Figure 2-12 Relationship between drought duration and annual flow (left), recovery time and annual flow (middle), and drought duration and recovery time (right) over the Pacific Northwest (top), Arkansas (middle) and South Atlantic (bottom) river basins....

Figure 2-13 Spatial distribution of normalized drought severity over the CONUS during 1950-2016. Severity is defined as the ratio of accumulated streamflow deficit to streamflow in normal condition during drought episodes

Figure 2-14 The correlation coefficient between drought severity with water temperature, dissolved oxygen, and turbidity variations and over 18 river basins of the U.S 47

Figure 2-15 Cumulative probability distribution (CDF) of drought duration in Ohio, Missouri, and South Texas-Gulf coast basins, representing least, most, and mean drought duration among all US basins, respectively. 48 
Figure 2-16 Spatial distribution of average time needed for; a) water temperature, b) dissolved oxygen, and c) turbidity using t-test to investigate when the mean of water quality reverts to its pre-drought condition after the hydrological drought termination (i.e. after the streamflow has reached normal conditions).

Figure 2-17 Monthly increase in average water temperature in Missouri, red line and orange line show water temperature changes for A2 and B1 scenarios respectively (Van Vliet et al., 2013)

Figure 2-18 Observed air temperature vs normal condition for; a) South Carolina, b) Kansas, and c) Oregon, during 3 drought episodes. 55

Figure 3-1 The framework for analyzing terrestrial drought recovery considering Gross Primary Production (GPP), and assessing Water Use Efficiency (WUE) response to drought and decomposing the influential factors.

Figure 3-2 Spatial distribution of mean water use efficiency (WUE) over the CONUS for the study period (2000-2014).

Figure 3-3 Spatial distribution of land cover over the CONUS and the average WUE of each biome during 2000-2014. The lines indicate \pm 1 standard deviation for each case. . 68

Figure 3-4 Spatial distribution of drought severity (left) and drought recovery duration in months (right) for 2002, 2008, 2011, and 2012 drought episodes.

Figure 3-5 Spatial distribution of WUE anomalies during 2002, 2008, 2011, and 2012 drought episodes.

Figure 3-6 The relation between drought recovery time, drought duration, and drought intensity for 2002, 2008, 2011, and 2012 drought episodes over the study area 75

Figure 3-7 The distribution of WUE changes over each drought severities for 2002, 2008, 2011, and 2012 drought episodes over the study area. 
Figure 3-8 The distribution of relative anomaly of ET, GPP, and WUE for 2002, 2008, 2011, and 2012 drought episodes. In each plot, the blue curves on the axes show the distribution of the corresponding variable. .......................................................... 78

Figure 3-9 Spatial distribution of ET anomalies for 2002, 2008, 2011, and 2012 drought

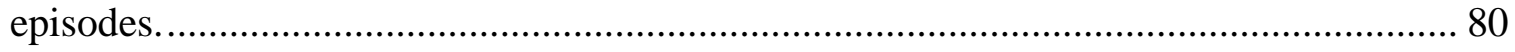




\section{Introduction}

\subsection{Drought}

Drought is a creeping phenomenon; as a result, the recognition of its onset and termination is complex. This complexity results in billions of dollars loss in the USA and over the world (Below et al., 2007; Madadgar and Moradkhani, 2013; 2016 Van Loon, 2015; Irannezhad et al., 2017; Hameed, et al., 2018). Droughts have also degraded riverine natural habitats as well as changes in flow regime and poor water quality (Lake, 2011; Mosley, 2015; Hellwig et al., 2017). Due to its non-structural damages, drought does not catch the spotlight of media until its impacts reach shocking level as it has been seen in many countries recently (Schwabe et al., 2013; Huang et al., 2017). Moreover, in many regions around the world, climate change, which is a consequence of increased greenhouse gas emission and global warming (Zeng et al., 2004; IPCC, 2007a; Zahn, 2009), will lead to an increase in drought occurrence and severity in the 21 st century (IPCC, 2007b; Stahl et al., 2012; Karamouz et al. 2012; Madadgar and Moradkhani, 2014; Ahmadalipour et al., 2017). Therefore, a systematic framework for drought onset and termination detection can not only provide a better understanding of drought propagation but also dampen its impacts (Karamouz et al., 2011; 2013; Yan et al., 2017).

There is no unanimous definition for the term "Drought" (Mishra and Singh, 2010; Van Loon and Van Lanen, 2012). However, drought as defined by the UN Convention to Combat Drought and Desertification (1994) is "the naturally occurring phenomenon that exist when precipitation has been significantly below normal recorded levels, causing serious hydrological imbalances that adversely affect land resource 
production system". Historically, drought has been viewed in terms of its agricultural, hydrological, and socioeconomic impacts. How drought affects ecosystems - and the services they provide human communities - is often not discussed. In response, the National Climate Adaptation Science Center (NCASC) is leading a national-scale initiative that's addressing this gap in drought research. A new concept - ecological drought - was needed to capture this emphasis on how drought impacts ecosystems. Ecological drought is: An episodic deficit in water availability that drives ecosystems beyond thresholds of vulnerability, impacts ecosystem services, and triggers feedbacks in natural and/or human systems (Crausbay et al., 2017).

\subsection{Drought Impacts on Riverine Ecosystem}

The fresh water quality is a function of streamflow, biogeochemical and anthropogenic influences. Mosley (2015) reviewed and integrated efforts that studied drought impacts on the water quality of freshwater system. Most of studies concluded on increasing water temperature during hydrological drought episodes (Baures et al., 2013; Hanslík, et al. 2016; Ha et al. 1999; van Vliet \& Zwolsman, 2008) while there are few studies observing no significant changes in water temperature (Mosley et al 2012; Wilbers et al. 2009). Higher water temperature intensifies biological activity, leading to more oxygen release. While, the solubility of gasses such as oxygen depends on temperature and theoretically, higher temperature causes less solubility of oxygen. Therefore, dissolved oxygen shows dual patterns of change during drought episodes. 
Although some studies found an increase in dissolved oxygen (Ha et al., 1999; van Vliet \& Zwolsman, 2008), some other studies found dissolved oxygen deterioration during drought events (Mulholland et al., 1997; Mimikou et al., 2000; Murdoch et al., 2000). There are studies which investigated turbidity changes during droughts and in most of them turbidity is reported to decrease (van Vliet \& Zwolsman, 2008; Hrdinka et al., 2012 and Mosley et al., 2012). In contrast, few studies showed increase in turbidity during drought (Anderson and Faust 1972 and Caruso 2002). These show that droughts have profound impact on water quality which depends on the characteristics of study area. Nonetheless, the duration of water quality recovery has not been assessed in previous studies. Specifically, the possible lag time existence between drought recoveries in terms of water quantity and quality has not been investigated.

\subsection{Drought Impacts on Terrestrial Ecosystems}

Streamflow, evapotranspiration (ET), and gross primary productivity (GPP), are the critical ecosystem functions (Xiao et al., 2008, 2010; Jung et al., 2010; Sun et al., 2011a, 2011b) that maintain stable and high quality water supply, carbon sequestration, climate regulation, and biodiversity conservation, which are ecosystem services. For example, over half of U.S. fresh water supply originates from forests and grasslands (Brown et al., 2008; Sun et al., 2015a, 2015b). It is estimated that forests and grasslands offset 10-40\% of annual carbon emissions from burning fossil fuels each year of the U.S. (Ryan et al., 2010; McKinley et al., 2011; Xiao et al., 2011). However, with a changing 
climate, the tightly coupled water and carbon cycles are changing from the leaf to global scales (IPCC, 2014). Consequently, there are concerns about the diminishing potential for forest ecosystem services under a changing environment (Zhao and Running, 2010). Therefore a sustain and resilient terrestrial ecosystem can ensure water availability and prevent environmental and economic losses.

Vegetation, wildlife, climate, soils and many other ecosystem features are affected by drought episodes globally. Some biotic and abiotic factors recover when the droughts are over, while, others never recover again. Soil moisture is the key for the breakdown of organic matter. Droughts lower the quality of soils, because there is less organic activity, more wind erosion, and soil insects or organisms perish. Water bodies (lakes, creeks, ponds, lagoon and lakes) dry out, and aquatic wildlife disappears, which is called habitat destruction. When aquatic animals (and other wild life) die, entire food chains and ecosystems are also affected. Desertification is when fertile lands (vegetation lands) become bare and infertile, often as a result of overgrazing, deforestation and other economic activity. Droughts make this process even worse and eliminate any chances of the land recovering. The health and quality of Freshwater Biomes such as lakes and ponds, rivers and streams, wetlands are affected and living organism in there are also endangered. Animals (wildlife) migrate long distances in search of water. Living in new habitats, makes them vulnerable and endangered, whiles others face new threats. 


\subsection{Objectives of Dissertation}

The objective of this dissertation is to assess the drought recovery in terrestrial and riverine ecosystems over the CONUS. Therefore, there are two components (drought detection and recovery analysis) for droughts in each ecosystems that should be studied separately. The primary objectives of the study can be categorized as follows:

1) Developing a framework for hydrological drought detection, and categorizing drought episodes into different stages of growth, persistence, and retreat.

2) Investigating water quality variations during hydrological drought episodes.

3) Analyzing drought recovery considering both water quality and quantity criteria.

4) Assessing spatiotemporal and probabilistic characteristics of hydrological drought including frequency, severity, and recovery duration.

5) Root-zone soil moisture percentile is utilized to characterize agricultural drought episodes, using land surface soil moisture simulations, across the CONUS.

6) The relationships between agricultural droughts and ecosystem WUE is examined using remotely sensed GPP and ET products.

7) The response of WUE and ET to drought are investigated across different regions.

8) Terrestrial drought recovery duration is assessed for various drought events with diverse intensities. 


\section{Hydrological Droughts Considering Water Quality \\ 2.1 Background}

Drought is among the most devastating natural disasters, which imposes severe impacts on various environmental and ecological aspects of the affected region (Van Loon and Van Lanen, 2012; Mishra et al., 2017). Despite its distinction as a climatic extreme event, there is no unanimous definition for drought because of its different types and distinct origins (Ahmadalipour and Moradkhani, 2017). Meteorological droughts start when precipitation drops below normal level and may lead to hydrological imbalances, which disturbs the normal environmental functioning of a region (Van Loon and Laaha, 2015; Heudorfer and Stahl, 2016). Crausbay, et al. (2017) defined ecological drought by combining drought impacts from ecologic, climatic, hydrologic, socioeconomic, and cultural aspects. In ecological drought, water deficit is defined such that it drives ecosystems beyond their threshold of vulnerability, influencing the ecosystem services and triggering feedbacks in natural and human systems.

Several studies have discussed that the severity and frequency of droughts have increased in many parts of the world as a consequence of the changes in rainfall and streamflow patterns, which may be associated with anthropogenic activities and climate change (Karamouz et al., 2012; Ahmadalipour et al., 2017a, 2017b). Thus, a systematic framework for detecting drought onset-termination can mitigate drought impacts (Karamouz et al., 2011; 2013; Yan et al., 2017).

Although it is necessary to understand drought recovery mechanism and duration, few studies have investigated these topics over large spatial domains. (Pan et al., 2013; 
DeChant and Moradkhani, 2014), while others elaborated on restoring function in plants (Martorell et al., 2014; Secchi et al., 2014). Schwalm et al. (2017) stated that recovery time is the duration that "an ecosystem requires to revert to its pre-drought condition". Ecological drought recovery was presumed to coincide with hydrological drought termination (Anderegg et al., 2015). In riverine ecosystems, water quality is an important ecological factor, which has been neglected in the majority of drought recovery assessments. Understanding drought recovery duration is essential; if a region experiences a new drought episode before complete recovery from an antecedent drought event, the ecosystem would experience more severe ecological impacts (Sawada and Koike, 2016). Categorizing a drought episode into different stages can shed light on drought propagation and provide a better understanding of drought recovery. There have been few attempts to utilize variable spatiotemporal thresholds for categorizing droughts into different stages (Bonsal et al., 2011; Parry et al., 2016a, 2016b; Ahmadi et al., 2019). Most of the assessments merely focused on water availability (quantity), while the recovery of water quality has not been investigated. More specifically, the possible lag time between drought recovery in terms of water quantity and quality has not been studied.

The fresh water quality is correlated to streamflow, biogeochemical, and anthropogenic influences. Several studies explored water quality variations during hydrological drought episodes at different spatial scales (Van Vliet and Zwolsman, 2008; Hrdinka et al., 2012; Hellwig et al., 2017). Mosley (2015) outlined three driving forces for water quality changes during a drought episode, explicitly, 1) hydrological drivers, dilution, and mass balance, 2) the role of increased temperature, and 3) increased 
residence times. Many studies concluded on increasing water temperature during hydrological drought episodes (Sprague, 2005; Baures et al., 2013; Hanslík, et al., 2016). Higher water temperature intensifies biological activity, leading to a higher rate of nutrient uptake and more oxygen release. Therefore, during drought or low flow condition, which causes higher water temperature and less nutrient inflow to water bodies (Hellwig et al., 2017; Mosley 2015), the likelihood of eutrophication increases. Recently, Sinha et al. (2017) showed that the precipitation changes induced by climate change will substantially increase the riverine total nitrogen loading across the U.S., which will exacerbate eutrophication, especially over the northeastern parts. The solubility of gasses, such as oxygen, depends on water temperature and theoretically, higher temperature causes less solubility of oxygen. Previous studies showed that in most cases when water temperature increases, dissolved oxygen decreases, indicating solubility is the dominant process for the concentration of dissolved oxygen (Mulholland et al., 1997; Mimikou et al., 2000; Murdoch et al., 2000). Additionally, decreased streamflow during hydrological drought episodes causes lower velocities and longer residence times (Mosley 2015). Therefore, sedimentation and higher interaction of groundwater and surface water lead to lower turbidity during drought episodes (Hrdinka et al., 2012; Mosley et al., 2012). Most of the above-mentioned analyses have been carried out at regional scales, and there have been just few attempts for investigating water quality changes during drought episodes over the CONUS.

There are two primary groups of drought identification methods, both of which require long time series of hydro-meteorological data. The first method is the probabilistic-based approach, which provides drought intensity according to the deviation 
from normal condition. Most of the standardized drought indices follow this approach, which have been employed in numerous studies (McKee et al., 1993; Vicente-Serrano et al., 2010; Irannezhad et al., 2017). The second drought identification method is the threshold-based approach: drought onset happens when the variable of interest falls below a predefined threshold (KO and Tarhule, 1994; Shiau and Shen, 2001; Wong et al., 2013). Moreover, there are two threshold level families: the constant (i.e., a constant percentile of annual long-term cumulative frequency distribution) and the variable threshold level. The variable threshold method is more appropriate when seasonal patterns should be taken into account, and is broadly used in recent studies (Sung and Chung, 2014; Van Loon and Laaha, 2015; Heudorfer and Stahl, 2016). Since the environmental functions are related to seasonal cycles, droughts are considered as deviations from seasonal cycles and the variable threshold method is implemented in this study.

This study integrates hydrological drought concepts and its environmental impacts, and represents a multi-stage framework to detect and characterize hydrological droughts considering water quality parameters. The overarching objectives of this study are to fill the following gaps, which have not been adequately addressed in previous assessments:

1) Developing a framework for hydrological drought detection, and categorizing drought episodes into different stages of growth, persistence, and retreat.

2) Investigating water quality variations during hydrological drought episodes. 
3) Analyzing drought recovery considering both water quality and quantity criteria.

4) Assessing spatiotemporal and probabilistic characteristics of hydrological drought including frequency, severity, and recovery duration.

\subsection{Methodology}

The approach taken in this study consists of three main processes as presented in Figure 2-1. Before the drought detection process, it is necessary to determine the daily variable threshold level. In order to calculate this, daily quantiles are computed for the flow duration curve over the entire observation period. Since the low flow regime of a catchment is captured by the variable threshold level, daily quantile based on the long time series is considered as the optimum value, that is, every day during a year has a different threshold level (Sung and Chung, 2014). Therefore, 365 flow duration curves are developed to determine 365 threshold levels. Basically, the threshold selection is affected by the objectives of a study, characteristics of the region, and data availability. Kjeldsen et al. (2000) suggested the range of $70^{\text {th }}-95^{\text {th }}$ percentile for the threshold level. In this study, the $80^{\text {th }}$ percentile is considered as the threshold level and the time series of the daily thresholds are generated. Understandably, the resulted time series is a jagged curve showing many short period deficits which are not considered as drought events. Therefore, a centered moving average of 30 days is employed as a smoothing technique to prevent this problem (Beyene et al., 2014): 


$$
\begin{gathered}
\text { Flow }_{\text {Quant }}(i)=\text { Quantile }\left(\text { Flow }_{i, j}\right) \\
\operatorname{Thr}_{\text {Flow }}(i)=\text { average }_{\text {Flow } \left._{\text {Quant }}(i-14): \text { Flow }_{\text {Quant }}(i+15)\right]}
\end{gathered}
$$

Where Flow ${ }_{\text {Quant }}(\mathrm{i})$ is the daily quantile of day $i$ of the calendar year, Flow $\mathrm{i}_{\mathrm{j}, \mathrm{j}}$ is the observed flow of day $i$ and year $j$, and $\operatorname{Thr}_{\text {Flow }}(i)$ is the threshold level of day $i$ of the calendar year.

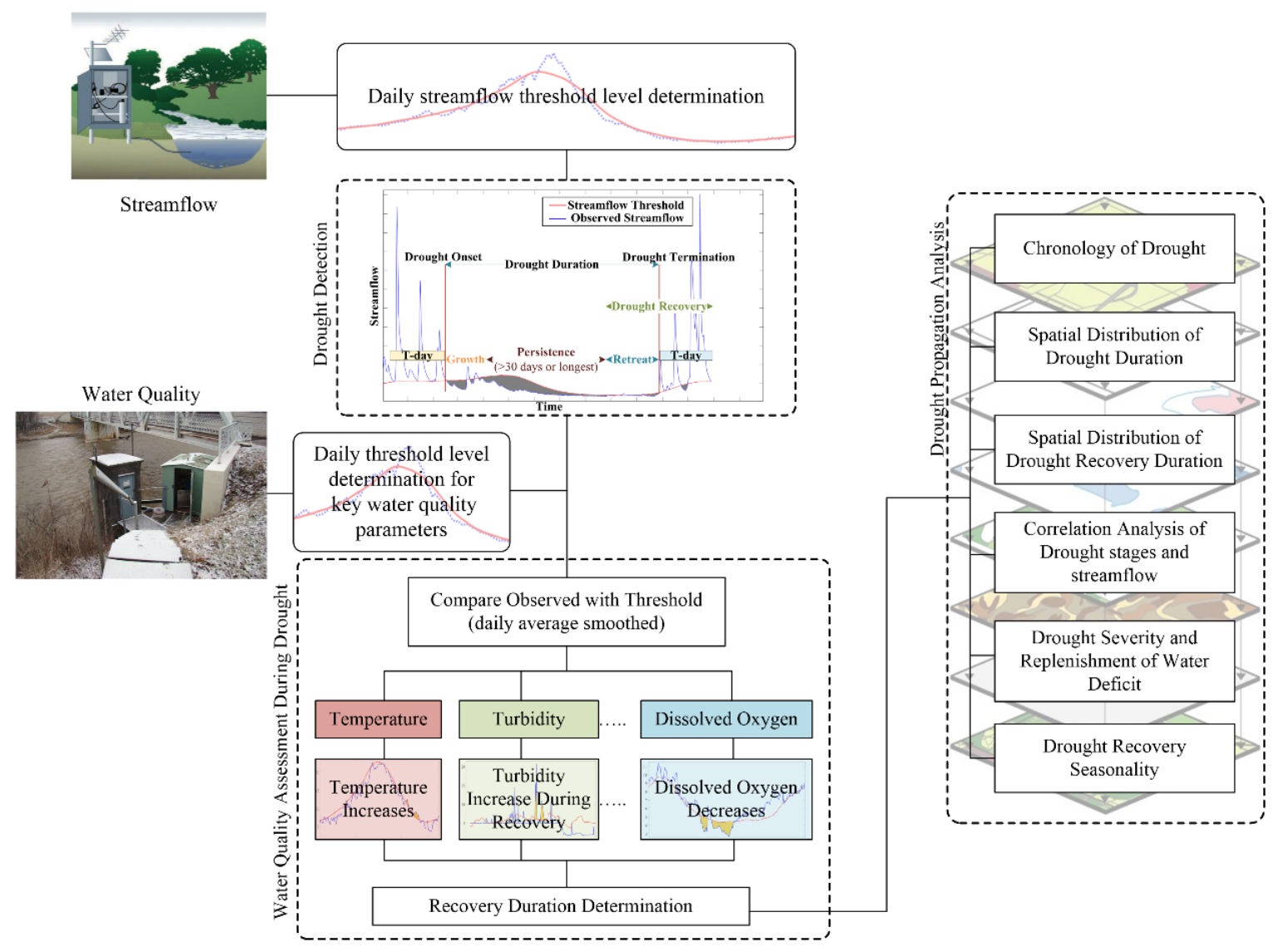

Figure 2-1 The flowchart of drought analysis given water quantity and quality parameters. having determined streamflow threshold, drought stages are detected for each drought episode. The key water quality parameter thresholds are used to determine water quality recovery duration. 
Applying the observed flow and threshold level for drought detection may result in a sequence of drought events that in many cases are not separated (Tallaksen et al., 1997; Van Loon and Laaha, 2015). This led us to develop a method to unify these discrete events (see the drought detection box in Figure 2-1). The drought persistence period is the main criterion for hydrological drought assessment. Having identified drought persistence, drought growth and retreat can then be investigated. The following steps explain each hydrological drought stage (see Figure 2-2):

- Persistence: the period that streamflow remains below the normal threshold level for at least 30 consecutive days. If there are more than one period fulfilling this condition during a drought episode, the longest period is considered as the drought persistence stage.

- Growth: moving backwards from the beginning of drought persistence, drought onset is the point when streamflow falls below the threshold level for less than 15 days in a T-day window (explained in the drought recovery section). Drought growth stage starts from drought onset until the beginning of drought persistence.

- Retreat: moving forward from the end of drought persistence stage, drought termination is the time when streamflow falls below the threshold level for less than 15 days in a T-day window (explained in the drought recovery section). Drought retreat stage starts following the end of drought persistence until drought termination. 


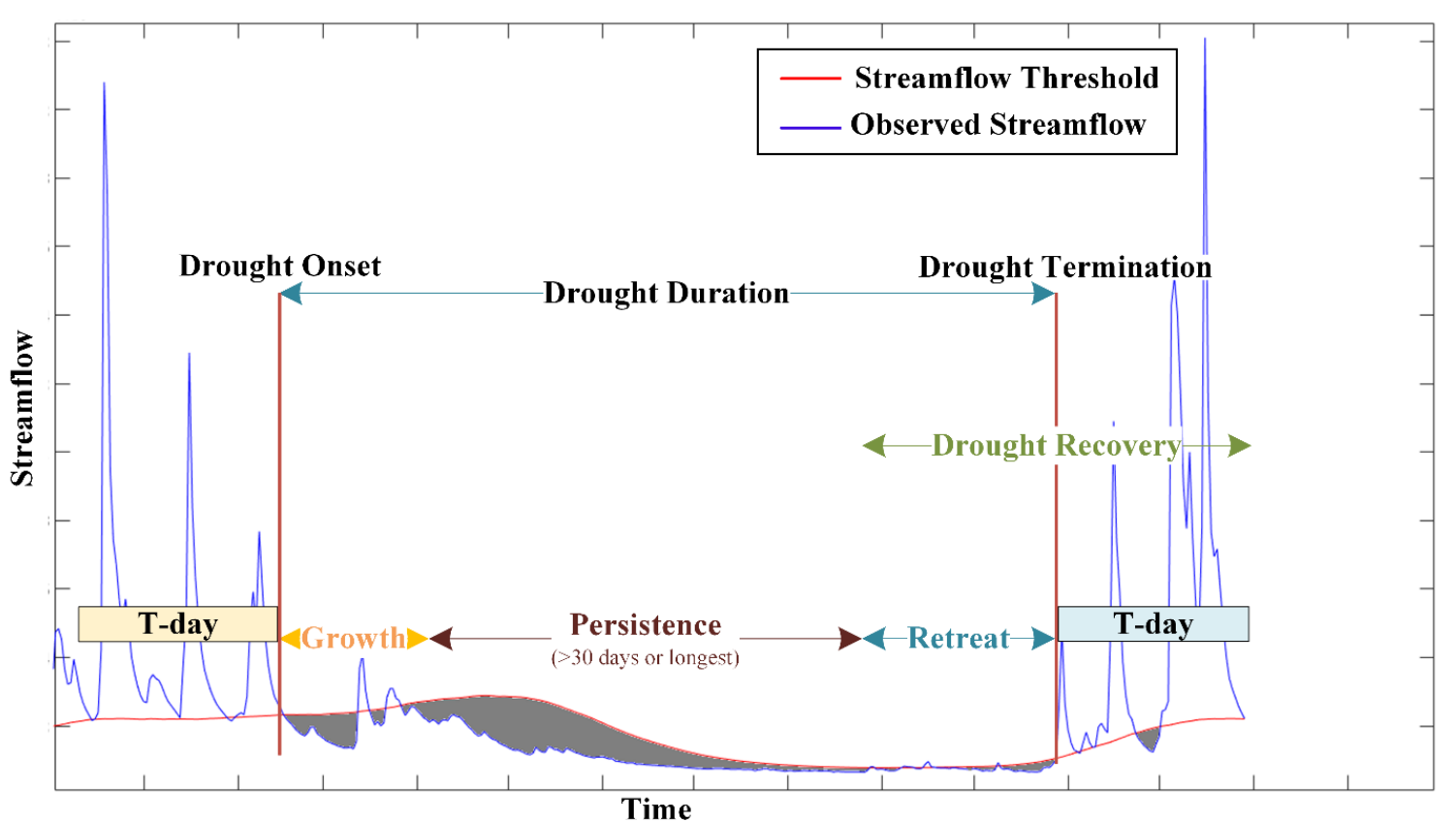

Figure 2-2 A conceptual diagram of drought growth, persistence, retreat, and recovery stages. In this study, persistence is when the flow remains below threshold for 30 days or more; moving backward/forward from persistence begin/end, drought onset/termination is when there is 15 or less days with flow below the threshold level in a T-day window ( $\mathrm{T}$ $=60$ days for this study). The gray shaded area shows streamflow deficit.

Drought recovery can be viewed from different angles as it involves several factors and may last long until a region recovers completely (hydrologically and ecologically). Thus, in this study, drought recovery is considered as a phase starting within the drought period and it continues after drought termination. Based on our definition, drought recovery starts from the beginning of the retreat and continues until $\mathrm{T}$ days after drought termination. Even if streamflow reaches its desired threshold, the T days after drought termination is added to drought retreat as drought recovery, because the basin needs more time to replenish flow deficit (Mo, 2011; Parry et al. 2016a) and meet normal water quality condition (Mosley, 2015). As a result, $\mathrm{T}$ days is defined as an 
average time that each water quality parameter requires to return to its normal condition. Water quality is assumed recovered, when there is no significant difference between the median of variable of interest and its threshold (combining methods by Caruso, 2001; 2002; van Vliet \& Zwolsman, 2008). The Kruskal-Wallis test (Kruskal and Wallis, 1952), as a nonparametric method, is employed at 0.05 significance level in order to investigate such difference. The normal condition (threshold) is defined as long-term daily average of each water quality parameter when there is no drought (within the interquartile range in this period), which is smoothed by thirty-day moving average.

$$
\begin{aligned}
& \operatorname{Qual}_{a v g}(i)=\frac{\sum_{j=1}^{n} Q_{u a l}, j}{n} \\
& \left.\operatorname{Thr}_{\text {Qual }}(i)=\operatorname{average}_{\text {Qual }}^{\text {avg }}(i-14): \text { Qual }_{\text {avg }}(i+15)\right]
\end{aligned}
$$

Where Qualavg (i) is the daily average of each water quality parameter on day i, Qual $_{i, j}$ is the observed water quality parameter of day $i$ and year $\mathrm{j}, \mathrm{n}$ is the number of years with available data and $\mathrm{Thr}_{\mathrm{Qual}}$ (i) is the normal condition of day $\mathrm{i}$ of the calendar year.

The final step is drought propagation analysis. The drought propagation analysis is carried out on the detected droughts to demonstrate the chronology of drought stages. Then, the average drought duration and average drought recovery duration are analyzed spatially.

In this study we also seek to assess the flow deficit, which is replenished during the recovery period: 


$$
\begin{aligned}
& \text { flow deficit }=\sum_{i=\text { onset }}^{\text {Termination }}\left[\text { Observed Flow }_{i}-\text { Threshold }_{i}\right], \text { when Observed Flow } \\
& \\
&<\text { Threshold }_{i}
\end{aligned}
$$$$
\text { Target threshold }=\sum_{i=\text { onset }}^{\text {Termination }}\left[\text { Threshold }_{i}\right]
$$

Flow deficit is also shown in Figure 2-2 as shaded area between observed streamflow and threshold curves. Having calculated flow deficit, drought severity can be calculated by dividing flow deficit for each drought episode by target threshold for a given drought duration (Sung and Chung, 2014).

\subsection{Data}

The Contiguous United States (CONUS) is selected as the study area because of its widely variable climate, which leads to the existence of perennial and ephemeral rivers in different regions. There are eighteen river basins across the CONUS, which are delineated based on the USGS 2-digit hydrologic unit codes (excluding Alaska, Hawaii, and Caribbean) as shown in Figure 2-3. Hydrologic Units (HU) are areas of land from which surface water drains to a particular point. Among all the streamflow stations across the CONUS, a small fraction of them monitor water quality parameters. We considered all the stations operated by USGS over the CONUS and selected the ones that meet our criteria. The criteria for selecting stations are as follows: 
1- Streamflow data availability for at least 30 consecutive years during the study period (1950-2016);

2- Recording at least one water quality parameter with 5 consecutive years of observed data and total duration of 10 years; and

3- Being least affected by anthropogenic influences (i.e., dams, abstraction and return flows)

Assessing all stations for the above criteria, we included all the active stations with over 30 years of streamflow observation that collects at least one of the water quality parameters. Therefore, 400 USGS (the US Geological Survey) stations were selected considering the study period (1950-2016), recording at least one water quality parameter, and being least affected by anthropogenic influences (such as dams, abstractions, and return flows from irrigation systems and power plants). Water temperature, dissolved oxygen, and turbidity are assessed as vital water quality parameters (SWAMP, 2010), and rest of the water quality parameters are neglected due to their short record or poor spatial coverage. Missing data for streamflow and water quality parameters are estimated by the USGS therefore significant gaps of observed data are filled. Figure 2-3 shows the location of the 400 selected stations, all of which measure water temperature; whereas some stations do not record either dissolved oxygen or water turbidity. 


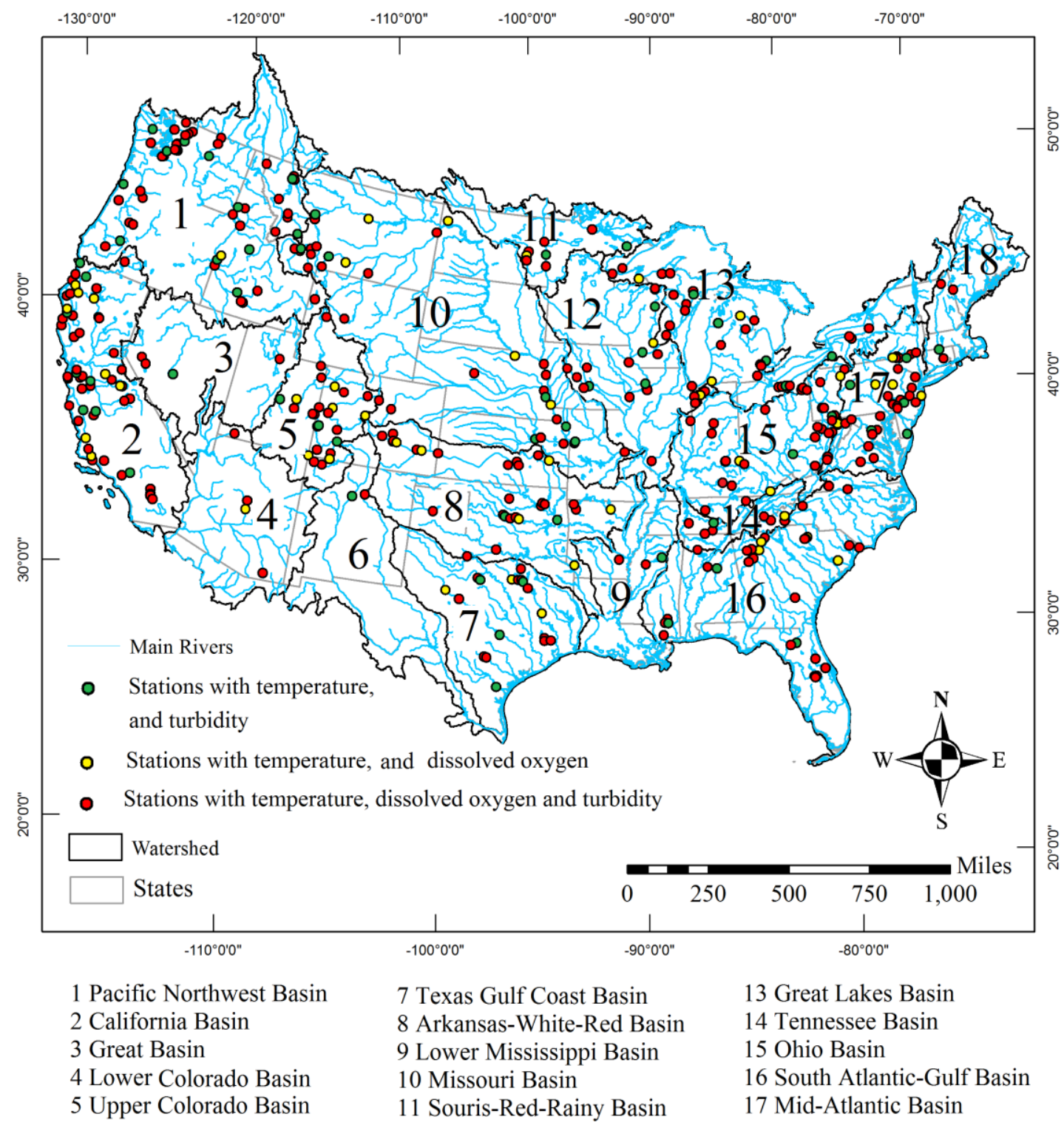

Figure 2-3 Study area, river basin boundaries, and location of the selected streamflow/water quality stations. All the stations record streamflow observations, and the water quality variables are specified using three colors.

\subsection{Results}

\subsubsection{Verification of the hydrological drought detection framework: California (regional Study)}


California was selected as the study area given its widely variable climate, which leads to the existence of perennial and ephemeral rivers in different regions. Stations that are located in California, cover all watersheds located in California.

To verify the results of the drought detection method elaborated above, we utilize the California state climate reports published by the National Oceanic and Atmospheric Administration (NOAA) for the study period of 1999-2017 and the US Drought Monitor (USDM) for the study period of 2000-2017. Based on NOAA reports, two meteorological dry periods from June 2001 to May 2002 and January 2008 to January 2009 were declared affecting the entire US and southern US respectively. There is usually a time lag between meteorological drought and hydrological response, which can last on average between one to four (or even longer) months depending on hydrological conditions and drought severity (Lorenzo-Lacruz et al., 2013; Haslinger et al., 2014; Wu et al., 2016). To provide additional supporting evidence, the USDM reports are also compared with this study results for 2002 and 2008 drought episodes. USDM (Svoboda et al., 2012) shows that a drought episode started in California in late March 2002 and was terminated in February 2003 with severe to extreme drought severity. Additionally, USDM identified the onset of a drought episode in April 2008, which grew from moderate severity to severe and extreme, then retreated to moderate and abnormally dry conditions in November 2008. The drought episode exacerbated to severe in early 2009 in southern California, and finally terminated by the end of 2009. The results of our analysis also show that onset of two hydrological droughts could be detected all over California in 2001 (Nov-Dec) and 2008 (Mar-Apr), with durations of 5 months (range 4-7 months) and 8 months (range 4-20 months), respectively. The onset, termination and duration of each 
drought stage for these drought episodes are shown in Figure 4. This figure clearly shows that in northern California, the onset and termination of drought follow the same pattern for all stations and all drought stages happen almost simultaneously in every station. The map for 2002 drought shows that in almost all watersheds located in northern California, except two, the drought recovery started in fall and finished in winter. However, in southern California there is not such a clear pattern. While the 2002 northern California recovery pattern repeated in 2008 (watersheds recovered in fall), significant differences are observed for the watersheds located in southern California. Considering the 2008 drought, most coastal watersheds located in southern California, start to recover in summer lasting one to three seasons, while most inland watersheds located in southern California tend to start recovering in summer and fall (with one exception that started in spring). 

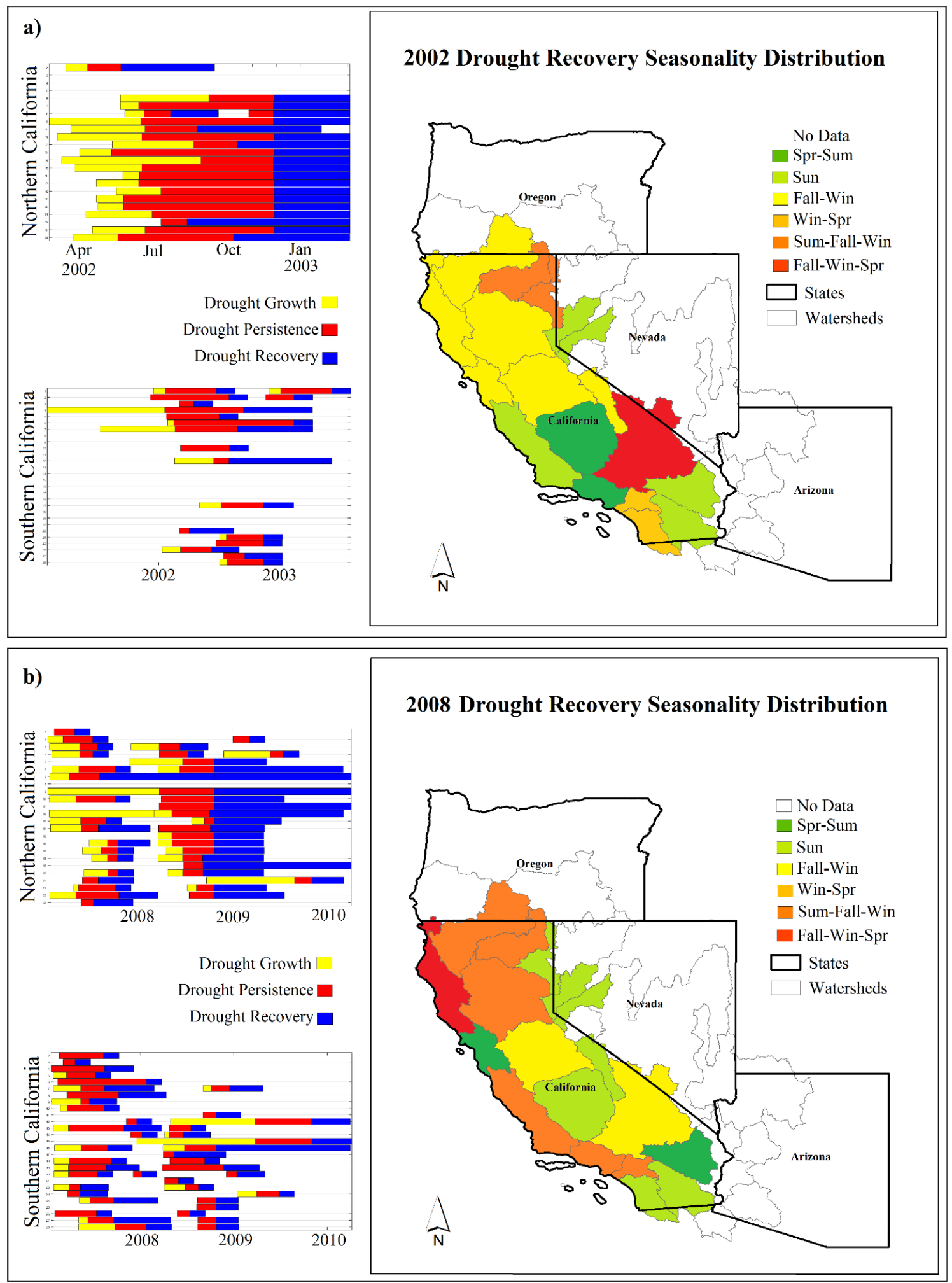

Figure 2-4 Chronology of drought stages and spatial distribution of drought recovery seasonality over California; a) 2002 hydrological drought, b) 2008 hydrological drought. 
In Figure 2-5, the three defined stages of hydrological drought in the period of 1950 to 2010 are shown for all the stations located in California. Yellow, red, and blue boxes show the growth, persistence, and recovery periods, respectively. Figure 2-5-b clearly displays that southern stations do not follow a specific pattern as there are large differences among the characteristics of southern watersheds, thereby drought growth/recovery show different durations in some drought episodes. Additionally, there are more ephemeral rivers in southern California. Therefore, in dry seasons (months with no flow), longer periods of drought growth/recovery are observed for those rivers, whereas the opposite is valid for northern California, where all the stations demonstrate a meaningful pattern (Figure 2-5-a). The onset of major drought episodes in northern California happened at almost the same time, which was also the case for drought termination in the region (specifically from 1970 to 2010). In addition, Figure 2-5 reveals that California did not experience any major hydrological drought, for the period of 1995 to 2000. However, the state experienced drought more frequently in the periods of 1987 to1995 and 2001 to 2005.

In addition, validation of the proposed method and chronology of detected droughts are carried out by comparing the results with declared drought episodes in previous studies. A study by Lund and Madeline-Azuara (2015) discussed that a severe drought occurred in 1976-77 when the state government was not prepared, leading to operational changes including urban water conservation in the Bay Area. Our result confirms that in the 1976-1978 period, California experienced a hydrological drought that is in agreement with the above study. The present study captured several consecutive hydrologic droughts from 1986 to 1993, across California with very small time gap 
between the events. This is also in agreement with findings of Brumbaugh et al. (1994) and Israel and Lund (1995). These drought events (1986-1993) were devastating not only for the state to supply urban water demand, but also for the native fish species. This led the state to trade water from agriculture sector to fulfill the urban demands and consequently, put the native fish on the list of threatened or endangered species. A significant rise in water temperature was the main reason of ecological impacts for these drought events, bringing up the necessity of fundamental changes in reservoirs operation. 

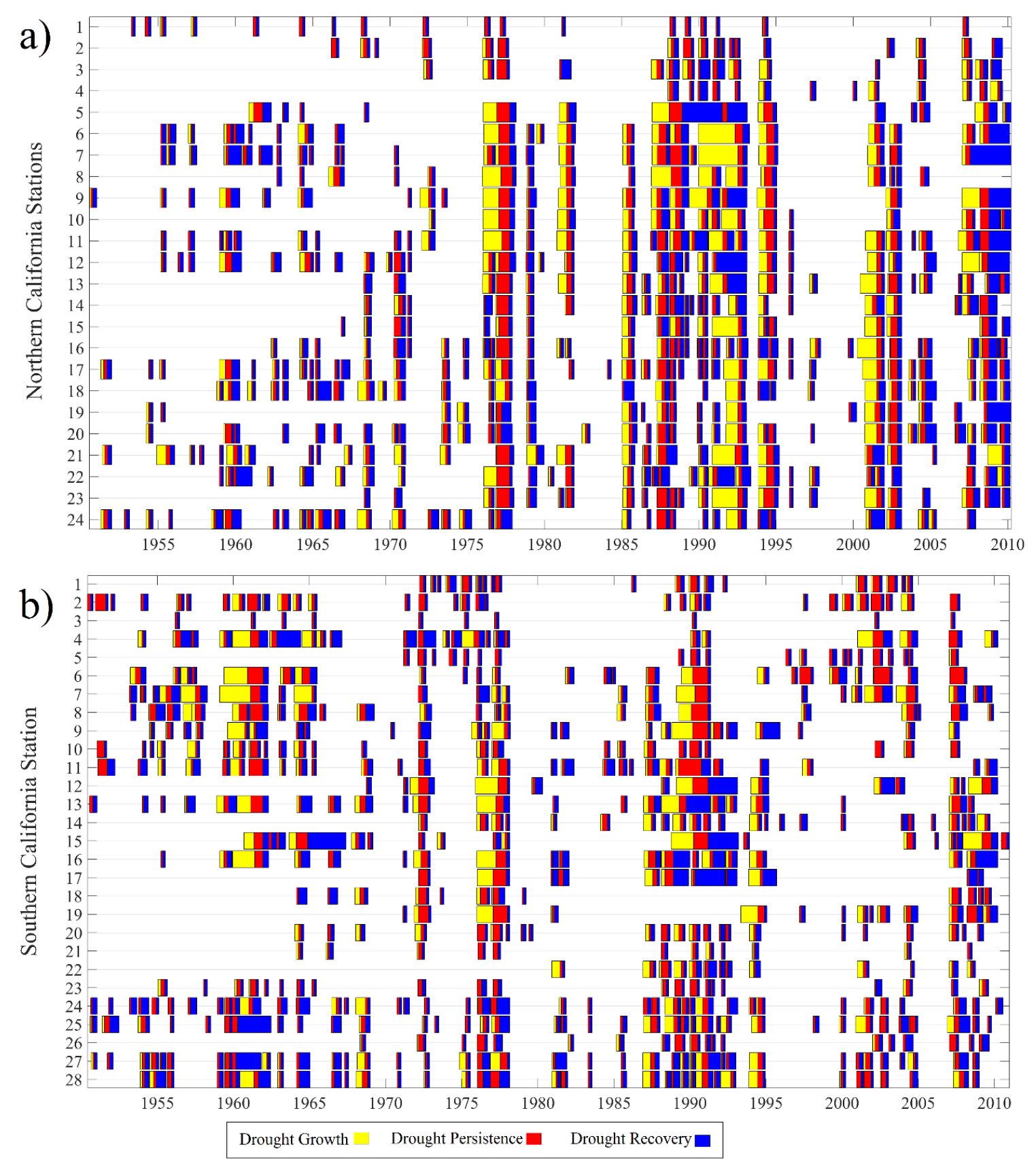

Figure 2-5 Chronology of drought stages during 1950-2010 for: a) northern California, b) southern California. 


\subsubsection{Verification of the hydrological drought detection framework: The 2012 US drought}

The drought detection method applied in this study is verified for the historic drought event (Rippey, 2015; Ahmadi and Moradkhani, 2019). An unusually dry winter in 2011-2012 coincided with warm and dry spring and summer, and affected most parts of the CONUS. It led to catastrophic drought impacts over the affected states and caused \$40 billion damage, mostly due to agricultural losses (Rippey, 2015). Nearly two-thirds of the nation dealt with drought on September 2012 according to the US Drought Monitor (USDM). The USDM (Svoboda et al., 2012), detected a severe to extreme drought episode affecting all over the CONUS with higher persistence duration in south and Midwest. The results of our analysis also detect a hydrological drought event in 38 states, with a duration of 11 months on average (ranging from 4 to 15 months). The onset, termination, and duration of the 2012 US drought are shown in Figure 2-6 for each of the affected states. Figure 2-6 shows that in Midwestern and Southeastern states, the 2012 drought tended to persist longer and drought recovery took more time for these regions, while drought recovery in the Pacific Northwest took shorter time.

In this study, drought growth is defined as the period that the hydrological variable (e.g., streamflow) falls below threshold for at least 15 days in 60 days. Drought persistence is the period that streamflow remains below the threshold for over 30 consecutive days. In other words, drought growth focuses on capturing the onset of a drought and its initial stages, whereas drought persistence is the period that drought intensifies and lasts until amelioration and then proceeds to the recovery stage. Therefore, 
the persistence period of drought is generally longer than the growth stage. For example, in the 2012 US drought, prolonged period of high air temperature in late spring resulted in soaring atmospheric evaporative demand in central US that quickly translated to severe and extreme drought conditions, drying the soil moisture and substantially reducing the streamflow, especially in central US (Hobbins et al., 2016; Otkin et al., 2017a). Therefore, for the 2012 drought the growth stage was very short, making its detection very challenging and subsequently causing considerable impacts (McEvoy et al., 2016; Yan et al., 2017).

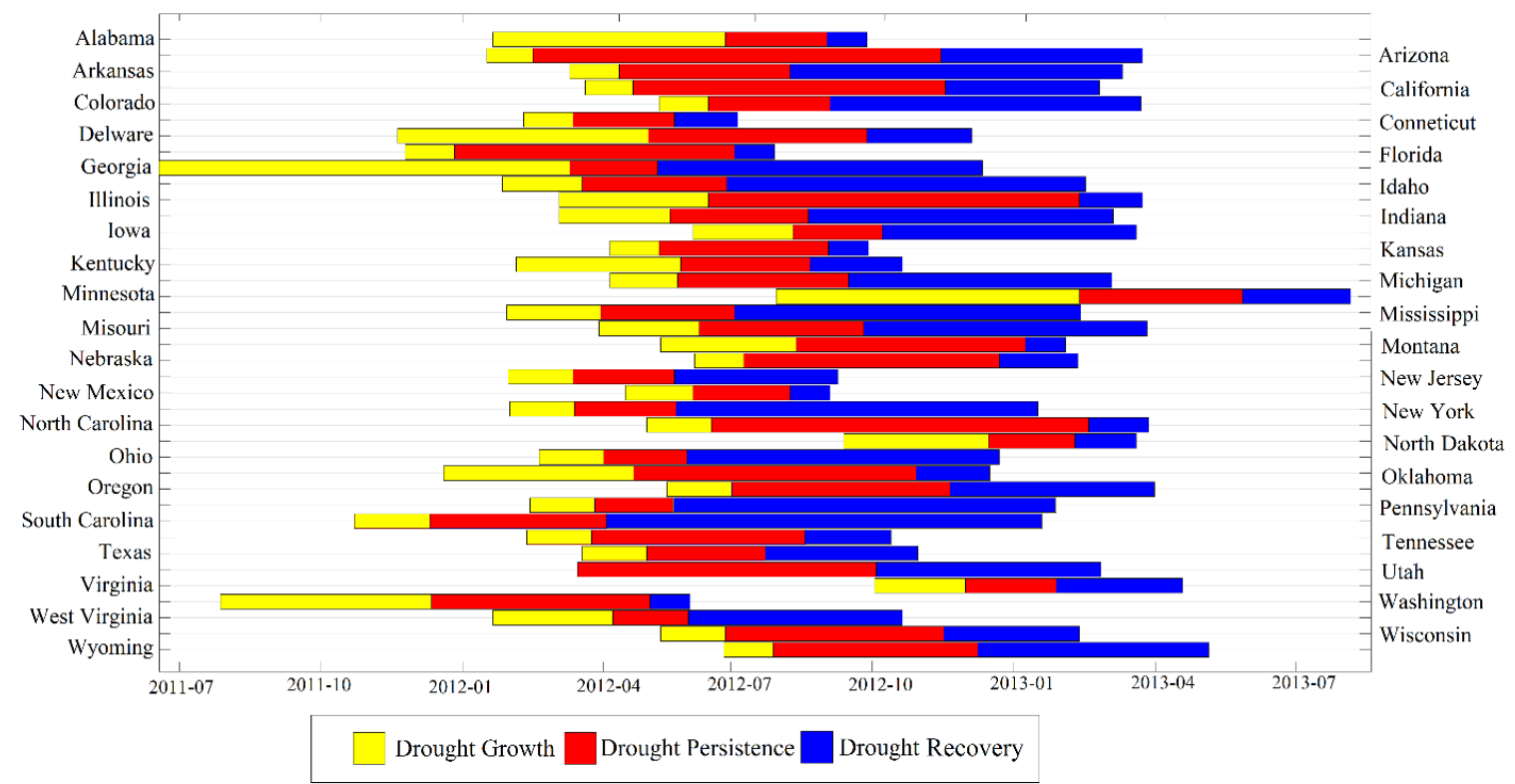

Figure 2-6 Chronology of drought stages for the 2012 drought over the affected US states.

A thorough examination of water quality changes over this drought episode is executed. Water temperature shows the maximum deviation from threshold occurred in 
the river basins that are located in lower latitude (see Figure 2-7). Additionally, Figure 26 reveals that in the sates that are located in lower latitudes, drought persistence tends to be longer. Dissolved oxygen shows the same pattern where California, Arizona, Texas and South Carolina experienced the most deviation from the normal condition with relatively longer persistence. On the other hand, turbidity tends to deviate most for this drought episode in mountainous areas that are located in dry climate. Southeast US and generally the areas located on east coast show the least deviation of turbidity compared to other regions. 

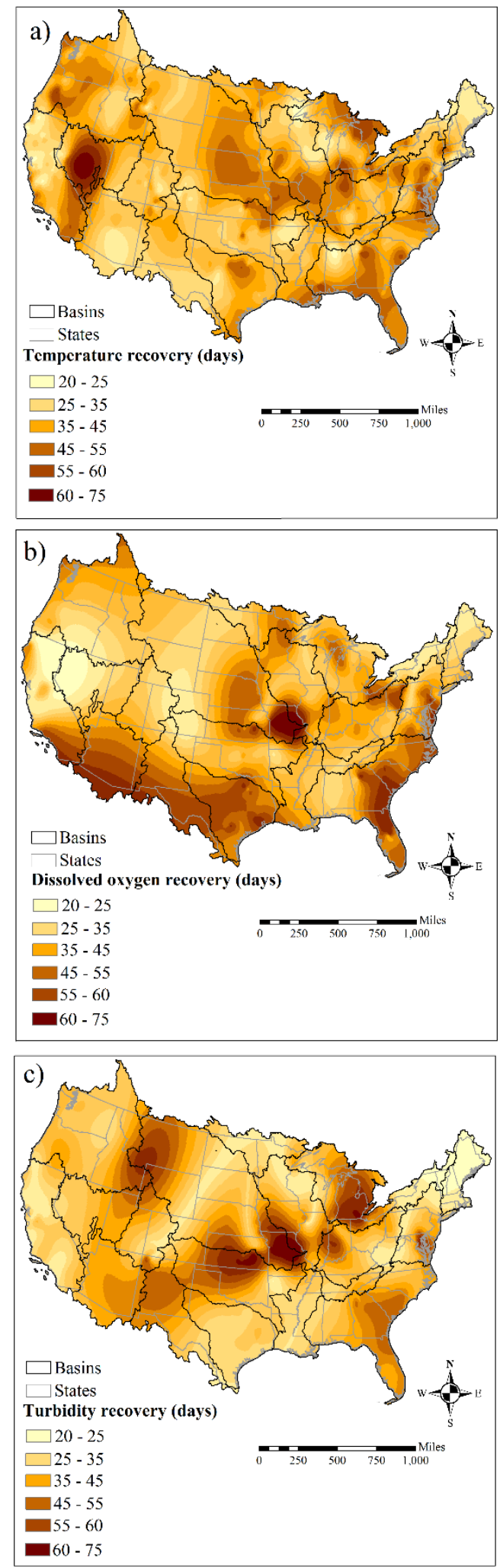

Figure 2-7 Spatial distribution of water temperature, dissolved oxygen and turbidity deviations from thresholds over the 2012 drought episode 


\subsubsection{Spatial analysis of drought stages}

Figure 2-8 (top) shows the number of hydrological drought episodes over the CONUS during the study period (1950-2016). It is worth mentioning that, in order to keep the maps easier to follow, all the presented results are interpolated using inverse distance weighted interpolation method. The figure reveals that generally, the Pacific Northwest, Mid-Atlantic, and Great lakes basins experienced droughts more frequently than other basins. The Upper Colorado and Ohio River basins also experienced relatively frequent drought episodes. In general, Western US indicates a tendency towards more frequent hydrological drought events. Another drought characteristic investigated in the figure is drought duration. Figure 2-8 (bottom) shows the average duration of drought over the CONUS. Texas, South Atlantic and Missouri show longer drought duration compared to other regions. Comparing drought frequency and drought duration, the regions with more frequent droughts tend to have shorter drought episodes. 

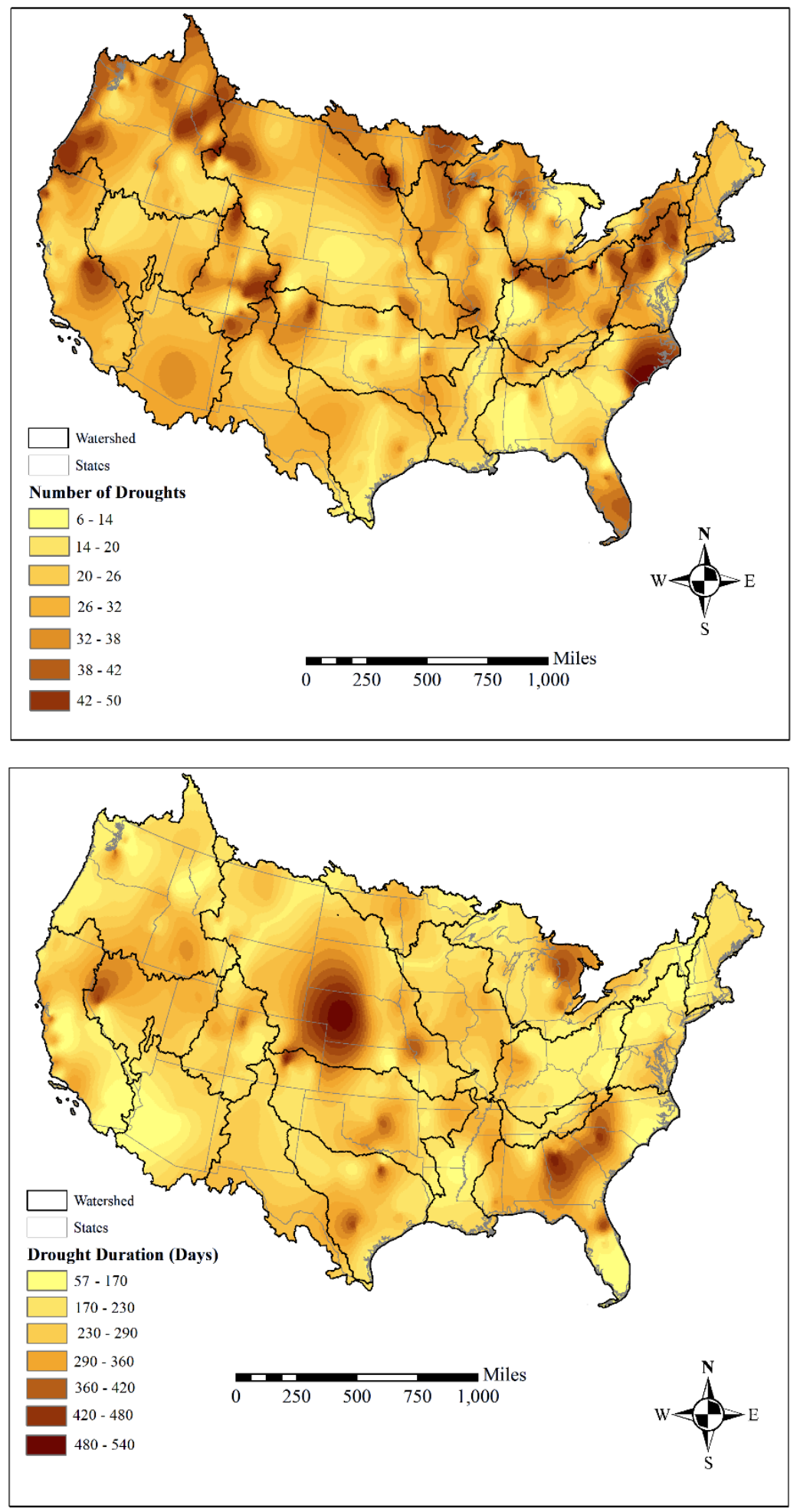

Figure 2-8 Spatial distribution of number of drought (top) and average drought duration in days (bottom) during the historical period of 1950-2016. 
Besides the total duration of drought (shown in Figure 2-8), the duration of each stage of drought is also assessed. Figure 2-9 illustrates the duration of drought growth, persistence, and recovery across the CONUS for the study period. Figure 2-9a shows the average duration of drought growth (days). As seen in this figure, the South Atlantic, Texas gulf, and Missouri basins indicate longer drought growth duration compared to other regions. Generally, prolonged drought growth periods cause drought identification complex, since the streamflow deviation is not significant and it usually does not get attention until it reaches the persistence period. Another parameter presented in the figure is duration of drought persistence (Figure 2-9b). The figure illustrates that drought, on average, persists less than 2 months in most of the Eastern US. Whereas in California, Upper Colorado, Texas, and Souris-Red-Rainy basins, droughts tend to persist more than three months. Lastly, mean drought recovery duration is presented in Figure 2-9c. It can be seen that there are regions located in South Atlantic, mid-Atlantic, Texas, and Arkansas River basins with average drought recovery duration of 6 months. Whereas, California, Pacific Northwest, Great lakes, and Ohio River basins tend to recover from drought in less than 4 months. Comparing the average duration of drought stages (Figure 2-9a, b, and c) discloses that drought recovery takes longer time than drought growth and persistence. Moreover, the regions corresponding to longer drought growth require more time for drought recovery. 

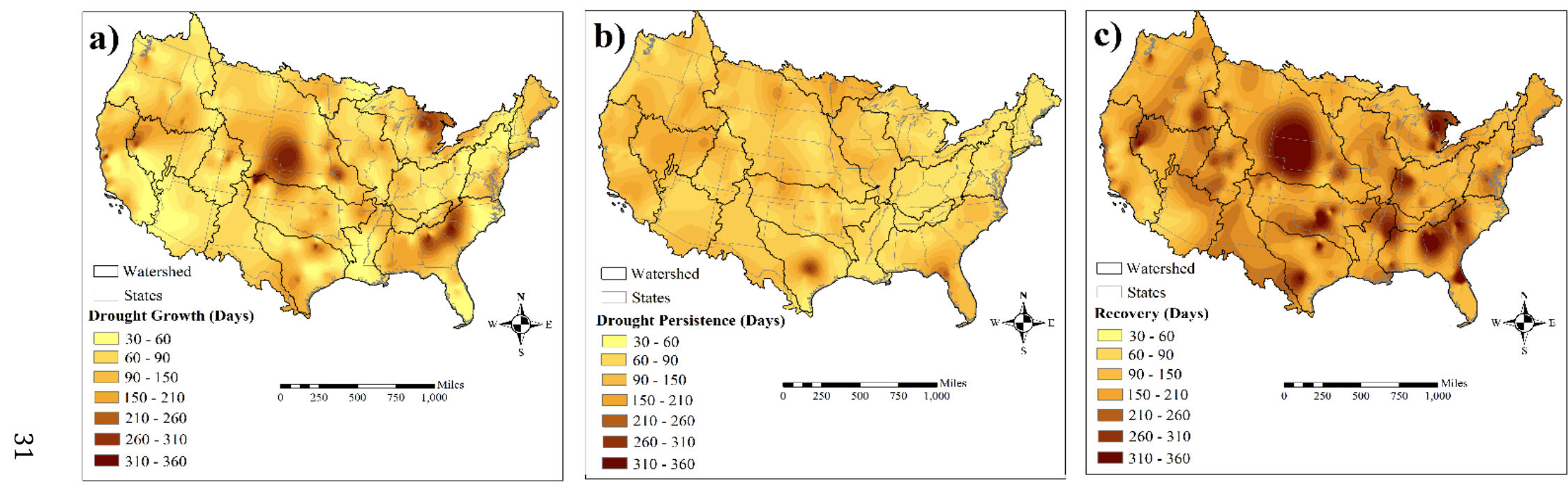

Figure 2-9 Mean duration (in days) of a) drought growth; b) persistence; and c) recovery in the historical period of 1950-2016. 


\subsubsection{Drought impacts on water temperature}

Figure 2-10 shows temporal changes of water temperature, dissolved oxygen, and turbidity during three hydrological drought episodes affecting three selected stations in South Carolina in 2009, Kansas in 2014, and Oregon in 2012. These stations are chosen since they represent the mean pattern of the river basin they are located, and they provide the same length of records for water quality. A statistical analysis on all stations reveals that a hydrological drought is associated with an increase in water temperature (see Table 2-1). Kruskal-Wallis test is applied to detect whether there is a significant difference (at $\mathrm{p}$-value $<0.05)$ between the median of water temperature during a drought episode and the water temperature threshold level. Additionally, Figure 2-10 reveals the water temperature threshold follows a seasonal pattern and tends to be higher (/lower) in the warmer (/colder) seasons. It is worth mentioning that the same pattern is seen all over the study area. Results of the Kruskal-Wallias test indicated that for most drought episodes (more than $85 \%$ of all stations) there is a significant difference between water temperature during drought episodes and the normal water temperature threshold. Additionally, the mean, median and the maximum water temperature in all stations were higher than the mean, median and the maximum water temperature threshold, respectively. Figure 2-10 (first column) shows that water temperature during 2-month (/4month) drought episodes in South Carolina and Oregon (/Kansas) are mostly above the normal water temperature threshold level (normal condition). The figure illustrates that 
water temperature reverts to its normal range 42, 68, and 27 days after drought termination in South Carolina, Kansas, and Oregon, respectively. On average, among all stations over the CONUS, water temperature reverts to its pre-drought normal state 52 days after drought termination (the required time for water temperature to recover from a hydrological drought). The spatial distribution of the average time required for water temperature to recover from a hydrological drought is presented in Figure 2-11-a. 


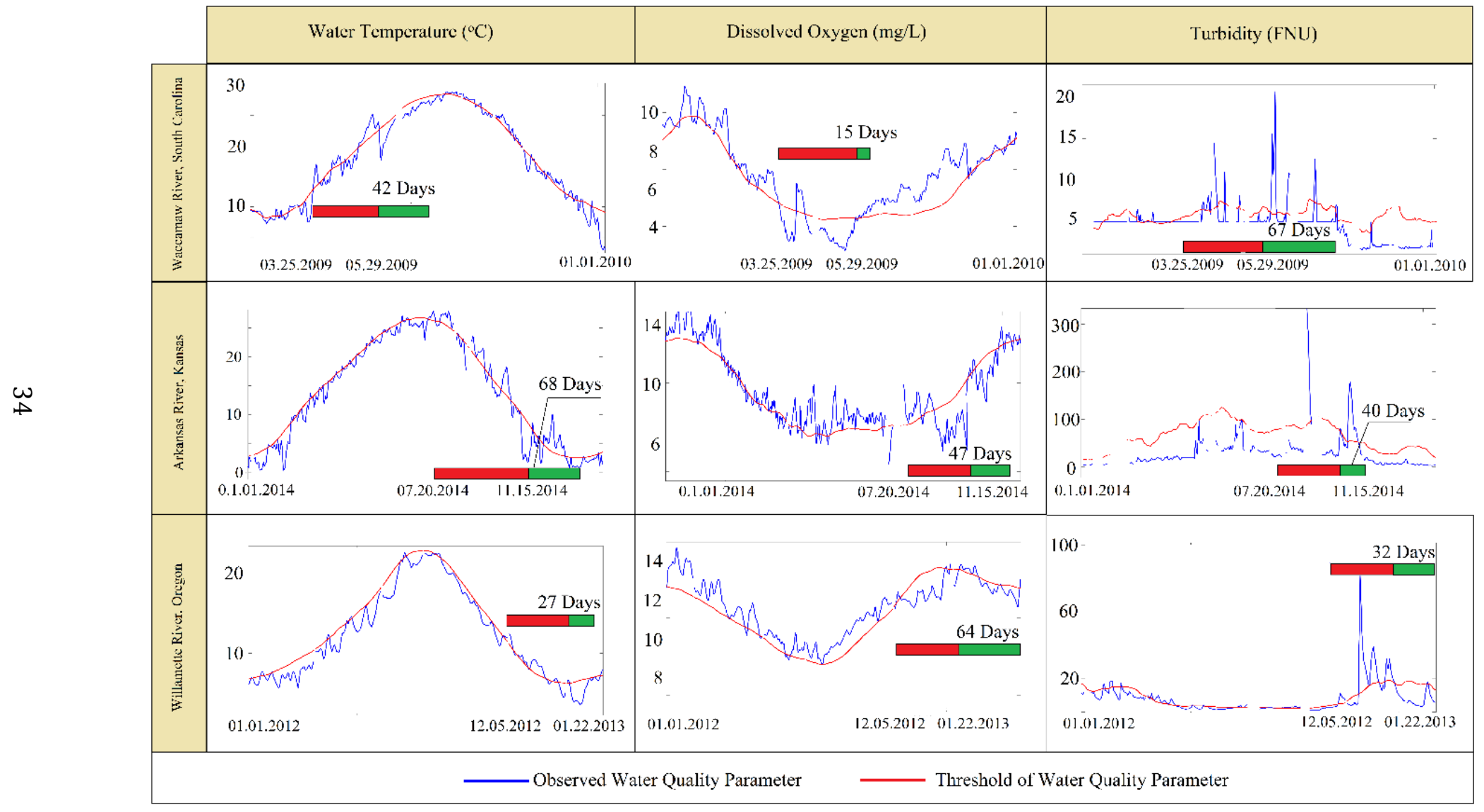

Figure 2-10 Drought impacts on water temperature, dissolved oxygen, and turbidity during three hydrological drought episodes occurred in South Carolina in 2009 (first row), Kansas in 2014 (middle row), and Oregon in 2012 (bottom row). The red bar shows drought duration (onset to termination) and the green bar indicates the required time for water quality to recover. 
This study showed that water temperature increased during hydrological drought episodes, which is in agreement with many previous assessments (Chessman and Robinson, 1987; Caruso, 2001; Zielinski, 2009). Our analyses on all studied stations demonstrated that water temperature considerably increases from the beginning of the persistence stage of drought and it remains above the normal threshold even after drought termination. If the growth stage lasts for more than 40 days, water temperature may increase even during the growth stage. In most cases, water temperature reaches its maximum deviation when the maximum departure is happened in streamflow. The minimum, median, and maximum deviation of water temperature from the normal threshold for each river basin are presented in Table 2-1. The table shows that the basins located in lower latitudes experienced higher water temperature rise. It is worth mentioning that the maximum water temperature increase coincided with the most severe drought episode in all river basins. 
Table 2-1 Minimum, median, and maximum deviation of water temperature, dissolved oxygen, and water turbidity during drought for each river basin.

\begin{tabular}{lccccccccc} 
& \multicolumn{3}{c}{ Temperature $\left({ }^{\circ} \mathrm{C}\right)$} & \multicolumn{3}{c}{ Dissolved Oxygen $(\mathbf{m g} / \mathbf{L})$} & \multicolumn{3}{c}{ Turbidity (FNU) } \\
\cline { 2 - 8 } & Min & Median & Max & Min & Median & Max & Min & Median & Max \\
\hline 1. Pacific Northwest & 1 & 1.5 & 2.8 & 1 & 1.5 & 2.3 & 14 & 25 & 50 \\
2. California & 2 & 2.8 & 5.8 & 1.3 & 1.8 & 2.8 & 18 & 32 & 55 \\
3. Great Basin & 2 & 2.5 & 4.8 & 1.2 & 1.6 & 2.7 & 36 & 68 & 110 \\
4. Lower Colorado & 2.2 & 3 & 5.6 & 1.4 & 1.7 & 2.8 & 40 & 72 & 95 \\
5. Upper Colorado & 1.5 & 2 & 3.2 & 1.1 & 1.5 & 2.3 & 35 & 68 & 114 \\
6. Rio Grande & 2.2 & 3.2 & 5.7 & 1.4 & 1.8 & 2.6 & 42 & 61 & 103 \\
7. Texas Gulf & 2.1 & 3 & 5.9 & 1.3 & 1.7 & 3 & 29 & 36 & 68 \\
8. Arkansas & 1.5 & 1.9 & 5.5 & 1 & 1.4 & 2.8 & 33 & 66 & 120 \\
9. Lower Mississippi & 2.5 & 3 & 4.8 & 1.3 & 1.6 & 2.6 & 15 & 29 & 48 \\
10. Missouri & 1.3 & 2.8 & 4.3 & 1.2 & 1.5 & 2.2 & 44 & 72 & 113 \\
11. Souris-Red-Rainy & 1.2 & 1.9 & 2.8 & 1.1 & 1.4 & 1.8 & 16 & 30 & 62 \\
12. Upper Mississippi & 1.5 & 1.9 & 3 & 1.2 & 1.5 & 2.1 & 18 & 28 & 52 \\
13. Great Lakes & 1.4 & 2.1 & 2.7 & 1 & 1.4 & 2.2 & 17 & 31 & 56 \\
14. Tennessee & 2 & 3 & 3.3 & 1.2 & 1.6 & 2.5 & 14 & 26 & 50 \\
15. Ohio & 1.2 & 2.2 & 3 & 1.1 & 1.4 & 2.3 & 11 & 26 & 46 \\
16. South Atlantic & 2.2 & 2.9 & 4.9 & 1.4 & 1.9 & 2.9 & 10 & 21 & 39 \\
17. Mid-Atlantic & 1.5 & 2.3 & 3.1 & 1.2 & 1.5 & 2.3 & 11 & 20 & 44 \\
\hline 18. New England & 1.2 & 1.8 & 2.6 & 1.1 & 1.4 & 2.1 & 15 & 31 & 56 \\
\hline
\end{tabular}



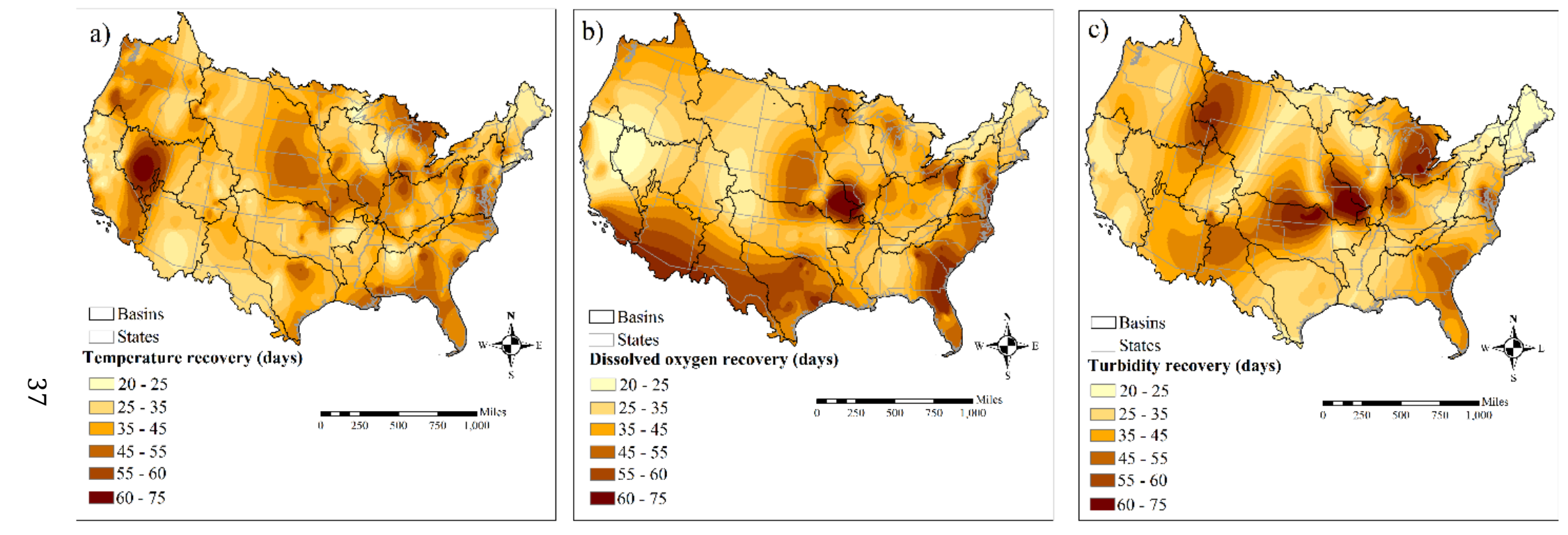

Figure 2-11 Spatial distribution of average time needed for; a) water temperature, b) dissolved oxygen, and c) turbidity to recover from drought after the hydrological drought termination (i.e. after the streamflow has reached normal conditions). 


\subsubsection{Drought impacts on turbidity}

Decreased turbidity is detected during drought episodes using the Kruskal-Wallis test (Figure 2-10 right column). The test indicated that for most of the stations $(90 \%$ of them), the median observed turbidity during drought was significantly lower (p-value $<0.05)$ than the normal turbidity threshold. There were few stations that the difference between the medians was not significant. However, for all stations, the mean and median of observed turbidity during drought episodes were lower than the mean and median of the normal turbidity threshold, respectively (see Table 2-1). Low turbidity is generally desired for most water consumption purposes (specifically domestic demand). On the other hand, since drought terminations mostly coincide with a sudden increase of flow (i.e. higher runoff causes higher turbidity), the turbidity thrusts up during the drought termination. This implies that more time is required for the turbidity to recover after hydrological drought termination. Figure 2-10 (right column) shows that after a 2-month (/4-month) drought episodes in South Carolina and Oregon (/Kansas), turbidity needs 67 and 24 (/40) days to recover, respectively. On average, among all stations over the CONUS, turbidity requires 42 days to recover after hydrological drought termination. Spatial distribution of turbidity recovery time reveals that it takes less than 60 days for most of the regions to recover from drought (Figure 2-11c). There are some scattered areas in Arkansas, Pacific Northwest, southeast Missouri, and great Lakes river basins with recovery times more than 60 days. 
Our analysis detected that turbidity is usually lower than the normal threshold during hydrological droughts, which is in agreement with the findings of several previous studies (Caruso, 2001, 2002; Golladay and Battle, 2002; Goransson et al., 2013). The improvement of water turbidity can be attributed to less storm events that causes decreased runoff, which is associated with less erosion of solid transports to the watercourses during drought. Lower streamflow during the hydrological drought also causes slower velocity, which increases sedimentation and decreases turbidity. Table 2-1 showed that for the river basins located in dry climate with mountainous characteristics (e.g. Lower Colorado and Great basins), the maximum deviation of turbidity is higher than other river basins. Such higher deviation implies the tendency of these basins to terminate droughts with a sudden increase in streamflow (Paulson et al., 1985; Mensing et al., 2008; Asadi Zarch et al. 2011). It has been discussed that turbidity can have various impacts on ecology and natural habitats. High concentration of particulate matter during drought recovery period decreases light penetration, and consequently reduces productivity and natural habitat quality. It also increases sedimentation, which makes siltation more likely, and can result in harming the habitat for fish and aquatic life (Lake, 2011).

\subsubsection{Drought impacts on dissolved oxygen}

Dissolved oxygen alteration is investigated in all stations using the KruskalWallis test to examine if the median of observed dissolved oxygen is significantly different from the threshold. The test shows that there is a significant difference between 
the medians of dissolved oxygen during drought episodes and the normal dissolved oxygen threshold ( $\mathrm{p}$-value $<0.05)$. During drought, the mean and median of dissolved oxygen in all stations were lower than the mean and median of dissolved oxygen threshold, respectively (see Table 2-1). Figure 2-10 (middle column) illustrates that after a drought episode with 2 (/4) months duration, dissolved oxygen recovery lasts for 15 and 64 (/47) days in south Carolina and Oregon (/Kansas), respectively. On average, among all stations over the CONUS, dissolved oxygen requires 51 days to recover after hydrological drought termination. Dissolved oxygen recovery takes more than 2 months in southeast Missouri, Texas, and South-Atlantic river basins (see Figure 2-11b). Moreover, Figure 2-10 shows that the dissolved oxygen follows a seasonal pattern and it reaches to the lowest (/highest) level during warmer (/colder) seasons. This pattern is seen all over the study area. This diagram shows the reverse relationship between water temperature and dissolved oxygen and explains the decreases of dissolved oxygen level during drought episodes due to the increases in temperature.

Our analysis also identified a decline in dissolved oxygen when a hydrological drought takes place, which is in agreement with findings of many studies showing a decrease in dissolved oxygen during hydrological droughts (Boulton and Lake, Ylla et al., 2010; 1992; Hellwig et al., 2017). Generally, in river basins with perennial rivers and higher streamflow, the variability range of dissolved oxygen is limited due to the deeper flow in rivers, which leads to less reaeration. On the other hand, most ephemeral rivers with shallow flow are located in lower latitude. Dissolved oxygen requires longer recovery time in these river basins because of higher water temperature and less oxygen solubility in spite of better reaeration. Therefore, in most river basins, water temperature 
is the dominant process (rather than reaeration and biological activity) that controls dissolved oxygen level. During drought persistence stage, dissolved oxygen shows a similar pattern to water temperature, and the maximum deviation of dissolved oxygen happens in the persistence stage. Many aquatic species can survive only within a specific temperature range and a minimum dissolved oxygen level. Therefore, considering dissolved oxygen and water temperature is essential for maintaining the ecology and biology of water resources systems (Mathews and Marsh-Mathews, 2003; Lake, 2011). Droughts have caused flora and fauna fatalities in different parts of the world, for instance in Australia (Leigh at al., 2015), southern US (Buskey et al., 2001), and California (Brumbaugh et al., 1994; Israel and Lund, 1995). The reported reasons for aquatic fatalities due to droughts were decline in dissolved oxygen level, vanishing the natural habitat of species, loss of streams connectivity, and alteration of food (Lake 2003, 2011; Leigh at al., 2015).

\subsection{Discussion}

Applying the hydrological drought detection method, a total of 9247 drought episodes were identified in 400 stations across the CONUS during 1950-2016. Figure 212 shows the relationship between drought duration, recovery time (required time for streamflow and water quality to revert to its pre-drought state), and annual flow across three different river basins with diverse climate (i.e. Pacific Northwest, Arkansas, and South Atlantic). The figure illustrates that there is a significant inverse relationship between drought duration and the annual flow in all three river basins (R2> 0.5 and p- 
value $<0.05$ ). Therefore, annual streamflow deficits are probably more intense during prolonged drought events compared to shorter drought episodes. Similar results are found for recovery time and annual flow, and severe annual streamflow deficits are more likely to result in longer recovery time. However, recovery time is positively correlated to drought duration for these river basins ( $\mathrm{R} 2>0.5$ and $\mathrm{p}$-value $<0.05$ ), and similar pattern is found in all the river basins over the CONUS. The positive correlation found between drought duration and annual flow is in agreement with the findings of Spinoni et al. (2014) and Austin et al. (2018). These studies also showed that if a drought episode lasts longer, drought severity increases and the affected area deals with exacerbated water stress. Thomas et al. (2014) investigated hydrological droughts and recovery time for south and southeastern USA, and concluded that for longer and more severe hydrological droughts, longer drought recovery duration should be expected. These findings are in consensus with the findings of the present study, indicating an inverse relationship between recovery time and annual flow and a direct relationship between drought duration and recovery time. 

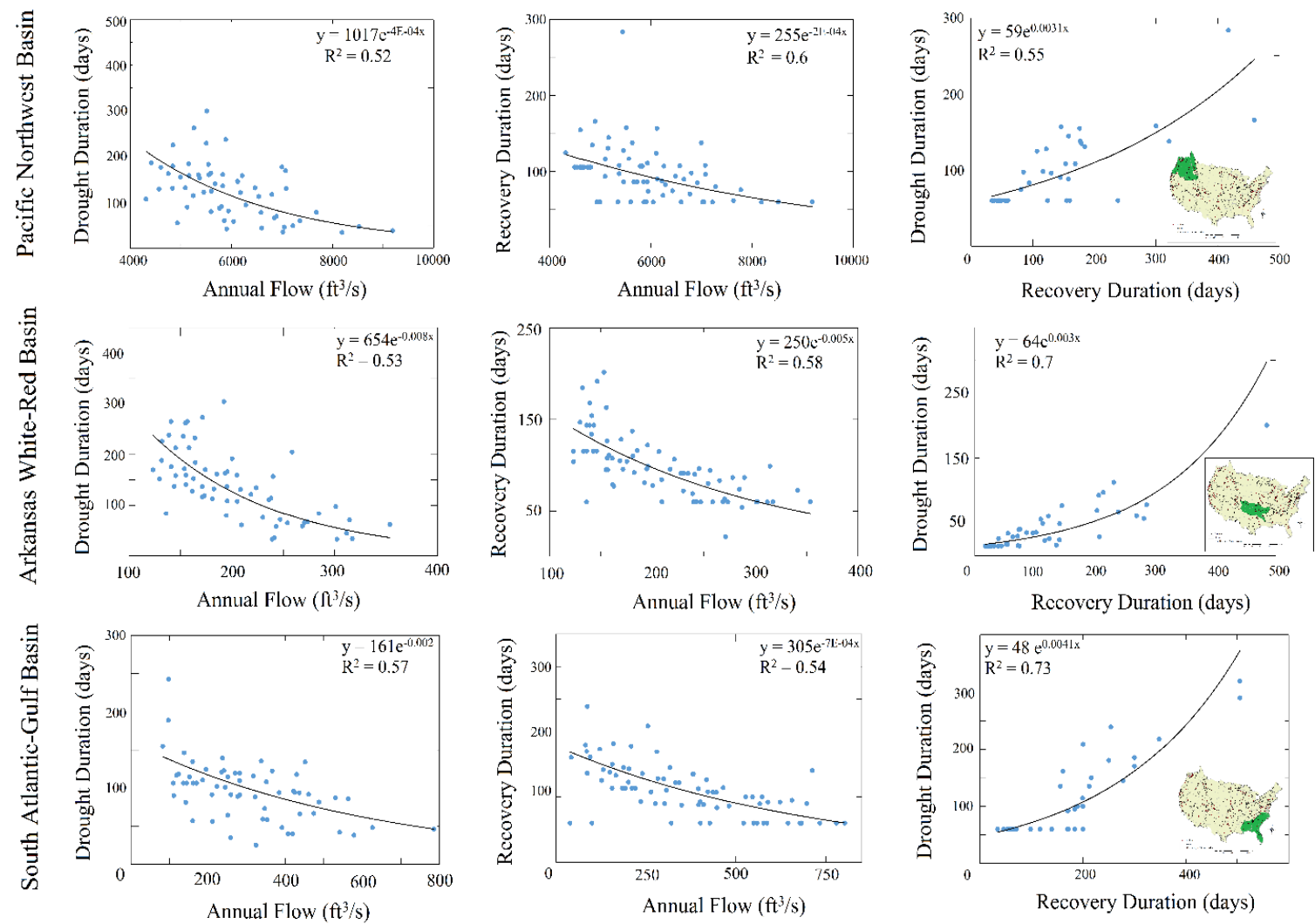

Figure 2-12 Relationship between drought duration and annual flow (left), recovery time and annual flow (middle), and drought duration and recovery time (right) over the Pacific Northwest (top), Arkansas (middle) and South Atlantic (bottom) river basins.

Figure 2-13 shows hydrological drought severity over the CONUS for the study period. Severity indicates the ratio of accumulated streamflow deficit to streamflow in normal condition during drought episodes (elaborated in the following equation).

Drought Severity $=\frac{\sum_{I=\text { onset }^{\text {Termination }}} \text { Observed Streamflow }_{i}-\text { Threshold }_{i}}{\sum_{i=\text { onset }}^{\text {Termiontion }} \text { Threshold }_{i}} * 100$

if (Observed Streamflow - Threshold $\left._{i}\right)<0$ 
The figure shows that California, Great basin and South Atlantic river basins experienced more severe droughts during the study period. Texas and Souris basins also experienced severe droughts. Comparing Figure 2-13 (drought severity) and Figure 2-8 (number of droughts) reveals an inverse relation between drought severity and frequency in areas located in the Pacific Northwest, California, Great Basin, Upper Colorado, Texas, Arkansas, Ohio, New England, Upper Mississippi, and Mid-Atlantic river basins. This inverse relationship implies that the regions affected by more frequent droughts, experienced less severe droughts, in general. This is found in the Pacific Northwest, Upper Colorado, and mid-Atlantic river basins. Whereas, those parts of the CONUS that experienced less frequent droughts (e.g. California, Texas and South-Atlantic river basins), suffered from more severe droughts. Griffin and Anchukaitis (2014) showed that for the period of 2012-2014, California experienced the most severe drought condition in the last century. Our analysis also finds Southern California among the regions that the most severe hydrological droughts have happened during the study period. Additionally, California experienced a hydrological drought in 2012, which lasted for almost a year (Figure 2-6), and that drought episode was accompanied by two major hydrological droughts in the following years. Anderson et al. (2013) and Long et al. (2013) showed that Southern US experienced more severe drought episodes compared to Northern regions during the period of 2000-2012. Figure 2-13 also corroborates that these areas (i.e. Florida, Southern Plains, and Southwestern US) experienced more severe hydrological droughts compared to the rest of the US. 


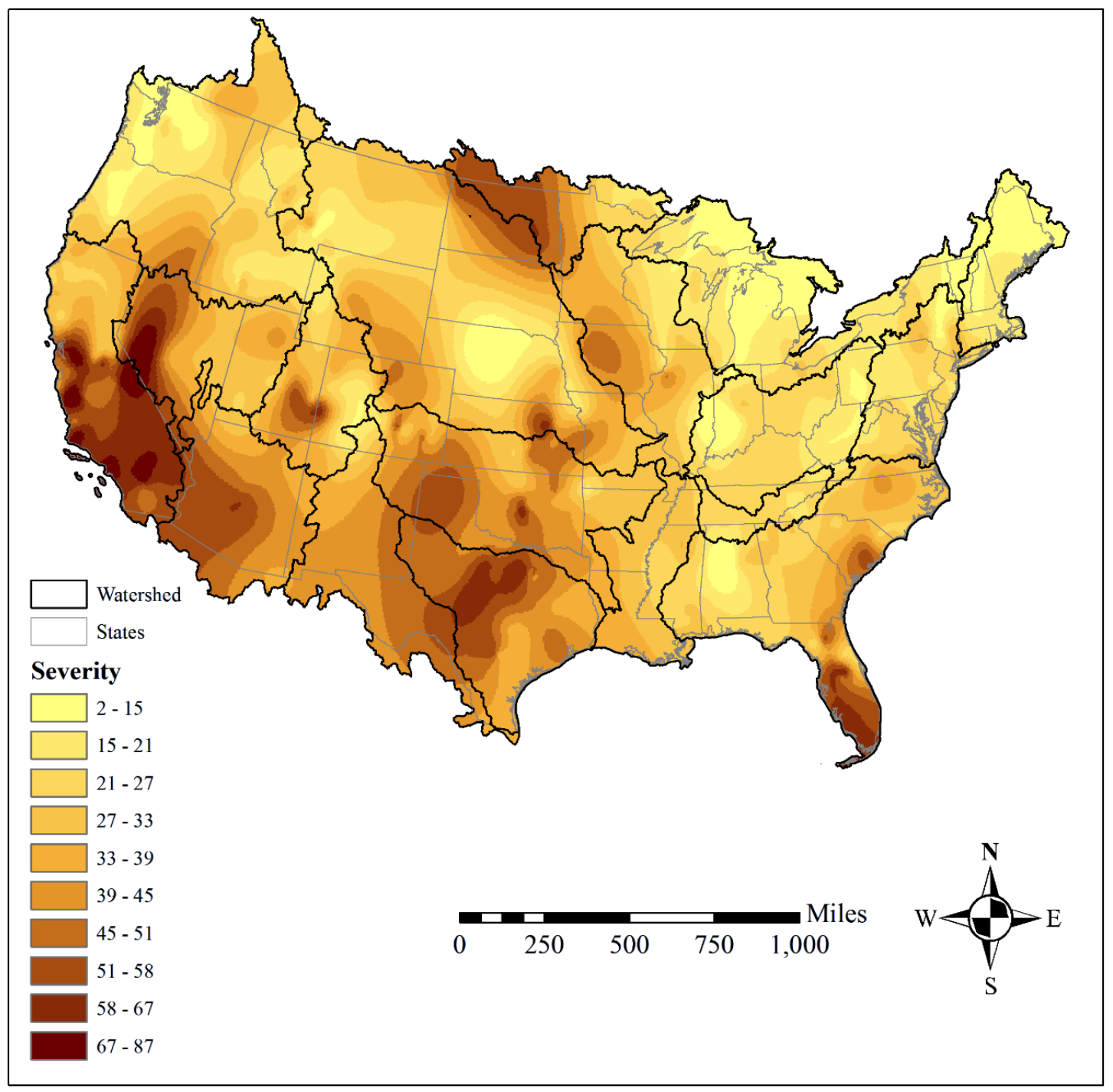

Figure 2-13 Spatial distribution of normalized drought severity over the CONUS during 1950-2016. Severity is defined as the ratio of accumulated streamflow deficit to streamflow in normal condition during drought episodes

Figure 2-14 illustrates the correlation between the deviation of water quality parameters (during drought episodes) and drought severity over 18 river basins. In general, water temperature and dissolved oxygen are more correlated with drought 
severity than turbidity. Dissolved oxygen and drought severity are highly correlated in California, Lower Colorado, Texas, Rio Grande and South Atlantic river basins, all of which are located in the lower latitudes. Turbidity and drought severity correlation is the highest in Missouri and Arkansas, both located in arid climate. Comparing Figure 2-14 with Figure 2-11 reveals that in the river basins that require longer recovery time for dissolved oxygen, the correlation between dissolved oxygen and drought severity is highest. Similar pattern is found for turbidity recovery time in the Great Lakes, Missouri, and Arkansas, where the correlation between drought severity and turbidity is the highest, compared to other water quality parameters. Figure 2-14 shows that the southern US regions (basins 2-7 and 16) indicate higher correlation between water quality variations and drought severity, with dissolved oxygen indicating the highest correlation, which reveals the higher vulnerability of aquatic life to drought severity in southern US. 


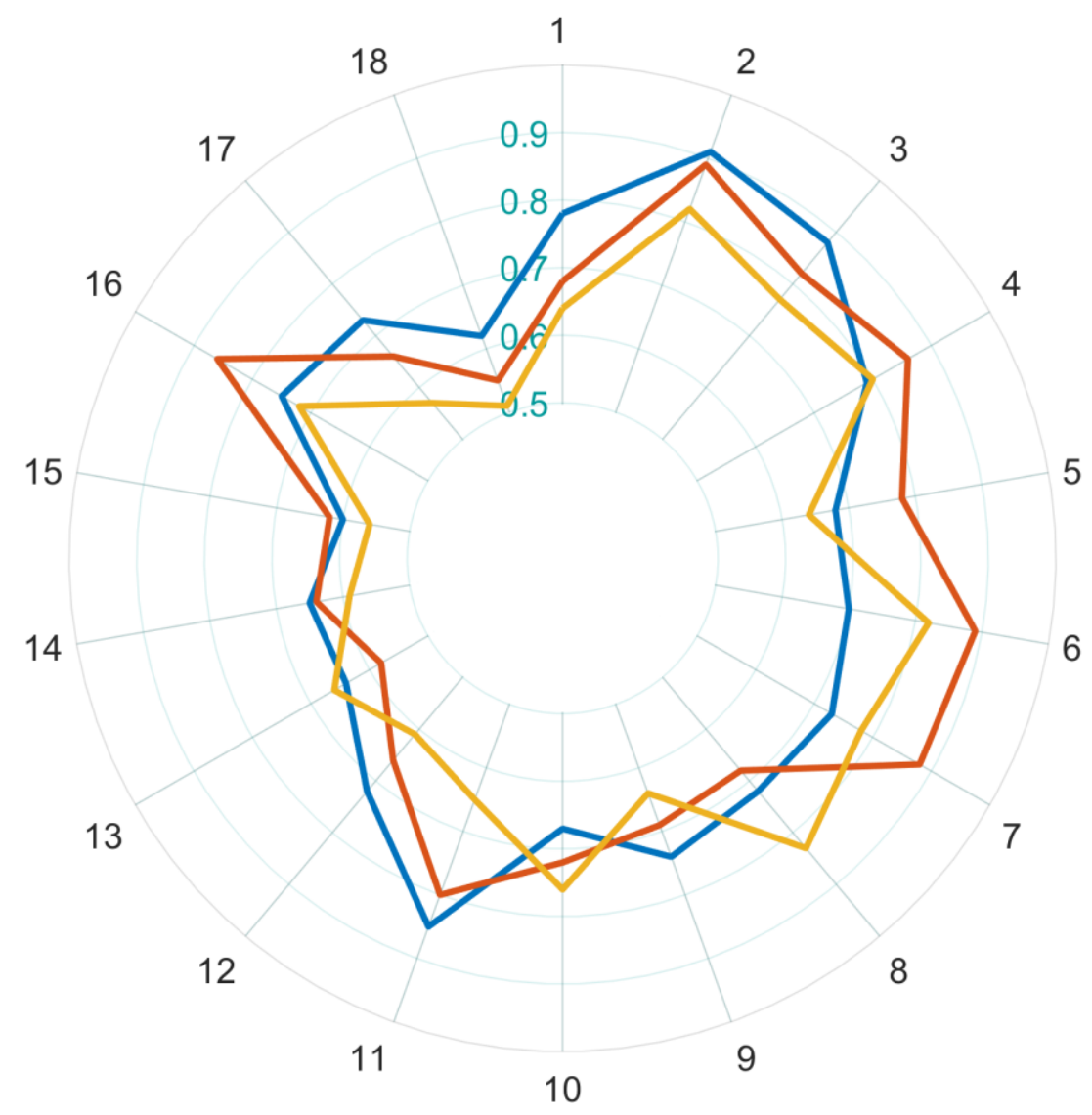

1. Pacific Northwest

2. California

3. Great Basin

4. Lower Colorado

5. Upper Colorado

6. Rio Grande

7. Texas Gulf

8. Arkansas

9. Lower Mississippi

10. Missouri

11. Souris-red-Rainy

12. Upper Mississippi

13. Great Lakes

14. Tennessee

15. Ohio

16. South Atlantic

17. Mid-Atlantic

18. New England

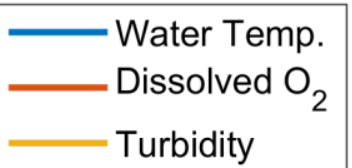

Figure 2-14 The correlation coefficient between drought severity with water temperature, dissolved oxygen, and turbidity variations and over 18 river basins of the U.S.

The empirical cumulative distribution functions (CDFs) are developed to probabilistically analyze drought duration in the study period. Figure 2-15 shows the CDF of drought duration for Ohio, Missouri, and South Texas-Gulf river basins. These river basins are selected as they show the lowest, highest, and mean drought duration, respectively. The figure shows that with $75 \%$ probability, drought durations are 180, 220, and 300 days in Ohio, Missouri, and Texas river basins, respectively. Additionally, 
historical hydrological droughts indicated a median (50\% probability) duration of 110 , 125, and 140 days for Ohio, Missouri and Texas river basins, respectively. In another interpretation, if a drought episode begins in these river basins, it is 55, 68 and $75 \%$ probable that it lasts for 200 days or less in Texas, Missouri and Ohio, respectively. In conclusion, it is more likely for Texas to experience more long-term drought events compared to other river basins.

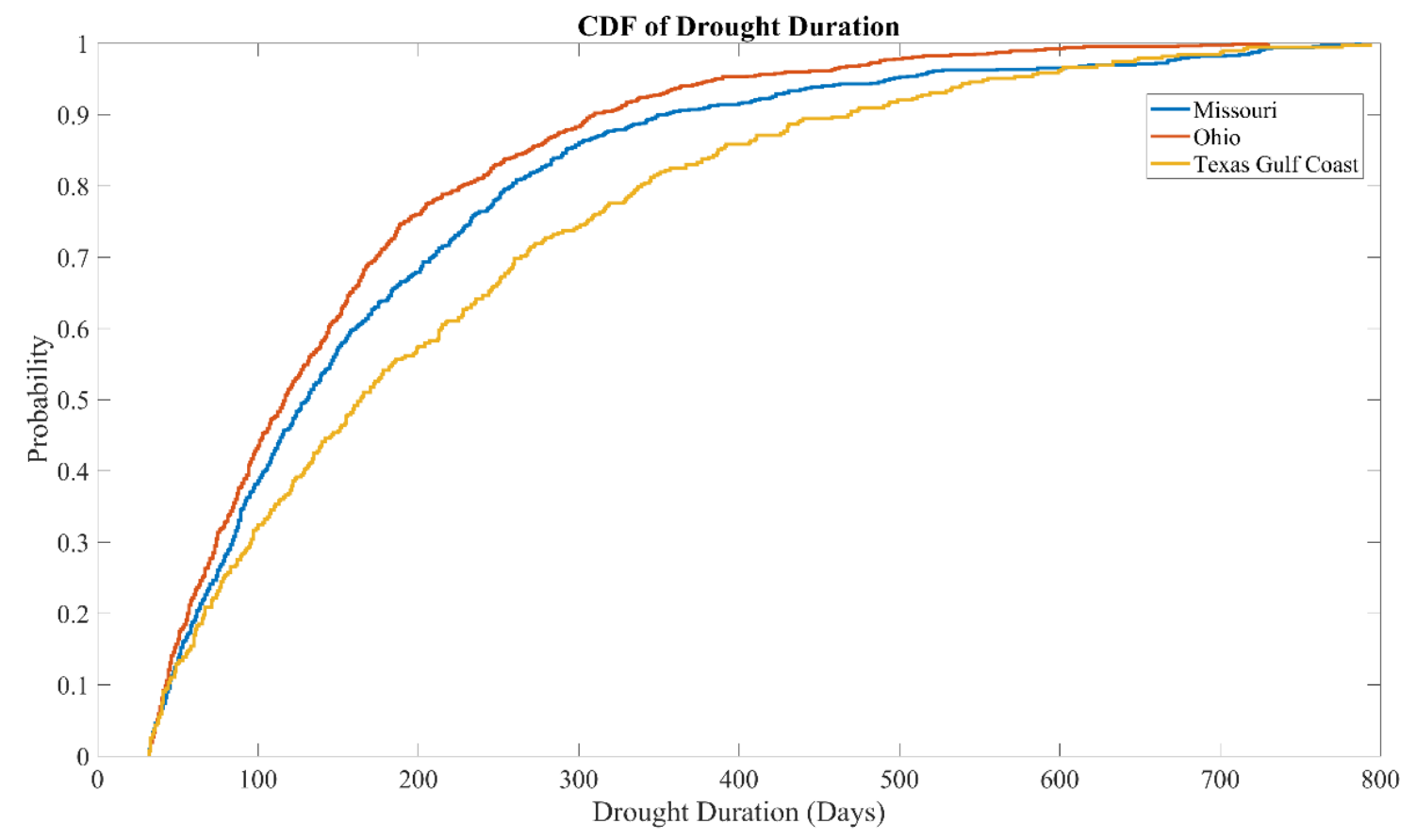

Figure 2-15 Cumulative probability distribution (CDF) of drought duration in Ohio, Missouri, and South Texas-Gulf coast basins, representing least, most, and mean drought duration among all US basins, respectively

Many studies reported temperature increase in rivers and streams during drought and unusual low-flow condition (Baurès et al., 2013; BOULTON and LAKE, 1990; Caruso, 2002; Chessman and Robinson, 1987; Ha et al., 1999; Hanslík et al., 2016; 
Hrdinka et al., 2012; Sprague, 2005; van Vliet and Zwolsman, 2008; Zieliński et al., 2009). There were few studies that did not find a significant temperature increase during a drought on the river (Mosley et al., 2012; Wilbers et al., 2009) which was attributed to no increase in local air temperature, however there was no decrease in water temperature reported during drought in previous studies. Delpla, Jung, Baures, Clement, \& Thomas, (2009), reviewed the impacts of extremes (including drought and climate change) on the quality of water bodies (rivers and lakes), and modifying parameters values (physicochemical parameters, micro pollutants and biological parameters). In this study a comprehensive review on water quality changes was carried out and all the studies conclude on water temperature increase during drought periods (please see the table 1 in the appendix of this report).

To investigate further water temperature changes during droughts, the t-test is utilized to analyze water quality recovery. In this hypothesis, it is assumed that water quality is recovered, when there is no significant difference between the mean of variable of interest and its threshold. The analysis of hydrological drought was carried out using the new assumption and the Figure 2-16 shows the results of average recovery duration for this new assumption. Comparing Figure 2-16 and Figure 2-11 shows that spatial pattern of time needed for each water quality parameters is identical, however, if we consider the mean of water quality (t-test rather than Kruskal-Wallis test) as the criterion to investigate the recovery, recovery duration needs longer time. Further analysis is carried out to test if there is significant difference between the results of new hypothesis and the one that is elaborated in methodology (section 2-2). To this end, t-test and Kruskal-Wallis test are applied to investigate if there is a significant statistical difference 
between the average and median of recovery duration for each station. Table 2-2, shows the minimum $\mathrm{p}$-values for each river basin, as the table shows there is no significant difference between the results of these two hypothesis for all water quality parameter.
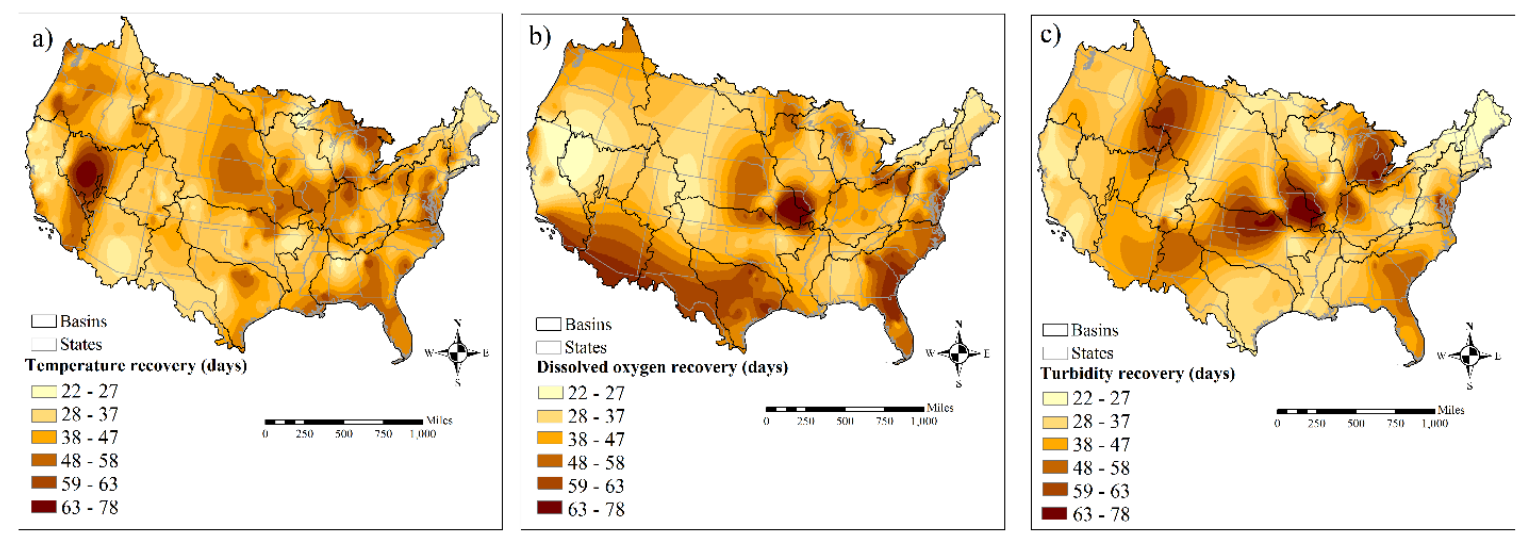

Figure 2-16 Spatial distribution of average time needed for; a) water temperature, b) dissolved oxygen, and c) turbidity using t-test to investigate when the mean of water quality reverts to its pre-drought condition after the hydrological drought termination (i.e. after the streamflow has reached normal conditions).

Table 2-2 Minimum p-value for t-test and Kruskal-Wallis test water temperature, dissolved oxygen, and water turbidity during drought for each river basin.

\begin{tabular}{lcccccc} 
& \multicolumn{2}{c}{ Water Temperature } & \multicolumn{2}{c}{ Dissolved Oxygen } & \multicolumn{2}{c}{ Turbidity } \\
\cline { 2 - 7 } & t-test & Kruskal-Wallis & t-test & Kruskal-Wallis & t-test & Kruskal-Wallis \\
\hline Pacific Northwest & 0.095 & 0.85 & 0.1 & 0.11 & 0.2 & 0.1 \\
California & 0.099 & 0.9 & 0.09 & 0.1 & 0.15 & 0.2 \\
Great Basin & 0.088 & 0.75 & 0.085 & 0.9 & 0.09 & 0.14 \\
Lower Colorado & 0.1 & 0.9 & 0.11 & 0.12 & 0.13 & 0.25 \\
Upper Colorado & 0.12 & 0.11 & 0.1 & 0.11 & 0.4 & 0.3 \\
Rio Grande & 0.09 & 0.08 & 0.12 & 0.13 & 0.25 & 0.1 \\
Texas Gulf & 0.11 & 0.1 & 0.55 & 0.6 & 0.12 & 0.3 \\
Arkansas & 0.095 & 0.85 & 0.08 & 0.1 & 0.2 & 0.4 \\
Lower Mississippi & 0.85 & 0.78 & 0.09 & 0.15 & 0.15 & 0.2 \\
Missouri & 0.075 & 0.7 & 0.1 & 0.2 & 0.25 & 0.1 \\
Souris-Red-Rainy & 0.1 & 0.09 & 0.085 & 0.15 & 0.08 & 0.15 \\
Upper Mississippi & 0.12 & 0.11 & 0.75 & 0.8 & 0.09 & 0.25 \\
Great Lakes & 0.13 & 0.12 & 0.09 & 0.2 & 0.1 & 0.16 \\
& & & & & &
\end{tabular}




\begin{tabular}{lcccccc} 
Tennessee & 0.11 & 0.1 & 0.8 & 0.7 & 0.6 & 0.45 \\
Ohio & 0.09 & 0.08 & 0.3 & 0.4 & 0.45 & 0.3 \\
South Atlantic & 0.085 & 0.075 & 0.4 & 0.3 & 0.35 & 0.2 \\
Mid-Atlantic & 0.075 & 0.07 & 0.2 & 0.3 & 0.18 & 0.35 \\
New England & 0.08 & 0.08 & 0.11 & 0.15 & 0.2 & 0.1 \\
\hline
\end{tabular}

Van Vliet et al., (2013) assess the impact of climate change on global river flows and river water temperatures, and identify regions that might become more critical for freshwater ecosystems and water use sectors. Their results showed that global mean and high (95th percentile) river water temperatures are projected to increase on average by 0.8-1.6 (1.0-2.2) oC in all months of year (see figure 3 for an example). This study concluded that the largest water temperature increases are projected for the United States, Europe, eastern China, and parts of southern Africa and Australia. In these regions, the sensitivities are exacerbated by projected decreases in low flows (resulting in a reduced thermal capacity). For seasonal rivers with highest water temperatures during the low flow period, up to $26 \%$ of the increases in high (95th percentile) water temperature can be attributed indirectly to low flow changes, and the largest fraction is attributable directly to increased atmospheric energy input. As the Figure 3 shows, warmer water temperature is expected for every month (including cold months of the year) due to the higher incident radiation (less cloud cover) and higher temperatures. Additionally, many studies confirmed that air temperature and water temperature are highly correlated in cooling and warming seasons (Baldwin et al., 2008; Harvey et al., 2011; Hellwig et al., 2017; Pen and Eriods, 2000). Therefore, the relationship between air temperature and water temperature was investigated to better understand the reason of increase in water temperature during drought episodes. 


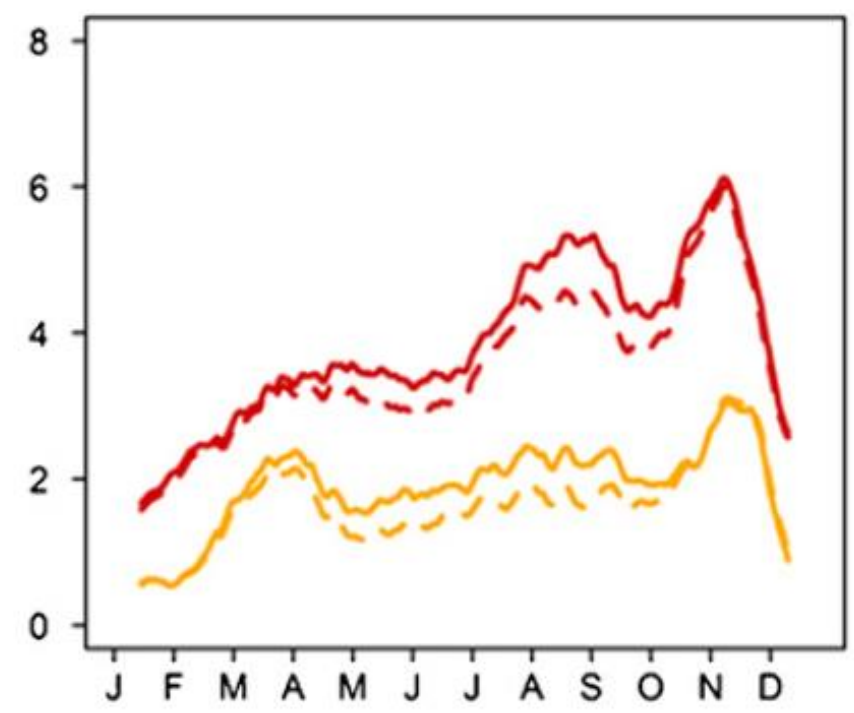

Figure 2-17 Monthly increase in average water temperature in Missouri, red line and orange line show water temperature changes for A2 and B1 scenarios respectively (Van Vliet et al., 2013)

Livneh daily CONUS near-surface gridded meteorological data is used with 1/16 degree resolution from 1915 to 2015 to calculate the correlation coefficient between air and water temperature (Livneh et al., 2013a). Table 3 shows the calculated Pearson correlation coefficient for river basins over the CONUS. The result of correlation analysis shows a significant correlation between air and water temperature ( $\mathrm{p}$-values are provided). Therefore in next step, the air temperature changes is investigated during drought episodes. 
Table 2-3 The lowest correlation coefficients between air and water temperature, and its p-values for river basins from 1915 to 2015 .

\begin{tabular}{lcc}
\cline { 2 - 3 } & $\begin{array}{c}\text { Pearson correlation } \\
\text { coefficient }\end{array}$ & p-value \\
\hline 1. Pacific Northwest & 0.87 & 0.001 \\
2. California & 0.82 & 0.001 \\
3. Great Basin & 0.9 & 0.001 \\
4. Lower Colorado & 0.88 & 0.001 \\
5. Upper Colorado & 0.85 & 0.001 \\
6. Rio Grande & 0.92 & 0.001 \\
7. Texas Gulf & 0.79 & 0.001 \\
8. Arkansas & 0.81 & 0.001 \\
9. Lower Mississippi & 0.86 & 0.001 \\
10. Missouri & 0.77 & 0.001 \\
11. Souris-Red-Rainy & 0.83 & 0.001 \\
12. Upper Mississippi & 0.87 & 0.001 \\
13. Great Lakes & 0.74 & 0.001 \\
14. Tennessee & 0.80 & 0.001 \\
15. Ohio & 0.84 & 0.001 \\
16. South Atlantic & 0.88 & 0.001 \\
17. Mid-Atlantic & 0.73 & 0.001 \\
18. New England & 0.75 & 0.001 \\
\hline
\end{tabular}

Further analysis is carried out to examine if there is a significant difference between the air temperature during drought and its normal condition. To this end, t-test and Kruskal-Wallis tests are applied to investigate if there is a significant statistical difference between the average and median of air temperature during droughts and its normal condition. The normal condition is considered as the daily average of air temperature over each grid in study period. Figure 2-18 shows the observed temperature and daily average temperature for three drought episodes took place in South Carolina, 
Kansas, and Oregon. This figure demonstrated that these regions during drought experienced warmer temperature compared to their climatology which leads to warmer water flow in the rivers and streams. Table 2-4 summarizes the maximum p-values of $t$ test and Kruskal-Wallis tests calculated for each river basin, as the table shows there is a significant difference between the mean and median of observed air temperature and its normal condition. Therefore, it can be concluded that since all drought episodes during the study period of this study, coincided with relatively warmer air temperature, increase in water temperature can be attributable directly to increased atmospheric energy input. 

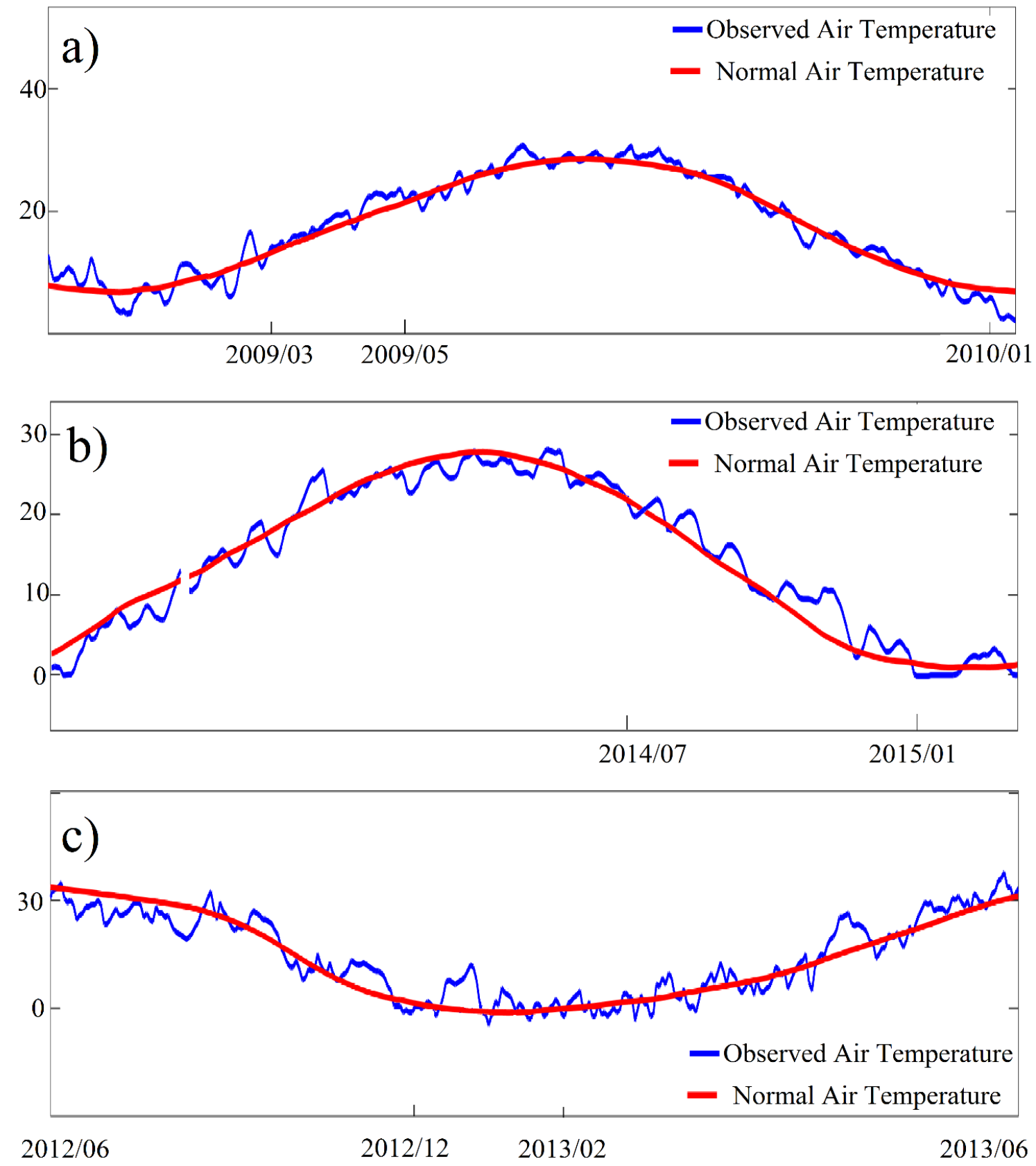

Figure 2-18 Observed air temperature vs normal condition for; a) South Carolina, b) Kansas, and c) Oregon, during 3 drought episodes. 
Table 2-4 the maximum p-values for t-test and Kruskal-Wallis tests between the mean and median of observed air temperature and normal condition during drought for each river basin.

\begin{tabular}{lcccc}
\cline { 2 - 5 } & t-test & p-value & Kruskal-Wallis & p-value \\
\hline 1. Pacific Northwest & 0.8 & 0.035 & 1 & 0.01 \\
2. California & 2 & 0.04 & 1.3 & 0.01 \\
3. Great Basin & 2 & 0.03 & 1.2 & 0.009 \\
4. Lower Colorado & 2.2 & 0.04 & 1.4 & 0.012 \\
5. Upper Colorado & 1.5 & 0.01 & 1.1 & 0.011 \\
6. Rio Grande & 2.2 & 0.02 & 1.4 & 0.01 \\
7. Texas Gulf & 2.1 & 0.015 & 1.5 & 0.026 \\
8. Arkansas & 1.5 & 0.045 & 1.1 & 0.03 \\
9. Lower Mississippi & 2.5 & 0.018 & 1.4 & 0.015 \\
10. Missouri & 1.3 & 0.01 & 1.1 & 0.02 \\
11. Souris-Red-Rainy & 1.2 & 0.02 & 1 & 0.015 \\
12. Upper Mississippi & 1.5 & 0.01 & 1.3 & 0.03 \\
13. Great Lakes & 1.4 & 0.012 & 1.2 & 0.02 \\
14. Tennessee & 1.9 & 0.02 & 1.3 & 0.015 \\
15. Ohio & 1.3 & 0.04 & 1.2 & 0.025 \\
16. South Atlantic & 2.3 & 0.015 & 1.4 & 0.03 \\
17. Mid-Atlantic & 1.6 & 0.025 & 1.3 & 0.015 \\
18. New England & 1 & 0.02 & 1 & 0.005 \\
\hline
\end{tabular}

\subsection{Summary and conclusions}

It is essential to understand drought impacts on freshwater resources quality and their recovery duration. To this end, this study developed a framework for hydrological drought detection in order to categorize droughts into three stages of growth, persistence, 
and retreat, investigated water quality variations during droughts, analyzed recovery time for each water quality parameter, and finally assessed spatiotemporal and probabilistic characteristics of drought episodes. The method was applied on 400 streamflow and water quality stations over the CONUS with daily observation. The historic 2012 US drought and California were selected to validate the presented methodology on national and regional scales respectively. On average, drought persistence was found to last less than 2 months in most of the Eastern US. Whereas in California, Upper Colorado and Texas river basins, drought tends to persist more than three months. Results showed that, drought frequency is negatively correlated with drought severity and duration, whereas drought duration and recovery time are positively correlated. In terms of water quality, results showed that increased temperature, decreased turbidity, and lower dissolved oxygen were observed during hydrological droughts. Average recovery time for water temperature, turbidity and dissolved oxygen were 52, 42 and 51 days following hydrological drought termination, respectively. Furthermore, turbidity recovery time was found to be less than 60 days after drought termination for most of the CONUS, whereas, dissolved oxygen recovery indicated to be more than 2 months (maximum 69 days) in the lower latitude river basins. 


\section{Agricultural droughts and terrestrial ecosystems recovery \\ 3.1 Background}

Drought, as a prolonged period of moisture deficiency in land surface, affects terrestrial ecosystems from structural and functional perspectives (i.e. constraining vegetation growth, causing plant mortality, and triggering wildfire), which leads to profound imbalances in the terrestrial carbon cycle (Huang et al., 2017; Yang et al., 2016; Yu et al., 2017). In addition, climate change, which is a consequence of increased greenhouse gas emission and global warming (Alley et al., 2007; Ning Zeng, Haifeng Qian, 2004), will exacerbate drought frequency and severity in the $21^{\text {st }}$ century (Ahmadalipour et al., 2016; Irannezhad et al., 2017; Karamouz et al., 2013).

An agricultural drought onset is typically perceived when the soil moisture level drops below a threshold causing crop water stress (affecting crop yield). Consequently, soil moisture is regarded as an indicator of agricultural drought (Keyantash and Dracup, 2002; Mishra et al., 2017; Sheffield and Wood, 2008). Spatially varying precipitation, land cover, soil, and topography cause heterogeneity, which makes soil moisture estimation from field measurement complicated (Escorihuela and Quintana-Seguí, 2016; Vereecken et al., 2008). Therefore, land surface models and/or remotely sensed data are often adopted to estimate soil moisture. There are many studies utilizing land surface models to estimate soil moisture and analyze historical agricultural drought episodes (Ceppi et al., 2014; Narasimhan and Srinivasan, 2005; Qin et al., 2015). Additionally, remote sensing advances have provided major soil moisture data availability at global 
scale (Ahmadalipour et al., 2017), which facilitates obtaining precise and frequent soil moisture maps globally (Rebel et al., 2012; Xu et al., 2014). There are several studies, which compared agricultural drought analysis obtained from in situ and remotely sensed soil moisture data (Champagne et al., 2011; Kang et al., 2016; Martínez-Fernández et al., 2016). Some studies combined land surface models simulations with remotely sensed data to minimize the uncertainty of soil moisture estimation ( Liu et al., 2011; Wagner et al., 2003). Recent studies by Yan et al. (Yan et al., 2018, 2017) have assimilated remotely sensed soil moisture observations to land surface models in order to improve the accuracy of soil moisture simulations and drought monitoring.

Ecosystem Water Use Efficiency (WUE) is defined as the ratio of carbon gain (i.e., Gross Primary Production) to water consumption (i.e., Evapotranspiration), which links biological and water cycles over the land surface (WUE = GPP/ET) (Liu et al., 2015; Tang et al., 2014). Gross Primary Production (GPP), which is a key component of the terrestrial carbon cycle, represents the sum of gross carbon $\left(\mathrm{CO}_{2}\right)$ uptake by plant photosynthesis (He et al., 2016; Yang et al., 2007). Theoretically, the ecological transpiration is the true water consumption by plant photosynthesis. However, due to the infeasibility of distinguishing soil and canopy evaporation and plant transpiration from evapotranspiration (ET) (Lawrence et al., 2007), precipitation (Zhang et al., 2014) or ET (Ponce-Campos et al., 2013) are usually used as indicators of water loss (i.e. used by the ecosystem). Among various definitions of WUE, GPP/ET is the most common indicator, and it is employed in this study too (Huang et al., 2017; Tang et al., 2016; Yang et al., 2016). 
WUE is a key variable to better understand the response of ecosystem productivity to any physical changes (e.g. water availability, climate change, etc.). Droughts can be associated with heatwaves and decreased water availability (Chiang et al., 2018; Mazdiyasni and Aghakouchak, 2015), which may result in increase or reduction of evapotranspiration, respectively, leading to significant disruptions in the global water balance and may cause permanent changes to the ecosystems (Huntington, 2006; Teuling et al., 2015a).

The WUE alteration and its effects on the ecosystem resilience to drought disturbances have been investigated in recent studies (Dan et al., 2018; Huang et al., 2017; Yang et al., 2016; Zhang et al., 2014). Regional assessments have concluded that ecosystem biomes are able to enhance their WUE in order to cope with water stress (Ponce-Campos et al., 2013). However, such a conclusion has been challenged by several regional and large-scale investigations implying that the response of WUE to drought depends on the ecosystems' condition (Huang et al., 2017; Liu et al., 2015; Yang et al., 2016). Therefore, more investigation is still needed to understand WUE-drought relations and reveal the spatiotemporal patterns and influential factors.

Drought recovery duration is often assumed to be rapid. In some studies, drought recovery is assessed focusing on the required precipitation to recover from a drought episode (Dechant and Moradkhani, 2015; Pan et al., 2013), whereas few studies elaborated on drought recovery considering restoring function of plants (Martorell et al., 2014; Secchi and Zwieniecki, 2014). For the hydrological drought, a region is assumed to recover from drought when the hydrologic variable of interest (e.g. streamflow) reverts to 
its pre-drought level (Parry et al., 2016). Schwalm et al. (2017) stated that recovery time is the duration that "an ecosystem requires to revert to its pre-drought condition". Understanding drought recovery duration is critical for ecosystem, since if a region experiences a new drought episode before full recovery from an antecedent drought event, the ecosystem may experience severe permanent ecological impacts (Connor et al., 2013; Nepstad et al., 2008).

\subsection{Data}

\subsubsection{Remotely sensed data}

The 8-day GPP (RUNNING et al., 2004; Zhao et al., 2005) and ET (Mu et al., 2011, 2007) data with 1-km spatial resolution are acquired from the MODIS instrument onboard Terra satellite during 2000 to 2014, from the Numerical Terradynamic Simulation Group (http://www.ntsg.umt.edu). The MODIS GPP product (MOD17A3) was developed based on a light-use efficiency model (Heinsch et al., 2003). GPP is the largest contributor of carbon flux and the largest carbon uptake by terrestrial ecosystems.

Many studies have confirmed the accuracy and validity of MODIS GPP (Cohen et al., 2006; Heinsch et al., 2006; Turner et al., 2006; Xiao et al., 2010; Xue et al., 2015; Zargar et al., 2011) and it is compared with station observations in many regions and biomes (Cohen et al., 2006; Zhao et al., 2005). The MODIS GPP product has been widely used in studies with various spatial scales and domains (regional to global) in different ecosystems (Wolf et al., 2016; Zscheischler et al., 2014). 
The Penman-Monteith model was adopted to estimate the global MODIS ET product (MOD16A3), which uses meteorological reanalysis data and vegetation property dynamics (e.g., land cover, leaf area index, and albedo). The forcing data for the model are retrieved from the MODIS data (Mu et al., 2013, 2011). The validation of MODIS ET product using station flux tower data showed reasonable accuracy over the Contiguous United States (CONUS) (Mu et al., 2013; Velpuri et al., 2013).

The biome types over the CONUS are determined according the MODIS global land cover product (MCD12Q1) acquired from the global land cover facility of the University of Maryland (http://glcf.umd.edu/data/lc/). In this study, the biomes are classified into 10 types as follows: Evergreen Needleleaf Forest (ENF), Evergreen Broadleaf Forest (EBF), Deciduous Needleleaf Forest (DNF), Deciduous Broadleaf Forest (DBF), Mixed forest, Shrublands, Savannas, Grasslands, Croplands/natural vegetation, and Wetlands. The original spatial resolution of biomes are $500 \mathrm{~m}$ which are aggregated to 1-km to be consistent with the GPP and ET datasets.

\subsubsection{Simulated data}

In this study, soil moisture simulations from the Phase 2 of the North American Land Data Assimilation System (NLDAS-2) is used over the CONUS from 1983 to 2014 with 8 days temporal resolution and spatial resolution of $1 / 8^{\circ}$ (about $12 \mathrm{~km}$ ). The data is available over the north America from 1979 to present (Xia et al., 2012). Soil moisture states are simulated using the Variable Infiltration Capacity (VIC) (Liang et al., 1994; 
Wood et al., 1997) which is a macroscale hydrologic model that ingests meteorological forcing data and solves for full water and energy balances. A Soil-VegetationAtmosphere Transfer (SVAT) scheme controls the moisture and energy fluxes within VIC and in comparison with most SVATs, it reproduces the runoff characteristics more accurately (Maurer et al., 2002). In NLDAS-2 dataset, VIC model, which is a semidistributed grid-based model, was run at a spatial resolution of $1 / 8^{\circ}$ with full energy balance mode at hourly time step. This model represents sub-grid variability of vegetation and runoff generation (Livneh et al., 2013b). The version of the VIC model used for the NLDAS-2 is VIC-4.0.3 which was used by Sheffield et al. (2004). The vadose (unsaturated) zone in each grid cell is partitioned into three layers with a depth of $10 \mathrm{~cm}$ for the top layer and varying depths for other layers.

Table 3-1 Summary of the data used in this study.

\begin{tabular}{|c|c|c|c|c|}
\hline Data & $\begin{array}{l}\text { Original Spatial } \\
\text { Resolution }\end{array}$ & $\begin{array}{l}\text { Temporal } \\
\text { Resolution }\end{array}$ & Unit & Type \\
\hline $\begin{array}{c}\text { Gross Primary Productivity } \\
\text { (GPP) (MOD17A2) }\end{array}$ & $1 \mathrm{~km}$ & 8 days & $\mathrm{gC} / \mathrm{kg} \mathrm{H}_{2} \mathrm{O}$ & $\begin{array}{c}\text { Remotely sensed } \\
\text { by MODIS }\end{array}$ \\
\hline $\begin{array}{c}\text { Evapotranspiration (ET) } \\
\text { (MOD16A2) }\end{array}$ & $1 \mathrm{~km}$ & 8 days & $\mathrm{mm} / \mathrm{m}^{2}$ & $\begin{array}{c}\text { Remotely sensed } \\
\text { by MODIS }\end{array}$ \\
\hline Land cover (MCD12Q1) & $500 \mathrm{~m}$ & monthly & -------- & $\begin{array}{c}\text { Remotely sensed } \\
\text { by MODIS }\end{array}$ \\
\hline Soil Moisture (NLDAS-2) & $1 / 8^{\circ}$ & 8 days & $\mathrm{cm} / \mathrm{cm}$ & $\begin{array}{l}\text { Simulated } \\
\text { by VIC }\end{array}$ \\
\hline
\end{tabular}




\subsection{Methodology}

\subsubsection{Drought Detection}

The root-zone soil moisture percentile is utilized to detect and characterize drought (Shukla et al., 2010; Yan et al., 2018, 2017). The root zone soil moisture percentiles are calculated for each grid each time step with reference to the period of Jan 1, 1984 to Dec 31, 2014. Drought intensity classifications are adopted from the National Drought Mitigation Center (NDMC) United States Drought Monitor (USDM) classes where five categories are defined as Table 3-2.

Table 3-2 USDM drought categories employed in this study to categorize drought intensity.

\begin{tabular}{ccc}
\hline Category & Description & Percentiles (\%) \\
\hline N & Normal/wet condition & 31 to 100 \\
D0 & Abnormally dry & 21 to 30 \\
D1 & Moderate drought & 11 to 20 \\
D2 & Severe drought & 6 to 10 \\
D3 & Extreme drought & 3 to 5 \\
D4 & Exceptional drought & 0 to 2 \\
\hline
\end{tabular}

\subsubsection{Drought Recovery Duration}

The sensitivity of GPP to drought is well documented, and its spatiotemporal patterns can be estimated in several ways (Beer et al., 2010; Zhao and Running, 2010). GPP, a metric of photosynthetic activity, is used in this study to detect the recovery 
duration of terrestrial ecosystem after drought episodes. First, the normal GPP threshold, which is the average of GPP over the study period, is calculated for each grid at 8-day time step (Yu et al., 2017). Then, the ecosystem recovery from a drought episode is defined when the post-drought GPP within one-month (4 consecutive 8-day period) reverts and stays above the normal condition (GPP normal threshold) (Schwalm et al., 2017; Yu et al., 2017). Figure 3-1 provides an overview of the methodology and analysis of this study.

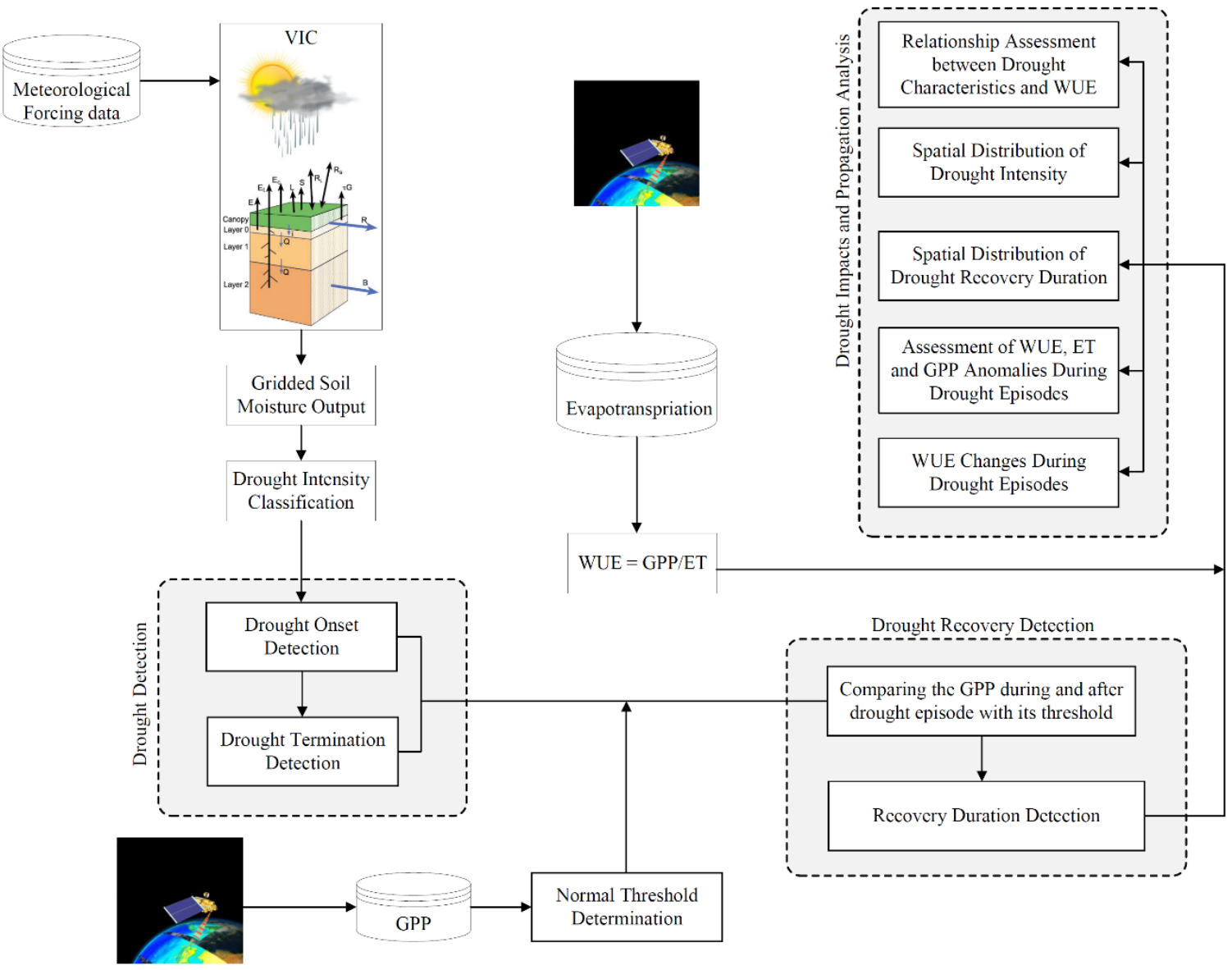

Figure 3-1 The framework for analyzing terrestrial drought recovery considering Gross Primary Production (GPP), and assessing Water Use Efficiency (WUE) response to drought and decomposing the influential factors. 


\subsection{Results and Discussions}

The carbon and water cycles have very strong relationship, which implies that a disturbance in each component of WUE (i.e., GPP or ET), which can be caused by a hydrological extreme event, may impacts carbon cycle as well. In other words, drought is an intermittent disturbance in the water cycle, which can significantly impact the terrestrial carbon cycle (Breshears et al., 2005; Zhao and Running, 2010).

During 2000 to 2014, the average WUE over the Contiguous US (CONUS) is $1.95 \mathrm{gC} / \mathrm{kg} \cdot \mathrm{H} 2 \mathrm{O}$ and shows great spatial variations (Figure 3-2). The dry ecosystems of California, Nevada, Arizona, New Mexico, Utah, and west Texas indicate high values of WUE ranging from $2.4 \mathrm{gC} / \mathrm{kg} \cdot \mathrm{H} 2 \mathrm{O}$ to $4 \mathrm{gC} / \mathrm{kg} \cdot \mathrm{H} 2 \mathrm{O}$. Whereas, WUE is generally less than $1.6 \mathrm{gC} / \mathrm{kg} \cdot \mathrm{H} 2 \mathrm{O}$ in the Midwestern US. At the biome level (shown in Figure 3-3), EBF and Shrublands shows the largest WUE, and Cropland and DNF indicate the lowest WUE. According to Figures 3-2 and 3-3, arid ecosystems indicate the highest WUE (3.2 $\mathrm{gC} / \mathrm{kg} \cdot \mathrm{H} 2 \mathrm{O})$, followed by the coastal regions that show comparable WUE values $(2.2$ $\mathrm{gC} / \mathrm{kg} \cdot \mathrm{H} 2 \mathrm{O})$. The observed differences in WUE among biomes and ecosystems have been well documented by previous studies (Huang et al., 2017; Tang et al., 2014; Yang et al., 2016). Caused by heterogeneities in both environmental conditions and plant physiological characteristics, the drivers controlling the spatial pattern of WUE are determined by elevation, latitude, plant morphology, and climate conditions (Huang et al., 2017; Xue et al., 2015). 


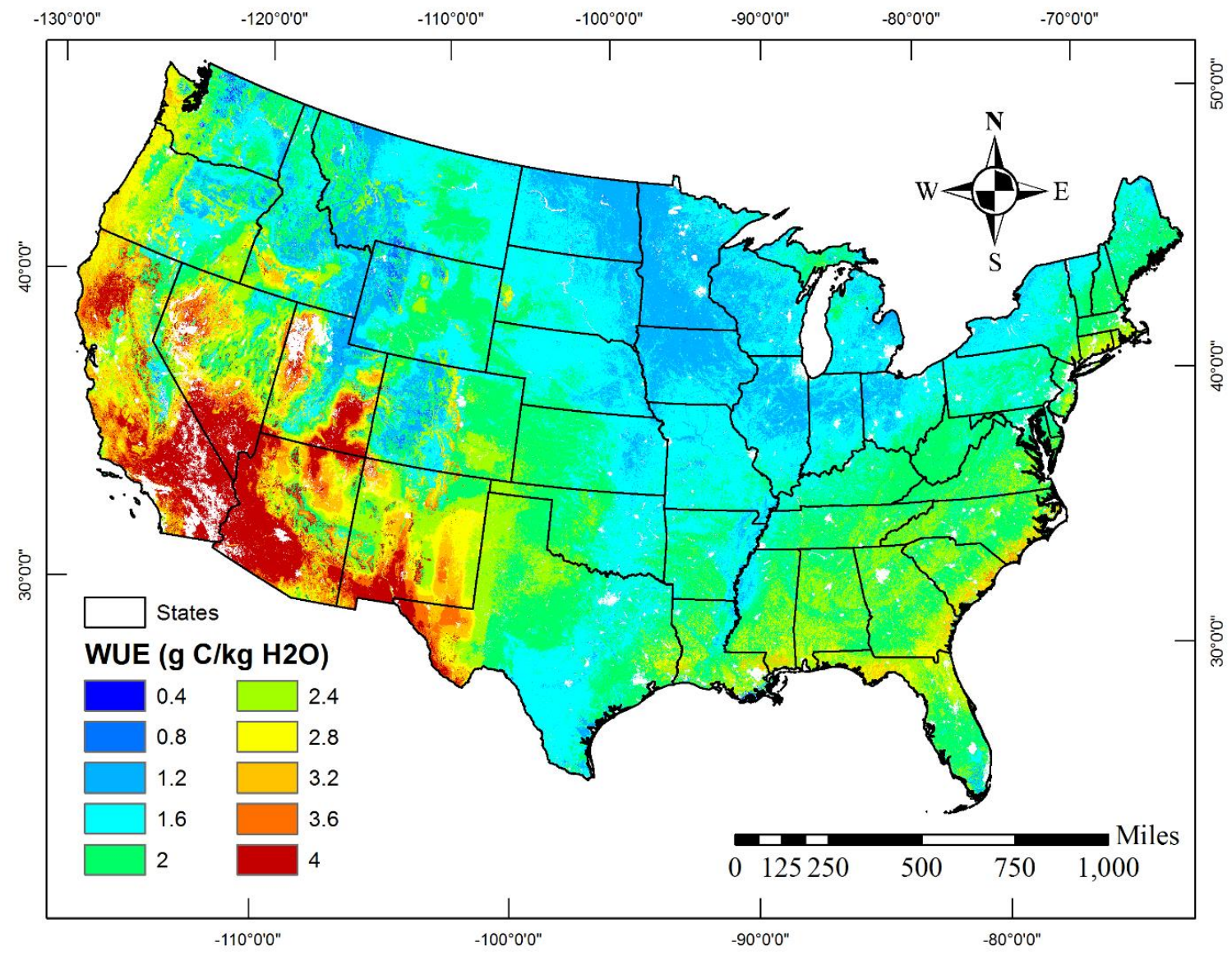

Figure 3-2 Spatial distribution of mean water use efficiency (WUE) over the CONUS for the study period (2000-2014). 


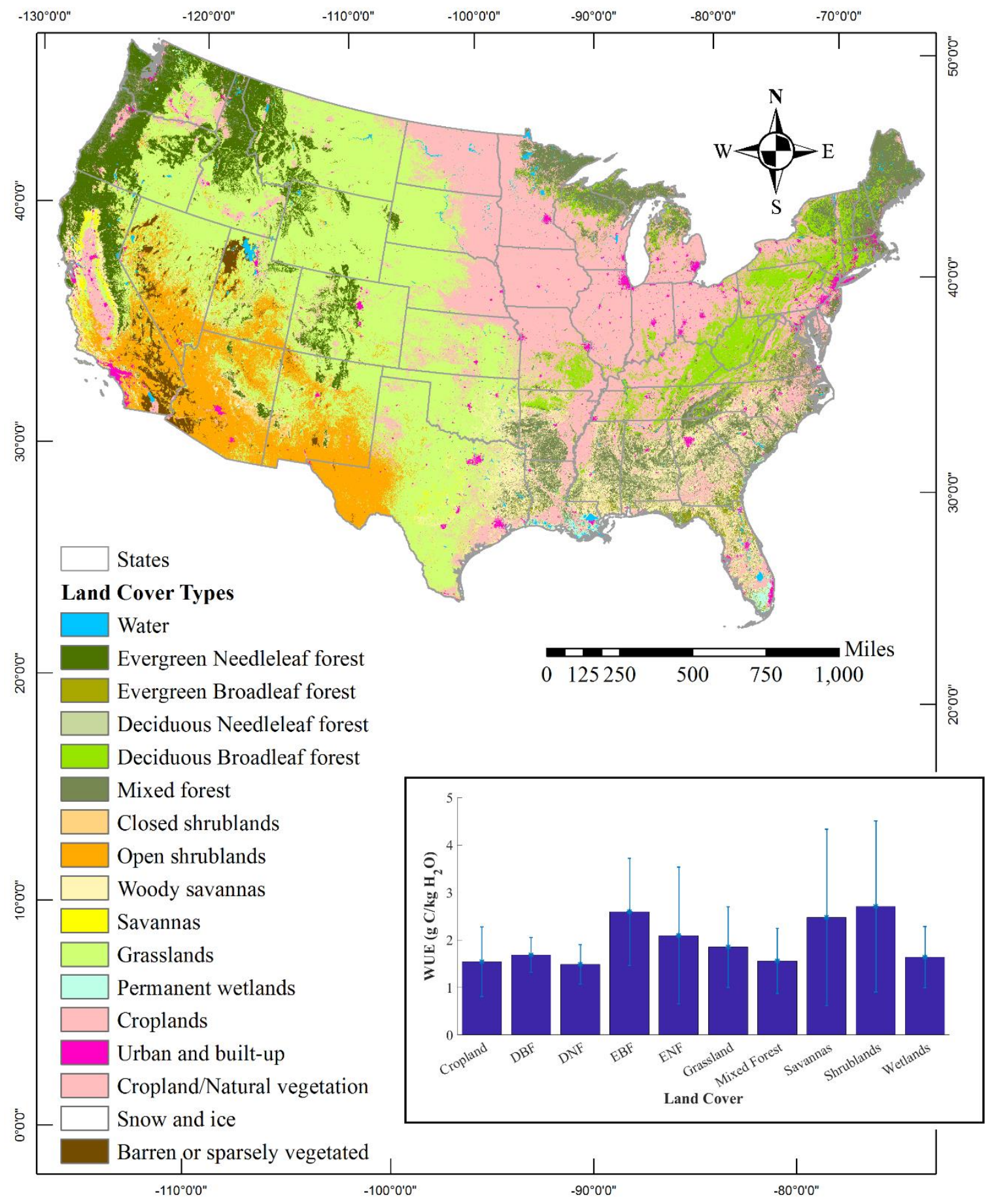

Figure 3-3 Spatial distribution of land cover over the CONUS and the average WUE of each biome during 2000-2014. The lines indicate \pm 1 standard deviation for each case.

Figure 3-4 shows the drought severity and drought recovery duration over the CONUS for 2002, 2008, 2011, and 2012 drought episodes. In 2002, the western US faced 
more severe drought, and some regions in Utah, Colorado, Arizona, and southern California and Nevada experienced extreme drought. Accordingly, drought recovery for these regions took longer time and for the regions that experienced extreme drought condition, the minimum drought recovery is found 3 months. On the other hand, eastern US regions (e.g. North and South Carolina and Virginia) experienced severe drought and the drought recovery duration for these regions was relatively shorter. In 2008 , the severe and extreme drought extent was less than 2002. California, Wisconsin and Washington were among the states that experienced severe drought in 2008. In California and Washington, the areas that was not covered with cropland biome indicates longer drought recovery. Meanwhile, Wisconsin is covered with more cropland biome, and drought recovery was relatively shorter for it in 2008. In North Dakota, Nevada, Utah, and Montana, most of which are covered with grasslands, the regions affected by severe drought show longer drought recovery duration.

Additionally, Figure 3-4 shows that Texas, Oklahoma, Kansas, New Mexico and Arizona faced an extreme drought episode in 2011 (Long et al., 2013; Seager et al., 2013), and the drought recovery duration is found to be over 3-4 months in the region. The 2012 drought was one of the worst drought episodes in recent years which had catastrophic impacts and caused $\$ 40$ billion damage, mostly due to agricultural losses (Hoerling et al., 2013; Rippey, 2015; Wang et al., 2014). Almost two-thirds of the nation dealt with drought on September 2012, according to the US Drought Monitor (Otkin et al., 2017b). Figure 3-4 shows that the central and Midwest states were impacted with severe and extreme drought in 2012. Drought recovery duration is found to be between 23 months for most of the region, which is actually a markedly long period, since the 
drought initiated during the growing season, lasted for several months, and then recovered 2-3 months after termination, which might have even affected the following year's harvest and yield. 


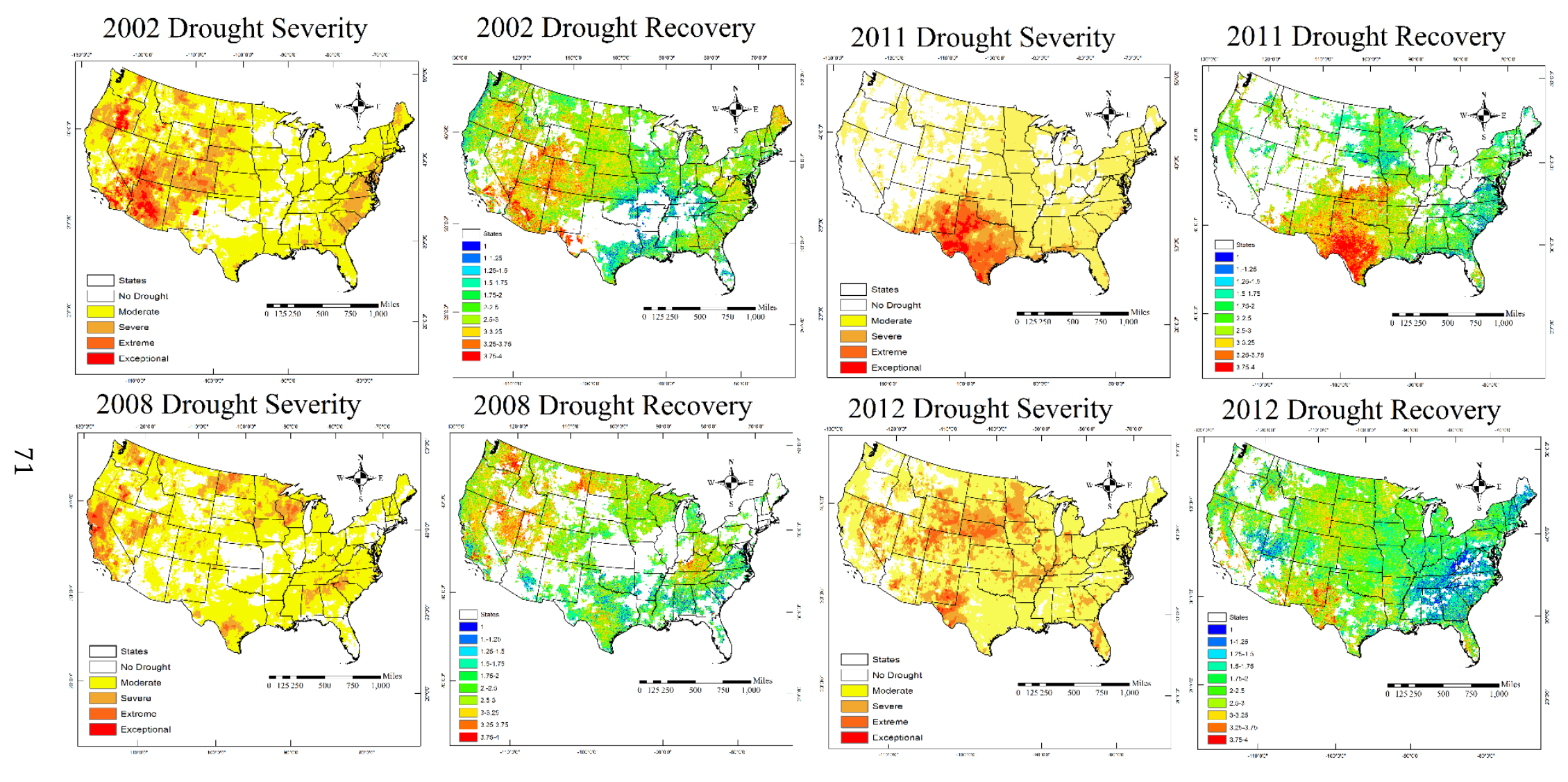

Figure 3-4 Spatial distribution of drought severity (left) and drought recovery duration in months (right) for 2002, 2008, 2011, and 2012 drought episodes. 
In order to better understand the terrestrial impacts of drought, the response of water use efficiency (WUE) is investigated for different drought episodes. Figure 3-5 shows the WUE anomaly during the four major drought episodes of 2002, 2008, 2011, and 2012 across the CONUS. From the figure, it can be seen that WUE responds differently to various drought events for different biomes and climates. In general, the arid areas which faced severe drought show significant increase in WUE during the drought episodes. This is in agreement with previous studies (Liu et al., 2015; VicenteSerrano et al., 2013) indicating that plants in arid regions are highly adapted to the water scarcity associated with arid climate and have more resiliency to water deficits owing to a series of conservative water-use strategies (Huang et al., 2017). Such an adaptation helps the vegetation in arid regions to reduce water loss and maintain vegetation growth. In cold regions, vegetation growth is mainly constrained by air temperature and solar radiation. The higher carbon uptake due to hotter weather that usually coincide with drought episodes (Haghighi et al., 2018; Schwingshackl et al., 2017) may increase WUE in these regions (Liu et al., 2015). Overall, comparing Figures 3-4 and 3-5, WUE is found to substantially increase in response to extreme droughts in each drought episode, indicating that if a region experiences severe drought (or worse), WUE is likely to increase during the drought episode. 

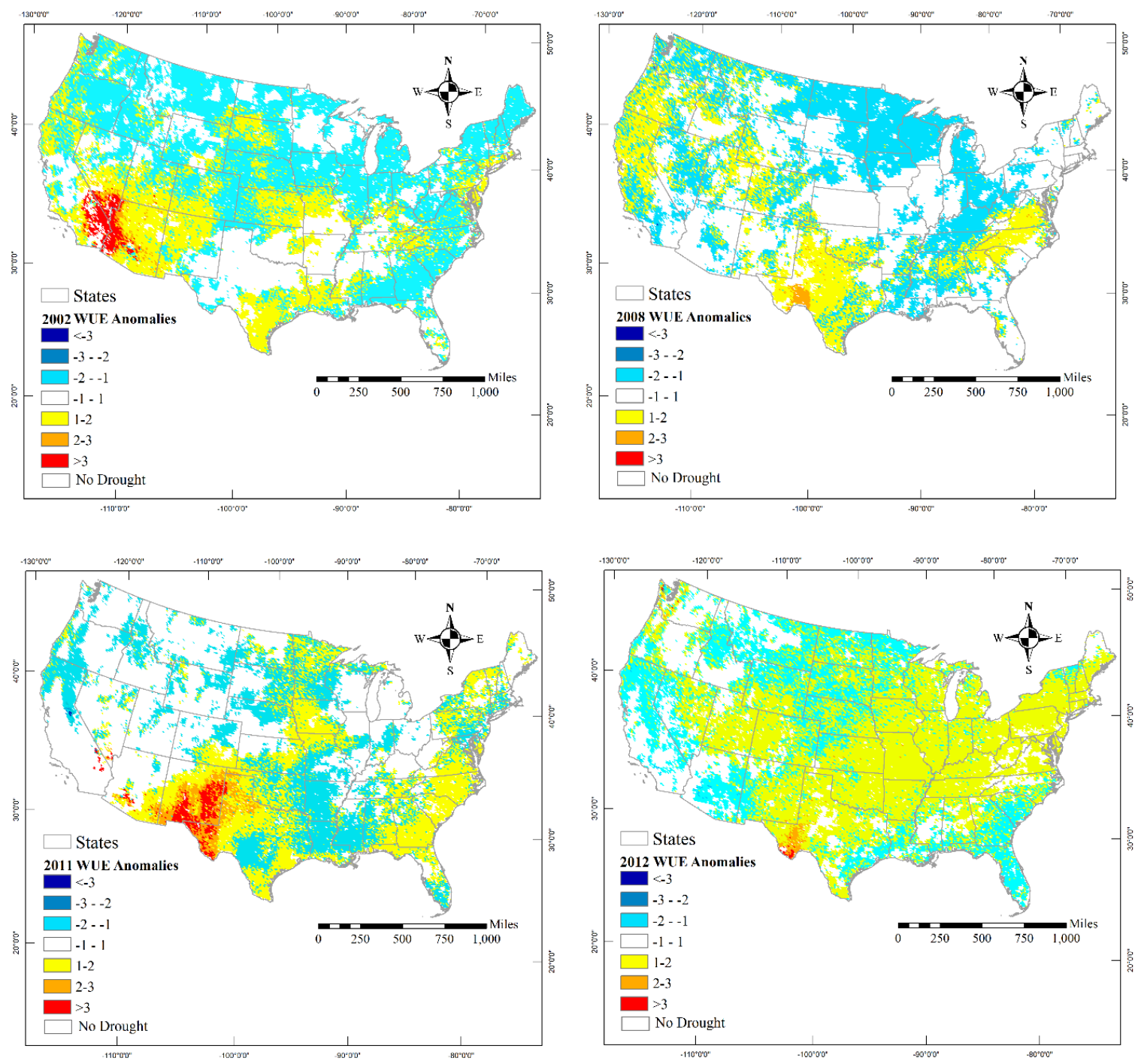

Figure 3-5 Spatial distribution of WUE anomalies during 2002, 2008, 2011, and 2012 drought episodes.

Figure 3-6 shows the relation between drought recovery time, and drought duration and intensity for 2002, 2008, 2011, and 2012 drought episodes. For each year, the areas affected by drought are considered, and the three characteristics are extracted and plotted against each other. In general, a more severe drought episode is expected to result in longer recovery time compared to moderate droughts, which is approved by the 
results of Figure 3-6. Additionally, a longer drought episode increases the likelihood of protracted drought recovery. Comparing these four drought episodes reveals that in 2008 , the area that experienced prolonged severe drought was relatively less than other drought episodes, and consequently, the affected regions needed rather short recovery time. In 2011, the area affected by a prolonged drought episode shows a wider range of recovery time, and recovery duration tends to be longer for the regions that experienced more severe drought. In general, Figure 3-6 implies that drought duration, recovery, and severity are positively correlated, meaning that a prolonged drought will generally result in longer drought recovery time. Similarly, the regions experiencing more severe drought episodes will require more time to recover from drought. 

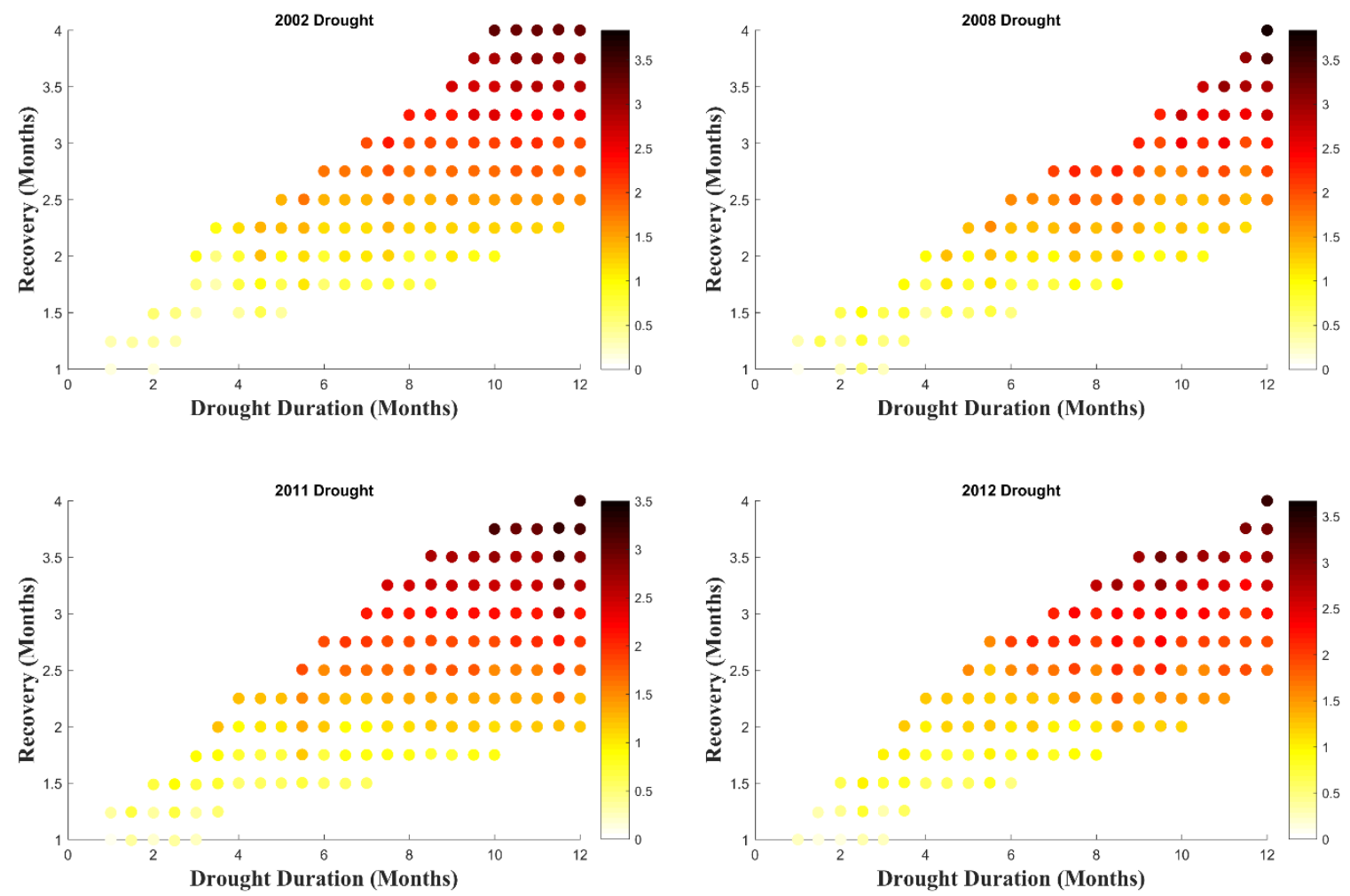

Figure 3-6 The relation between drought recovery time, drought duration, and drought intensity for 2002, 2008, 2011, and 2012 drought episodes over the study area.

To present a descriptive statistics of WUE changes and better understand terrestrial response to agricultural drought, the WUE changes is plotted versus drought severity. Figure 3-7 shows the WUE anomaly for each drought severity level for 2002, 2008, 2011, and 2012 drought episodes over the affected areas. From the figure, a similar respond from WUE changes can be found to various drought severities and episodes. In general, WUE shows sharper and more significant positive anomalies when a region is affected with more severe drought. During the 2002 drought episode, the areas affected by extreme or more intense drought showed an increase in WUE with a maximum value of $1.25 \mathrm{gC} / \mathrm{kg} \mathrm{H} 2 \mathrm{O}$. The regions affected by moderate drought showed relatively lower 
changes of WUE with the minimum and maximum anomaly of -0.3 and 0.5 , respectively. In the 2008 drought episode, more than $75 \%$ of the drought affected areas showed a positive anomaly for WUE. Meanwhile, WUE anomaly is almost always (93\%) positive for severe to extreme droughts. WUE changes in the 2011 drought episode showed wider range and higher maxima compared to other drought episodes. The median of WUE anomaly for the regions affected with severe to extreme drought was $0.5 \mathrm{gC} / \mathrm{kg} \mathrm{H} 2 \mathrm{O}$ in 2011. The 2012 drought event showed similar results, and more than $75 \%$ of the regions affected by drought indicate positive WUE anomaly. In general, Figure 3-7 reveals that WUE deviation and drought severity are positively correlated and a more severe drought increases the likelihood of positive WUE anomaly.
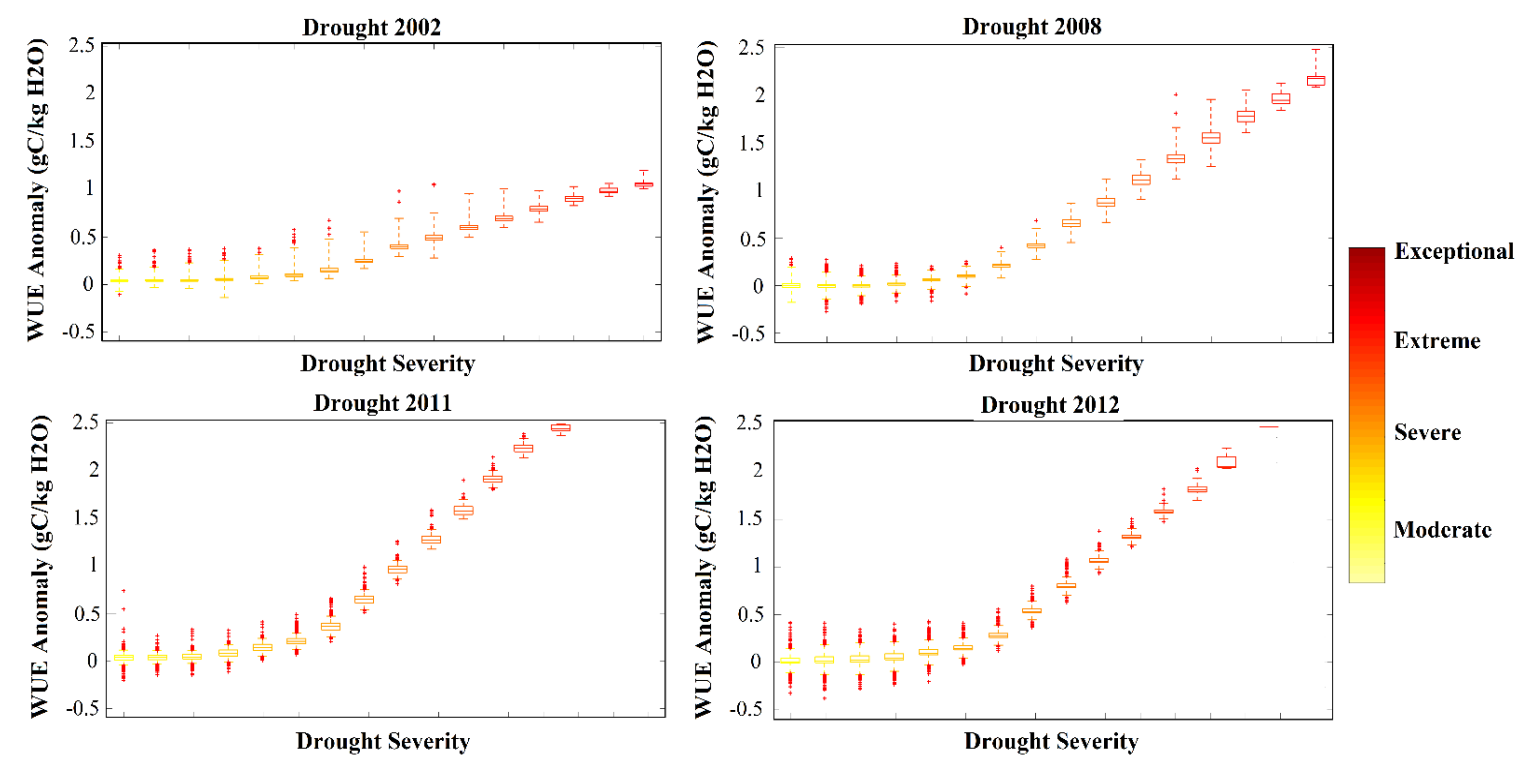

Figure 3-7 The distribution of WUE changes over each drought severities for 2002, 2008, 2011, and 2012 drought episodes over the study area. 
To better understand the WUE changes in relation to its components (ET and GPP) changes during drought episodes, the distribution of relative anomalies of Gross Primary Productivity (GPP), Evapotranspiration (ET), and ecosystem Water Use Efficiency (WUE) for 2002, 2008, 2011, and 2012 drought episodes are shown in Figure 3-8. In the figure, the blue curves on the axes represent the distribution of the corresponding variable. The figure reveals that GPP and ET indicate both positive and negative anomalies during drought. However, the distribution diagram reveals that negative anomaly occurs more often (i.e. the distributions are negatively skewed). Comparing the results of different years, WUE anomaly reaches higher values in 2002 and 2011, which can be attributed to higher severity in these years. Previous studies found drought causes intensively reduction in GPP over most biome land covers (approximately 35\%), while slightly enhanced GPP in evergreen broadleaf forests and shrublands (7\%) (Frank et al., 2015; Yu et al., 2017). In North America, a large reduction of GPP was found (>50\%) reporting net carbon uptake was reduced by $51 \%$ during the 2000-2004 drought in western North America (Liao and Zhuang, 2015; Schwalm et al., 2012). Similarly, previous studies found decreases in WUE ranging from $0.96 \%$ to $27.67 \%$ and increases in WUE ranging from $7 \%$ to $15 \%$ under drought stress (Huang et al., 2017; Schwalm et al., 2012; Yu et al., 2017). Overall, this figure illustrates that if the relative anomaly of ET is larger than that of GPP, WUE anomaly will be positive (shown in green color), and vice versa. 

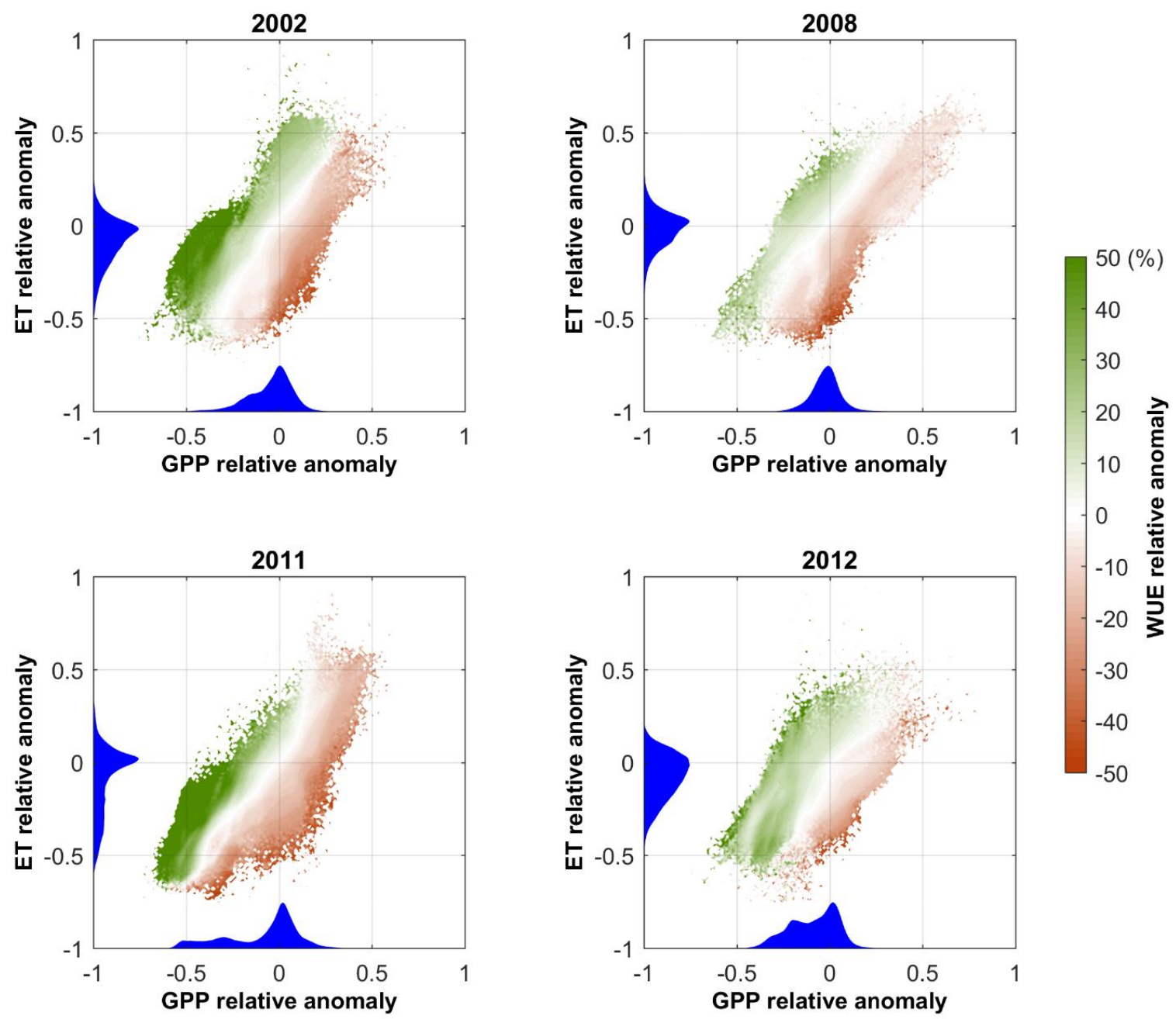

Figure 3-8 The distribution of relative anomaly of ET, GPP, and WUE for 2002, 2008, 2011, and 2012 drought episodes. In each plot, the blue curves on the axes show the distribution of the corresponding variable.

In order to better understand the terrestrial effects of drought on water resources, the changes of evapotranspiration (ET) during drought are investigated for different drought episodes. Figure 3-9 shows the ET anomaly during the four major drought episodes of 2002, 2008, 2011, and 2012 across the CONUS. From the figure, it can be seen that ET tends to be below average in the areas affected by severe (or more intense) 
drought. This negative anomaly is found to be common both dry and humid climates, which highlights that water availability is the dominant factor in evapotranspiration deviation (Stegehuis et al., 2013; Yu et al., 2017). Drought episodes usually start with lack of rainfall, which leads to drier soils, and it is often assumed that ET rates will decrease when soil moisture decreases. On the other hand, it has been discussed that ET is restricted to low values of available soil moisture (Seneviratne et al., 2012; Teuling et al., 2010). Therefore, for different soil moisture content, ET changes based on the variability in atmospheric conditions rather than variability in soil moisture. In humid climate regions, which is energy limited, during drought atmospheric conditions intensify ET and lead to increased rather than decreased ET (Seneviratne et al., 2012). Similarly, in dry climate regions that is water limited, increases in ET were also seen during warm conditions that often coincide with drought (Stegehuis et al., 2013; Teuling et al., 2015b, 2010). In dry climate, the observed increase in ET during droughts can be attributed to plants that have deep and extensive root systems and obtain water from larger area near the water table rather than from the smaller overlying soil zone and increase the transpiration (Stegehuis et al., 2013; Teuling et al., 2015b). 

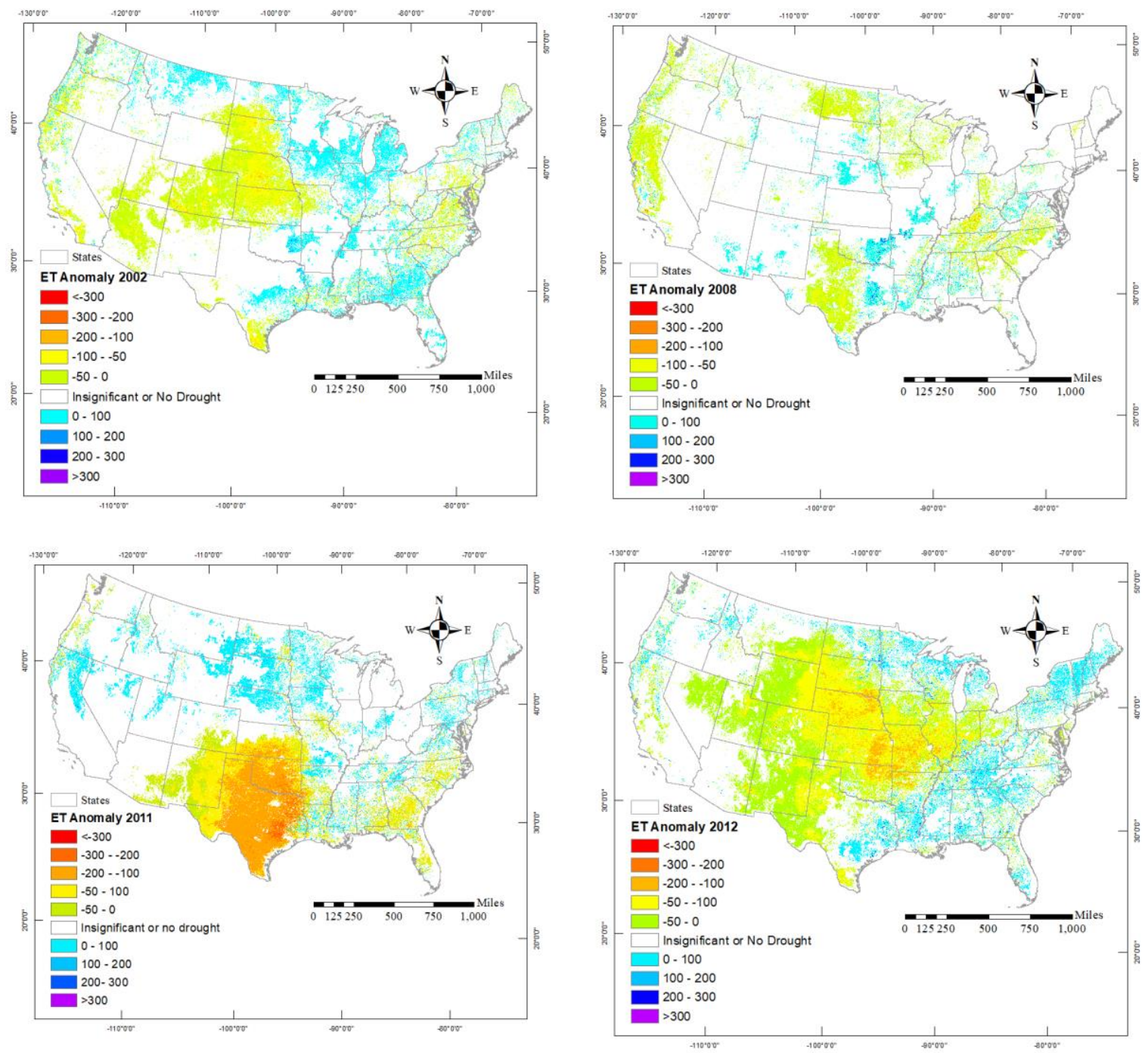

Figure 3-9 Spatial distribution of ET anomalies for 2002, 2008, 2011, and 2012 drought episodes.

\subsection{Summary and Conclusion}

This study investigated the agricultural drought impacts on water use efficiency (WUE) and its components, gross primary productivity (GPP) and evapotranspiration (ET), as well as the recovery duration that terrestrial ecosystem required to revert to its 
pre-drought state during the period of 2000 to 2014. WUE was analyzed for different land cover types. Arid and coastal ecosystems indicated the highest WUE, whereas, it was generally lowest in the Midwestern US. The ecosystem recovery from a drought episode is defined when the post-drought GPP within one-month (4 consecutive 8-day period) reverts and stays above the normal condition (GPP normal threshold). Drought recovery analysis reveals that, required time for each region to revert to its pre-drought condition is positively correlated with drought severity and when a region experienced more severe drought, a longer drought recovery is more likely. Additionally, a longer drought episode increases the likelihood of protracted drought recovery. During drought, WUE shows a tendency to increase in response to extreme severity in each drought episode, indicating that if a region was affected by a severe drought (or worse), WUE is likely to increase during the drought episode. Statistical analysis on WUE anomalies and its components during drought illustrated that if the relative anomaly of ET is larger than that of GPP, WUE anomaly will be positive and if the relative anomaly of ET is smaller than that of GPP, WUE anomaly will be negative. Spatial distribution of ET anomalies showed that ET has tendency to be below average in the regions affected by severe (or more intense) and prolonged drought in both dry and humid climates, which highlights that water availability is the dominant factor in evapotranspiration. 


\section{Conclusions and Future Studies}

In this dissertation, a comprehensive framework was developed to assess drought impacts on terrestrial and riverine ecosystems and analyze the recovery time for each ecosystem type. To this end, a multi-stage framework was developed to detect and characterize hydrological droughts, while considering water quality parameters. Employing the drought-stage classification, this study characterized the hydrological drought over the CONUS during 1950-2016. The method divides each drought event into three stages: Growth, Persistence and Retreat. This study also analyzed drought recovery, which is defined as a phase starting in the drought period (retreat) and continuing after drought termination. Correlation analysis confirmed that the stations that experience longer drought, longer drought recovery period is also expected.

From water quality perspective, droughts deteriorate dissolved oxygen and increase temperature but improve turbidity; however, turbidity rises at the time of drought termination and then degrades. Turbidity improvement is attributed to the decreased catchment runoff and increased sedimentation due to the lower flow velocity. Water quality analysis also proves that, water quality parameters need about 60 days (on average) to revert to their normal condition.

This study investigated the agricultural drought impacts on water use efficiency (WUE) and its components; gross primary productivity (GPP) and evapotranspiration (ET), as well as the recovery duration that terrestrial ecosystems require to revert to predrought normal conditions. WUE was analyzed for different land cover types, and arid and coastal ecosystems indicated the highest WUE, and Midwest US was associated with 
the lowest WUE. Drought recovery was analyzed according to the GPP rate, and it revealed that the required time for each region to revert to its pre-drought condition is positively correlated with drought severity. Therefore, a more severe drought will most likely result in a longer drought recovery time. Additionally, a prolonged drought episode increases the likelihood of protracted drought recovery. During drought, WUE showed a tendency to increase in response to extreme drought condition. Decomposing WUE anomalies to its components during drought illustrated that if the relative anomaly of ET is larger than that of GPP, WUE anomaly will be positive and if the relative anomaly of ET is smaller than that of GPP, WUE anomaly will be negative. Moreover, the spatial distribution of ET anomaly showed that ET has a tendency to be below average in the regions affected by severe (or more intense) and prolonged drought in both dry and humid climates, corroborating the dominance of water availability for evapotranspiration.

While comprehensive analyses were carried out to provide accurate and reliable assessments, this study can be further improved from various perspectives considering climate change impacts, longer datasets for remotely sensed data and forecasting drought episodes using the developed frameworks. Suggestions regarding improvements on each sector are introduced in the following:

\section{- Climate change impacts}

Multitude of studies have demonstrated that the global climate has changed in the past decades primarily due to the increase in concentration of greenhouse gases and numerous studies have pointed out the impacts of climate change on extreme events (drought). The impacts of climate change on droughts and water quality have been 
investigated on previous studies but the concurrent impact has not investigated. Meaning that future drought episodes and their impacts on water quality and drought recovery changes due to climate change are the topics that can be studied further for future studies.

\section{- longer datasets for remotely sensed data}

In this dissertation, the terrestrial drought recovery was assessed using the global MODIS dataset (MOD16A3, MOD17A3) during a 15 years' time period (2000-2014), which would introduce some uncertainties to our results. This highlights the need for

continued field observations, improvements in the accuracy of remote sensing and upgrades in the performance of models and doing further analysis when longer datasets are provided.

\section{- Forecasting drought episodes using the developed frameworks}

In this dissertation, the historic droughts and their ecological impacts were analyzed using the developed frameworks. These frameworks, which were verified in regional and national scales, can be utilized for forecasting future drought using the current conditions and the expected recovery duration for them can be estimated.

\section{- Climate variability}

The role of atmospheric circulation patterns on drought propagation can be analyzed and discussed. The correlation analysis can explain the role of atmospheric circulation pattern in drought spatial distribution and characteristics. 


\section{References}

Ahmadalipour, A., Moradkhani, H., Svoboda, M., 2016. Centennial drought outlook over the CONUS using NASA-NEX downscaled climate ensemble. Int. J. Climatol. 37, 2477-2491. https://doi.org/doi:10.1002/joc.4859

Ahmadalipour, A., Moradkhani, H., Yan, H., Zarekarizi, M., 2017. Remote Sensing of Drought: Vegetation, Soil Moisture, and Data Assimilation BT - Remote Sensing of Hydrological Extremes, in: Lakshmi, V. (Ed.), . Springer International Publishing, Cham, pp. 121-149. https://doi.org/10.1007/978-3-319-43744-6_7

Ahmadalipour, A., Moradkhani, H., (2017b). Analyzing the uncertainty of ensemblebased gridded observations in land surface simulations and drought assessment. J. Hydrol. 555, 557-568. https://doi.org/10.1016/j.jhydrol.2017.10.059

Ahmadalipour, A., Moradkhani, H., Demirel, M.C., (2017a). A comparative assessment of projected meteorological and hydrological droughts: Elucidating the role of temperature. J. Hydrol. 553, 785-797. https://doi.org/10.1016/j.jhydrol.2017.08.047

Ahmadi, B., Moradkhani, H., (2019), Revisiting hydrological drought propagataion and recovery considering water quantity and quality, J. Hydrological Processes, https://doi.org/10.1002/hyp.13417

Ahmadi, B., Ahmadalipour, A., Moradkhani, H., (2019), Hydrological drought persistence and recovery over the CONUS: a multi-stage framework considering water quantity and quality, Water Research, 150, 97-110.

Anderegg, W.R.L., Schwalm, C., Biondi, F., Camarero, J.J., Koch, G., Litvak, M., Ogle, K., Shaw, J.D., Shevliakova, E., Williams, A.P., Wolf, A., Ziaco, E., Pacala, S., (2015). Pervasive drought legacies in forest ecosystems and their implications for carbon cycle models. Science (80-. ). 349, 528-532. https://doi.org/10.1126/science.aab1833

Anderson, M.C., Hain, C., Otkin, J., Zhan, X., Mo, K., Svoboda, M., Wardlow, B., Pimstein, A., (2013). An Intercomparison of Drought Indicators Based on Thermal Remote Sensing and NLDAS-2 Simulations with U.S. Drought Monitor Classifications. J. Hydrometeorol. 14, 1035-1056. https://doi.org/10.1175/JHM-D$12-0140.1$

Asadi Zarch, M.A., Malekinezhad, H., Mobin, M.H., Dastorani, M.T., Kousari, M.R., (2011), Drought Monitoring by Reconnaissance Drought Index (RDI) in Iran, Water Resour Manage 25: 3485. https://doi.org/10.1007/s11269-011-9867-1

Austin, S.H., Wolock, D.M., Nelms, D.L., (2018). Variability of hydrological droughts in the conterminous United States, 1951 through 2014: U.S. Geological Survey Scientific Investigations Report 2017-5099, 16 p., https://doi.org/10.3133/sir20175099.

Alley, R.B., Berntsen, T., Bindoff, N.L., Chen, Z., Chidthaisong, A., Friedlingstein, P., 
Gregory, J.M., Hegerl, G.C., Heimann, M., Hewitson, B., Hoskins, B.J., Joos, F., Jouzel, J., Kattsov, V., Lohmann, U., Manning, M., Matsuno, T., Molina, M., Nicholls, N., Overpeck, J., Qin, D., Raga, G., Ramaswamy, V., Ren, J., Rusticucci, M., Solomon, S., Somerville, R., n.d. Summary for Policymakers.

Baldwin, D. S., Gigney, H., Wilson, J. S., Watson, G., \& Boulding, A. N. (2008). Drivers of water quality in a large water storage reservoir during a period of extreme drawdown. Water Research, 42(19), 4711-4724. http://doi.org/10.1016/j.watres.2008.08.020

Baurès, E., Delpla, I., Merel, S., Thomas, M.-F., Jung, A.-V., Thomas, O., (2013). Variation of organic carbon and nitrate with river flow within an oceanic regime in a rural area and potential impacts for drinking water production. J. Hydrol. 477, 8693. https://doi.org/10.1016/j.jhydrol.2012.11.006

Bonsal, B.R., Wheaton, E.E., Meinert, A., Siemens, E., (2011). Characterizing the surface features of the 1999-2005 Canadian prairie drought in relation to previous severe twentieth century events. Atmosphere-Ocean 49, 320-338. https://doi.org/10.1080/07055900.2011.594024

Boulton, A.J., Lake, P.S., (1992). The ecology of two intermittent streams in Victoria, Australia: II. Comparisons of faunal composition between habitats, rivers and years. Freshw. Biol. 27, 99-121. https://doi.org/10.1111/j.1365-2427.1992.tb00527.x

Brown, T.C., Hobbins, M.T., Ramirez, J.A., 2008. Spatial distribution of water supply in the coterminous United States. J. Am. Water Resour. Assoc. 6 (44), 1474- 1487

Brumbaugh, R., Werick, W., Teitz, W., Lund, J., (1994). Lessons Learned from the California Drought (1987-1992): Executive Summary, IWR Report 94-NDS-6, Institute for Water Resources, U.S. Army Corps of Engineers, Alexandria, VA.

Buskey, E.J., Liu, H., Collumb, C., Bersano, J.G.F., (2001). The decline and recovery of a persistent Texas brown tide algal bloom in the Laguna Madre (Texas, USA). Estuaries 24, 337-346. https://doi.org/10.2307/1353236.

B. Cohen, W., K. Maiersperger, T., P. Turner, D., D. Ritts, W., Pflugmacher, D., E. Kennedy, R., Kirschbaum, A., W. Running, S., Costa, M., Gower, S., 2006. MODIS land cover and LAI collection 4 product quality across nine sites in the western hemisphere, Geoscience and Remote Sensing, IEEE Transactions on. https://doi.org/10.1109/TGRS.2006.876026

Beer, C., Reichstein, M., Tomelleri, E., Ciais, P., Jung, M., Carvalhais, N., Rödenbeck, C., Arain, M.A., Baldocchi, D., Bonan, G.B., Bondeau, A., Cescatti, A., Lasslop, G., Lindroth, A., Lomas, M., Luyssaert, S., Margolis, H., Oleson, K.W., Roupsard, O., Veenendaal, E., Viovy, N., Williams, C., Woodward, F.I., Papale, D., 2010. Terrestrial Gross Carbon Dioxide Uptake: Global Distribution and Covariation with Climate. Science (80-. ). 329, 834-838. https://doi.org/10.1126/science.1184984

Breshears, D.D., Cobb, N.S., Rich, P.M., Price, K.P., Allen, C.D., Balice, R.G., Romme, W.H., Kastens, J.H., Floyd, M.L., Belnap, J., Anderson, J.J., Myers, O.B., Meyer, 
C.W., 2005. Regional vegetation die-off in response to global-change-type drought. Proc. Natl. Acad. Sci. 102, 15144-15148. https://doi.org/10.1073/pnas.0505734102

Ceppi, P., Zelinka, M.D., Hartmann, D.L., 2014. The response of the Southern Hemispheric eddy-driven jet to future changes in shortwave radiation in CMIP5. Geophys. Res. Lett. 41, 3244-3250. https://doi.org/doi:10.1002/2014GL060043

Champagne, C., McNairn, H., Berg, A.A., 2011. Monitoring agricultural soil moisture extremes in Canada using passive microwave remote sensing. Remote Sens. Environ. 115, 2434-2444. https://doi.org/https://doi.org/10.1016/j.rse.2011.04.030

Chiang, F., Mazdiyasni, O., Aghakouchak, A., 2018. Amplified warming of droughts in southern United States in observations and model simulations 1-7.

Connor, J.D., Crossman, N.D., Banerjee, O., Bark, R., Connor, J., Crossman, N.D., 2013. An ecosystem services approach to estimating economic losses associated with drought An ecosystem services approach to estimating economic losses associated with drought. Ecol. Econ. 91. https://doi.org/10.1016/j.ecolecon.2013.03.022

Caruso, B.S., (2001). Regional river flow, water quality, aquatic ecological impacts and recovery from drought. Hydrol. Sci. J. 46, 677-699. https://doi.org/10.1080/02626660109492864.

Caruso, B.S., (2002). Temporal and spatial patterns of extreme low flows and effects on stream ecosystems in Otago, New Zealand. J. Hydrol. 257, 115-133. https://doi.org/10.1016/S0022-1694(01)00546-7

Chessman, B.C., Robinson, D.P., (1987). Some effects of the 1982-83 drought on water quality and macroinvertebrate fauna in the lower La Trobe River, Victoria. Mar. Freshw. Res. 38, 289-299.

Crausbay, S.D., Ramirez, A.R., Carter, S.L., Cross, M.S., Hall, K.R., Bathke, D.J., Betancourt, J.L., Colt, S., Cravens, A.E., Dalton, M.S., (2017). Defining ecological drought for the 21st century. Bull. Am. Meteorol. Soc. https://doi.org/10.1175/BAMS-D-16-0292.1

Dan, L.I.U., Chenglong, Y.U., Fang, Z., 2018. Response of the water use efficiency of natural vegetation to drought in Northeast China. j Geor. Sci 28, 611-628. https://doi.org/https://doi.org/10.1007/s11442-018-1494-9 (C)

Dechant, C.M., Moradkhani, H., 2015. Analyzing the sensitivity of drought recovery forecasts to land surface initial conditions. J. Hydrol. 526, 89-100. https://doi.org/10.1016/j.jhydrol.2014.10.021

Delpla, I., Jung, A. V., Baures, E., Clement, M., \& Thomas, O. (2009). Impacts of climate change on surface water quality in relation to drinking water production. Environment International, 35(8), 1225-1233. http://doi.org/10.1016/j.envint.2009.07.001

Escorihuela, M.J., Quintana-Seguí, P., 2016. Comparison of remote sensing and 
simulated soil moisture datasets in Mediterranean landscapes. Remote Sens.

Environ. 180, 99-114. https://doi.org/https://doi.org/10.1016/j.rse.2016.02.046

Fleig, A.K., Tallaksen, L.M., Hisdal, H., Demuth, S., (2006). A global evaluation of streamflow drought characteristics. Hydrol. Earth Syst. Sci. Discuss. 10, 535-552. https://doi.org/10.5194/hess-10-535-2006.

Frank, D., Reichstein, M., Bahn, M., Thonicke, K., Frank, D., Mahecha, M.D., Smith, P., Velde, M., Vicca, S., Babst, F., Beer, C., Buchmann, N., Canadell, J.G., Ciais, P., Cramer, W., Ibrom, A., Miglietta, F., Poulter, B., Rammig, A., Seneviratne, S.I., Walz, A., Wattenbach, M., Zavala, M.A., Zscheischler, J., 2015. Effects of climate extremes on the terrestrial carbon cycle: concepts, processes and potential future impacts. Glob. Chang. Biol. 21, 2861-2880. https://doi.org/doi:10.1111/gcb.12916

Golladay, S.W., Battle, J., (2002). Effects of flooding and drought on water quality in gulf coastal plain streams in Georgia. J. Environ. Qual. 31, 1266-1272.

Göransson, G., Larson, M., Bendz, D., (2013). Variation in turbidity with precipitation and flow in a regulated river system-river Göta Älv, SW Sweden. Hydrol. Earth Syst. Sci. 17, 2529-2542. https://doi.org/10.5194/hess-17-2529-2013.

Griffin, D., Anchukaitis, K.J., (2014). How unusual is the 2012-2014 California drought? Geophys. Res. Lett. 41, n/a-n/a. https://doi.org/10.1002/2014GL062433

Ha, K., Cho, E.-A., Kim, H.-W., \& Joo, G.-J. (1999). <emph type $=$ " 2 " $>$ Microcystis $</$ emph $>$ bloom formation in the lower Nakdong River, South Korea: importance of hydrodynamics and nutrient loading. Marine and Freshwater Research, 50(1), 89-94. Retrieved from https://doi.org/10.1071/MF97039

Hameed, M., A. Ahmadalipour, H. Moradkhani (2018), Apprehensive Drought Characteristics over Iraq: Results of a Multidecadal Spatiotemporal Assessment, Geosciences, Special Issue Drought Monitoring and Prediction, 8, 8, 58

Hanslík, E., Marešová, D., Juranová, E., Vlnas, R., (2016). Dependence of selected water quality parameters on flow rates at river sites in the Czech Republic. J. Sustain. Dev. Energy, Water Environ. Syst. 4, 127-140. https://doi.org/10.13044/j.sdewes.2016.04.0011.

Harvey, R., Lye, L., Khan, A., \& Paterson, R. (2011). The Influence of Air Temperature on Water Temperature and the Concentration of Dissolved Oxygen in Newfoundland Rivers. Canadian Water Resources Journal, 36(2), 171-192. http://doi.org/10.4296/cwrj3602849

Halsinger, K., Koffler, D., Schoner, W., Laaha, G., 2014, Exploring the link between meteorological drought and streamflow: Effects of climate-catchment interaction, Water Resources Research, 50, 2468-2487.

Hellwig, J., Stahl, K., Lange, J., (2017). Patterns in the linkage of water quantity and quality during low-flows. Hydrol. Process. 31, 4195-4205. https://doi.org/10.1002/hyp.11354. 
Heudorfer, B., Stahl, K., (2016). Comparison of different threshold level methods for drought propagation analysis in Germany. Hydrol. Res. DOI: 10.2166/nh.2016.258.

Hisdal, H., Tallaksen, M., Clausen, B., Peters, E., Gustard A., (2004). Hydrological Drought Characteristics, Elsevier Science B.V., Amsterdam, the Netherlands, Developments in Water Science, 48, 2004, Chapter 5, pp. 139-198. https://doi.org/10.1016/j.jhydrol.2014.10.059.

Hobbins, M., Wood, A., McEvoy, D., Huntington, J., Morton, C., Verdin, J., Anderson, M., Hain, C., (2016). The Evaporative Demand Drought Index: Part I-Linking Drought Evolution to Variations in Evaporative Demand. J. Hydrometeorol. 17, 1745-1761. https://doi.org/10.1175/JHM-D-15-0121.1.

Hrdinka, T., Novický, O., Hanslík, E., Rieder, M., (2012). Possible impacts of floods and droughts on water quality. J. Hydro-environment Res. 6, 145-150. https://doi.org/10.1016/j.jher.2012.01.008.

Haghighi, E., Short Gianotti, D.J., Akbar, R., Salvucci, G.D., Entekhabi, D., 2018. Soil and Atmospheric Controls on the Land Surface Energy Balance: A Generalized Framework for Distinguishing Moisture-Limited and Energy-Limited Evaporation Regimes. Water Resour. Res. 54, 1831-1851. https://doi.org/doi:10.1002/2017WR021729

He, M., Kimball, J.S., Running, S., Ballantyne, A., Guan, K., Huemmrich, F., 2016. Remote Sensing of Environment Satellite detection of soil moisture related water stress impacts on ecosystem productivity using the MODIS-based photochemical re fl ectance index. Remote Sens. Environ. 186, 173-183. https://doi.org/10.1016/j.rse.2016.08.019

Heinsch, F., Reeves, M., Votava, P., Kang, S., Cristina, M., Zhao, M., Glassy, J., Jolly, W., Loehman, R., F. Bowker, C., Kimball, J., Nemani, R., 2003. User's guide GPP and NPP (MOD17A2/A3) products NASA MODIS land algorithm, Version 2.0.

Heinsch, F.A., Zhao, M., Running, S.W., Kimball, J.S., Nemani, R.R., Davis, K.J., Bolstad, P. V, Cook, B.D., Desai, A.R., Ricciuto, D.M., Law, B.E., Oechel, W.C., Kwon, H., Luo, H., Wofsy, S.C., Dunn, A.L., Munger, J.W., Baldocchi, D.D., Xu, L., Hollinger, D.Y., Richardson, A.D., Stoy, P.C., Siqueira, M.B.S., Monson, R.K., Burns, S.P., Flanagan, L.B., 2006. Evaluation of Remote Sensing Based Terrestrial Productivity From MODIS Using Regional Tower Eddy Flux Network Observations 44, 1908-1925.

Hoerling, M., Eischeid, J., Kumar, A., Leung, R., Mariotti, A., Mo, K., Schubert, S., Seager, R., 2013. Causes and Predictability of the 2012 Great Plains Drought. Bull. Am. Meteorol. Soc. 95, 269-282. https://doi.org/10.1175/BAMS-D-13-00055.1

Houser, P.R., Shuttleworth, W.J., Famiglietti, J.S., Gupta, H. V, Syed, K.H., Goodrich, D.C., 1998. Integration of soil moisture remote sensing and hydrologic modeling using data assimilation. Water Resour. Res. 34, 3405-3420. https://doi.org/doi:10.1029/1998WR900001 
Huang, L., He, B., Han, L., Liu, J., Wang, H., Chen, Z., 2017. Science of the Total Environment A global examination of the response of ecosystem water-use ef fi ciency to drought based on MODIS data. Sci. Total Environ. 601-602, 1097-1107. https://doi.org/10.1016/j.scitotenv.2017.05.084

Huntington, T., 2006. Evidence for Intensification of the Global Water Cycle: Review and Synthesis, Journal of Hydrology. https://doi.org/10.1016/j.jhydrol.2005.07.003

IPCC, 2014. Climate Change 2013: The Physical Science Basis. Cambridge University Press, 134p.

Irannezhad, M., Ahmadi, B., Kløve, B., Moradkhani, H., 2017. Atmospheric circulation patterns explaining climatological drought dynamics in the boreal environment of Finland, 1962-2011. Int. J. Climatol. 37. https://doi.org/10.1002/joc.5039

Israel, M., Lund, J.R., (1995). Recent California water transfers: Implications for water management. Nat. Resour. J. 1-32.

Jung, M., Reichstein, M., Ciais, P., Seneviratne, S.I., Sheffield, J., Goulden, M.L., Bonan, G., Cescatti, A., Chen, J., de Jeu, R., Dolman, A.J., Eugster, W., Gerten, D., Gianelle, D., Gobron, N., Heinke, J., Kimball, J., Law, B.E., Montagnani, L., Mu, Q., Mueller, B., Oleson, K., Papale, D., Richardson, A.D., Roupsard, O., Running, S., Tomelleri, E., Viovy, N., Weber, U., Williams, C., Wood, E., Zaehle, S., Zhang, K., 2010. Recent deceleration of global land evapotranspiration due to moisture supply limitation. Nature 467, 951-954. http://dx.doi.org/10.1038/nature09396.

Karamouz M, Yazdi MSS, Ahmadi B, Zahraie B (2011), A system dynamics approach to economic assessment of water supply and demand strategies. EWRI Proceedings of the 2011 World Environmental and Water Resources Congress 1194-1203, https://doi.org/10.1061/41173(414)123

Karamouz, M., Ahmadi, A., Yazdi, M.S.S., Ahmadi, B., (2013). Economic assessment of water resources management strategies. J. Irrig. Drain. Eng. 140, https://doi.org/10.1061/(ASCE)IR.1943-4774.0000654.

Karamouz, M., Ahmadi, B., Zahmatkesh, Z., (2012). Developing an agricultural planning model in a watershed considering climate change impacts. J. Water Resour. Plan. Manag. 139, 349-363. https://doi.org/10.1061/(ASCE)WR.1943-5452.0000263.

KO, M.-K., Tarhule, A., (1994). Streamflow droughts of northern Nigerian rivers. Hydrol. Sci. J. 39, 19-34. https://doi.org/10.1080/02626669409492717

Kruskal, W.H., Wallis, W.A., (1952). Use of ranks in one-criterion variance analysis. J. Am. Stat. Assoc. 47, 583-621.

Kang, C.S., Kanniah, K.D., Kerr, Y.H., Cracknell, A.P., 2016. Analysis of in-situ soil moisture data and validation of SMOS soil moisture products at selected agricultural sites over a tropical region. Int. J. Remote Sens. 37, 3636-3654.

https://doi.org/10.1080/01431161.2016.1201229 
Keyantash, J., Dracup, J.A., 2002. The Quantification of Drought: An Evaluation of Drought Indices. Bull. Am. Meteorol. Soc. 83, 1167-1180.

https://doi.org/10.1175/1520-0477-83.8.1167

Lake, P.S., (2011). Drought and aquatic ecosystems: effects and responses. John Wiley \& Sons.

Lake, P.S., (2003). Ecological effects of perturbation by drought in flowing waters. Freshw. Biol. 48, 1161-1172. https://doi.org/10.1046/j.1365-2427.2003.01086.x

Lawrence, D.M., Thornton, P.E., Oleson, K.W., Bonan, G.B., 2007. The Partitioning of Evapotranspiration into Transpiration, Soil Evaporation, and Canopy Evaporation in a GCM: Impacts on Land-Atmosphere Interaction. J. Hydrometeorol. 8, 862-880. https://doi.org/10.1175/JHM596.1

Leigh, C., Bush, A., Harrison, E.T., Ho, S.S., Luke, L., Rolls, R.J., Ledger, M.E., (2015). Ecological effects of extreme climatic events on riverine ecosystems: insights from Australia. Freshw. Biol. 60, 2620-2638. DOI: 10.1111/fwb.12515

Long, D., Scanlon, B.R., Longuevergne, L., Sun, A.Y., Fernando, D.N., Save, H., (2013). GRACE satellite monitoring of large depletion in water storage in response to the 2011 drought in Texas. Geophys. Res. Lett. 40, 3395-3401. https://doi.org/10.1002/grl.50655.

Lorenzo-Lacruz, J., Vincente-Serrano, S, M., Gonzalez-Hidalgo, J, C., Loperz-Moreno, J, I., Cortesi, N., 2013, Hydrological drought responses to meteorological drought in the Iberan Peninsula, Climate Research, 58(2), 117-131.

Liang, X., Lettenmaier, D.P., Wood, E.F., Burges, S.J., 1994. A simple hydrologically based model of land surface water and energy fluxes for general circulation models. J. Geophys. Res. Atmos. 99, 14415-14428. https://doi.org/doi:10.1029/94JD00483

Liao, C., Zhuang, Q., 2015. Reduction of Global Plant Production due to Droughts from 2001 to 2010: An Analysis with a Process-Based Global Terrestrial Ecosystem Model. Earth Interact. 19, 1-21. https://doi.org/10.1175/EI-D-14-0030.1

Liu, Y., Xiao, J., Ju, W., Zhou, Y., Wang, S., Wu, X., 2015. Water use efficiency of China's terrestrial ecosystems and responses to drought. Sci. Rep. 5, 13799.

Liu, Y.Y., Parinussa, R.M., Dorigo, W.A., De Jeu, R.A.M., Wagner, W., van Dijk, A.I.J.M., McCabe, M.F., Evans, J.P., 2011. Developing an improved soil moisture dataset by blending passive and active microwave satellite-based retrievals. Hydrol. Earth Syst. Sci. 15, 425-436. https://doi.org/10.5194/hess-15-425-2011

Livneh, B., Rosenberg, E.A., Lin, C., Nijssen, B., Mishra, V., Andreadis, K.M., Maurer, E.P., Lettenmaier, D.P., 2013. A Long-Term Hydrologically Based Dataset of Land Surface Fluxes and States for the Conterminous United States: Update and Extensions. J. Clim. 26, 9384-9392. https://doi.org/10.1175/JCLI-D-12-00508.1

Long, D., Scanlon, B.R., Longuevergne, L., Sun, A.Y., Fernando, D.N., Save, H., 2013. 
GRACE satellite monitoring of large depletion in water storage in response to the 2011 drought in Texas. Geophys. Res. Lett. 40, 3395-3401.

https://doi.org/doi:10.1002/grl.50655

Madadgar S, Moradkhani H (2014) Spatio-temporal drought forecasting within Bayesian networks. J Hydrol 512:134-146 . doi: 10.1016/j.jhydrol.2014.02.039

Madadgar S, Moradkhani H (2013) Drought Analysis under Climate Change Using Copula. J Hydrol Eng 18:746-759 . doi: 10.1061/(ASCE)HE.1943-5584.0000532

Madadgar, S, Moradkhani H. (2016), Copula Function and Drought, Handbook of Drought and Water Scarcity, Vol. 1: Principles of Drought and Water Scarcity, Francis and Taylor.

Martorell, S., DIAZ-ESPEJO, A., Medrano, H., Ball, M.C., Choat, B., (2014). Rapid hydraulic recovery in Eucalyptus pauciflora after drought: linkages between stem hydraulics and leaf gas exchange. Plant. Cell Environ. 37, 617-626.

DOI:10.1111/pce.12182

McEvoy, D.J., Huntington, J.L., Hobbins, M.T., Wood, A., Morton, C., Verdin, J., Anderson, M., Hain, C., (2016). The Evaporative Demand Drought Index: Part IICONUS-wide Assessment Against Common Drought Indicators. J. Hydrometeorol. 17, 1763-1779. https://doi.org/10.1175/JHM-D-15-0122.1

McKee, T.B., Doeskin, N.J., Kleist, J., (1993). The relationship of drought frequency and duration to time scales, in: 8th Conf. on Applied Climatology. Anaheim, Canada OR - Am. Meteorol. Soc., pp. 179-184.

McKinley, D.C., Ryan, M.G., Birdsey, R.A., Giardina, C.P., Harmon, M.E., Heath, L.S., Houghton, R.A., Jackson, R.B., Morrison, J.F., Murray, B.C., Pataki, D.E., Skog, K.E.,2011. A synthesis of current knowledge on forests and carbon storage in the United States. Ecol. Appl. 21 (6), 1902-1924.

Mensing, S., Smith, J., Norman, K.B., Allan, M., (2008). Extended drought in the Great Basin of western North America in the last two millennia reconstructed from pollen records. Quat. Int. 188, 79-89. https://doi.org/10.1016/j.quaint.2007.06.009.

Mimikou, M.A., Baltas, E., Varanou, E., Pantazis, K., (2000). Regional impacts of climate change on water resources quantity and quality indicators. J. Hydrol. 234, 95-109. https://doi.org/10.1016/S0022-1694(00)00244-4

Mo, K.C., (2011). Drought onset and recovery over the United States. J. Geophys. Res. Atmos. 116. https://doi.org/10.1029/2011JD016168

Mosley, L.M., (2015). Drought impacts on the water quality of freshwater systems; review and integration. Earth-Science Rev. 140, 203-214. https://doi.org/10.1016/j.earscirev.2014.11.010

Mosley, L.M., Zammit, B., Leyden, E., Heneker, T.M., Hipsey, M.R., Skinner, D., Aldridge, K.T., (2012). The impact of extreme low flows on the water quality of the 
Lower Murray River and Lakes (South Australia). Water Resour. Manag. 26, 3923 3946. https://doi.org/10.1007/s11269-012-0113-2

Mulholland, P.J., Best, G.R., Coutant, C.C., Hornberger, G.M., Meyer, J.L., Robinson, P.J., Stenberg, J.R., Turner, R.E., VERA-HERRERA, F., Wetzel, R.G., (1997). Effects of climate change on freshwater ecosystems of the south-eastern United States and the Gulf Coast of Mexico. Hydrol. Process. 11, 949-970. https://doi.org/10.1002/(SICI)1099-1085(19970630)11:8<949::AIDHYP513>3.0.CO;2-G

Murdoch, P.S., Baron, J.S., Miller, T.L., (2000). Potential effects of climate change on surface-water quality in North America. JAWRA J. Am. Water Resour. Assoc. 36, 347-366. https://doi.org/10.1111/j.1752-1688.2000.tb04273.x

Martínez-Fernández, J., González-Zamora, Á., Sanchez, N., Gumuzzio, A., HerreroJiménez, C., 2016. Satellite soil moisture for agricultural drought monitoring: Assessment of the SMOS derived Soil Water Deficit Index, Remote Sensing of Environment. https://doi.org/10.1016/j.rse.2016.02.064

Martorell, S., Diaz-espejo, A., Medrano, H., Ball, M.C., Choat, B., 2014. Rapid hydraulic recovery in Eucalyptus pauciflora after drought : linkages between stem hydraulics and leaf gas exchange 617-626. https://doi.org/10.1111/pce.12182

Maurer, E.P., Wood, A.W., Adam, J.C., Lettenmaier, D.P., Nijssen, B., 2002. A LongTerm Hydrologically Based Dataset of Land Surface Fluxes and States for the Conterminous United States. J. Clim. 15, 3237-3251. https://doi.org/10.1175/15200442(2002)015<3237:ALTHBD>2.0.CO;2

Mazdiyasni, O., Aghakouchak, A., 2015. Substantial increase in concurrent droughts and heatwaves in the United States 2015, 3-8. https://doi.org/10.1073/pnas.1422945112

Mishra, A., Vu, T., Veettil, A.V., Entekhabi, D., 2017. Drought monitoring with soil moisture active passive (SMAP) measurements. J. Hydrol. 552, 620-632. https://doi.org/https://doi.org/10.1016/j.jhydrol.2017.07.033

Mohammad, K., Behzad, A., Zahra, Z., 2013. Developing an Agricultural Planning Model in a Watershed Considering Climate Change Impacts. J. Water Resour. Plan. Manag. 139, 349-363. https://doi.org/10.1061/(ASCE)WR.1943-5452.0000263

Mu, Q., Heinsch, F.A., Zhao, M., Running, S.W., 2007. Development of a global evapotranspiration algorithm based on MODIS and global meteorology data. Remote Sens. Environ. 111, 519-536. https://doi.org/https://doi.org/10.1016/j.rse.2007.04.015

Mu, Q., Zhao, M., Running, S.W., 2013. Numerical Terradynamic Simulation Group MODIS Global Terrestrial Evapotranspiration ( ET ) Product ( NASA MOD16A2 / A3 ) Collection 5 . NASA Headquarters.

Mu, Q., Zhao, M., Running, S.W., 2011. Improvements to a MODIS global terrestrial evapotranspiration algorithm. Remote Sens. Environ. 115, 1781-1800. 
https://doi.org/https://doi.org/10.1016/j.rse.2011.02.019

Narasimhan, B., Srinivasan, R., 2005. Development and evaluation of Soil Moisture Deficit Index (SMDI) and Evapotranspiration Deficit Index (ETDI) for agricultural drought monitoring. Agric. For. Meteorol. 133, 69-88. https://doi.org/https://doi.org/10.1016/j.agrformet.2005.07.012

Nepstad, D.C., Stickler, C.M., Soares-filho, B., Merry, F., Nin, E., 2008. Interactions among Amazon land use, forests and climate : prospects for a near-term forest tipping point 1737-1746. https://doi.org/10.1098/rstb.2007.0036

Ning Zeng, Haifeng Qian, and E.M., 2004. How strong is carbon cycle-climate feedback under global warming? Geophys. Res. Lett. 31, 5. https://doi.org/10.1029/2004GL020904

Otkin, J.A., Svoboda, M., Hunt, E.D., Ford, T.W., Anderson, M.C., Hain, C., Basara, J.B., 2017. Flash Droughts: A Review and Assessment of the Challenges Imposed by Rapid-Onset Droughts in the United States. Bull. Am. Meteorol. Soc. 99, 911919. https://doi.org/10.1175/BAMS-D-17-0149.1

Parry, S., Wilby, R.L., Prudhomme, C., Wood, P.J., (2016b). A systematic assessment of drought termination in the United Kingdom. Hydrol. Earth Syst. Sci. 20, 4265. https://doi.org/10.5194/hess-20-4265-2016.

Paulson Jr, E.G., Sadeghipour, J., Dracup, J.A., (1985). Regional frequency analysis of multiyear droughts using watershed and climatic information. J. Hydrol. 77, 57-76.

Pan, M., Yuan, X., Wood, E.F., 2013. A probabilistic framework for assessing drought recovery. Geophys. Res. Lett. 40, 3637-3642. https://doi.org/10.1002/grl.50728

Parry, S., Prudhomme, C., Wilby, R.L., Wood, P.J., 2016. Drought termination : Concept and characterisation. https://doi.org/10.1177/0309133316652801

Pen, D. O., \& Eriods, W. A. P. (2000). L a /w t c o w p. Journal of Hydrologic Engineering, 5(July), 317-321.

Ponce-Campos, G.E., Moran, M.S., Huete, A., Zhang, Y., Bresloff, C., Huxman, T.E., Eamus, D., Bosch, D.D., Buda, A.R., Gunter, S.A., Scalley, T.H., Kitchen, S.G., McClaran, M.P., McNab, W.H., Montoya, D.S., Morgan, J.A., Peters, D.P.C., Sadler, E.J., Seyfried, M.S., Starks, P.J., 2013. Ecosystem resilience despite largescale altered hydroclimatic conditions. Nature 494, 349.

Qin, Y., Yang, D., Lei, H., Xu, K., Xu, X., 2015. Comparative analysis of drought based on precipitation and soil moisture indices in Haihe basin of North China during the period of 1960-2010. J. Hydrol. 526, 55-67.

https://doi.org/https://doi.org/10.1016/j.jhydrol.2014.09.068

Rebel, K.T., de Jeu, R.A.M., Ciais, P., Viovy, N., Piao, S.L., Kiely, G., Dolman, A.J., 2012. A global analysis of soil moisture derived from satellite observations and a land surface model. Hydrol. Earth Syst. Sci. 16, 833-847. 
https://doi.org/10.5194/hess-16-833-2012

Rippey, B.R., 2015. The U.S. drought of 2012. Weather Clim. Extrem. 10, 57-64. https://doi.org/https://doi.org/10.1016/j.wace.2015.10.004

RUNNING, S.W., NEMANI, R.R., HEINSCH, F.A.N.N., ZHAO, M., REEVES, M., HASHIMOTO, H., 2004. A Continuous Satellite-Derived Measure of Global Terrestrial Primary Production. Bioscience 54, 547-560. https://doi.org/10.1641/0006-3568(2004)054[0547:ACSMOG]2.0.CO;2

Rippey, B.R., (2015). The US drought of 2012. Weather Clim. Extrem. 10, 57-64. https://doi.org/10.1016/j.wace.2015.10.004.

Ryan, M.G., Harmon, M.E., Birdsey, R.A., Giardina, C.P., Heath, L.S., Houghton, R.A., Jackson, R.B., McKinley, D.C., Morrison, J.F., 2010. A synthesis of the science on forests and carbon for U.S. forests. Issues Ecol. 13, 1-16.

Sawada, Y., Koike, T., (2016). Towards ecohydrological drought monitoring and prediction using a land data assimilation system: A case study on the Horn of Africa drought (2010-2011). J. Geophys. Res. Atmos. 121, 8229-8242. https://doi.org/10.1002/2015JD024705.

Secchi, F., Zwieniecki, M.A., (2014). Down-regulation of PIP1 aquaporin in poplar trees is detrimental to recovery from embolism. Plant Physiol. pp-114. DOI: https://doi.org/10.1104/pp.114.237511

Shiau, J.-T., Shen, H.W., (2001). Recurrence analysis of hydrologic droughts of differing severity. J. Water Resour. Plan. Manag. 127, 30-40. https://doi.org/10.1061/(ASCE)0733-9496(2001)127:1(30)

Sinha, E., Michalak, A. M., \& Balaji, V. (2017). Eutrophication will increase during the 21 st century as a result of precipitation changes. Science, 357(6349), 405-408

Spinoni, J., Naumann, G., Carrao, H., Barbosa, P., Vogt, J., (2014). World drought frequency, duration, and severity for 1951-2010. Int. J. Climatol. 34, 2792-2804. https://doi.org/10.1002/joc.3875

Sprague, L.A., (2005). Drought effects on water quality in the South Platte River Basin, Colorado. JAWRA J. Am. Water Resour. Assoc. 41, 11-24. DOI: 10.1111/j.17521688.2005.tb03713.x

Sung, J.H., Chung, E.-S., (2014). Development of streamflow drought severity-durationfrequency curves using the threshold level method. Hydrol. Earth Syst. Sci. 18, 3341-3351. https://doi.org/10.5194/hess-18-3341-2014

Sun, G., Alstad, K., Chen, J., Chen, S., Ford, C.R., Lin, G., Liu, C., Lu, N., McNulty, S.G., Miao, H., Noormets, A., Vose, J.M., Wilske, B., Zeppel, M., Zhang, Y., Zhang, Z., 2011a. A general predictive model for estimating monthly ecosystem evapotranspiration. Ecohydrology 4, 245-255. http://dx.doi.org/10.1002/ eco.194.

Sun, G., Caldwell, P., Noormets, A., Cohen, E., McNulty, S., Treasure, E., Domec, J.C., 
Mu, Q., Xiao J, John, R., Chen, J., 2011b. Upscaling key ecosystem functions across the conterminous United States by a water-centric ecosystem model. Journal of Geophysical Research 116 (G00J05) http://dx.doi.org/10.1029/2010JG001573.

Sun, G., Caldwell, P.V., McNulty, S.G., 2015a. Modeling the potential role of forest thinning in maintaining water supplies under a changing climate across the Conterminous United States. Hydrol. Process. http://dx.doi.org/10.1002/ hyp.10469. Sun, S., Sun, G., Caldwell P., McNulty, S.G., Mack, E., Xiao, J., Zhang, Y., 2015b. Drought Impacts on Ecosystem Functions of the U.S. National Forests and Grasslands: Part II Model Application and Results Analysis. Forest Ecol. Manage.

Svoboda, M., LeComte, D., Hayes, M., Heim, R., Gleason, K., Angel, J., Rippey, B., Tinker, R., Palecki, M., Stooksbury, D., Miskus, D., Stephens, S., (2002). The drought monitor. Bull. Am. Meteorol. Soc. 83(8). DOI: 10.1175/15200477(2002)083<1181:TDM>2.3.CO;2

SWAMP, (2010), The Clean Water Team Guidance Compendium for Watershed Monitoring and Assessment State Water Resources Control Board, Section 3, Introduction to vital signs (SOP 3.1.0).

Schwalm, C.R., Anderegg, W.R.L., Michalak, A.M., Fisher, J.B., Biondi, F., Koch, G., Litvak, M., Ogle, K., Shaw, J.D., Wolf, A., Huntzinger, D.N., Schaefer, K., Cook, R., 2017. Global patterns of drought recovery. Nat. Publ. Gr. 548, 202-205. https://doi.org/10.1038/nature23021

Schwalm, C.R., Williams, C.A., Schaefer, K., Baldocchi, D., Black, T.A., Goldstein, A.H., Law, B.E., Oechel, W.C., Paw U, K.T., Scott, R.L., 2012. Reduction in carbon uptake during turn of the century drought in western North America. Nat. Geosci. 5, 551.

Schwingshackl, C., Hirschi, M., Seneviratne, S.I., 2017. Quantifying Spatiotemporal Variations of Soil Moisture Control on Surface Energy Balance and Near-Surface Air Temperature. J. Clim. 30, 7105-7124. https://doi.org/10.1175/JCLI-D-16-0727.1

Seager, R., Goddard, L., Nakamura, J., Henderson, N., Lee, D.E., 2013. Dynamical Causes of the 2010/11 Texas-Northern Mexico Drought. J. Hydrometeorol. 15, 3968. https://doi.org/10.1175/JHM-D-13-024.1

Secchi, F., Zwieniecki, M.A., 2014. Down-Regulation of Plasma Intrinsic Protein1 Aquaporin in Poplar Trees Is Detrimental to Recovery from Embolism 1 [ C ][ W ] 164, 1789-1799. https://doi.org/10.1104/pp.114.237511

Seneviratne, S.I., Lehner, I., Gurtz, J., Teuling, A.J., Lang, H., Moser, U., Grebner, D., Menzel, L., Schroff, K., Vitvar, T., Zappa, M., 2012. Swiss prealpine Rietholzbach research catchment and lysimeter: 32 year time series and 2003 drought event. Water Resour. Res. 48. https://doi.org/doi:10.1029/2011WR011749

Sheffield, J., Goteti, G., Wen, F., Wood, E.F., 2004. A simulated soil moisture based drought analysis for the United States. J. Geophys. Res. Atmos. 109. https://doi.org/doi:10.1029/2004JD005182 
Sheffield, J., Wood, E.F., 2008. Global Trends and Variability in Soil Moisture and Drought Characteristics, 1950-2000, from Observation-Driven Simulations of the Terrestrial Hydrologic Cycle. J. Clim. 21, 432-458. https://doi.org/10.1175/2007JCLI1822.1

Shukla, S., Steinemann, A.C., Lettenmaier, D.P., 2010. Drought Monitoring for Washington State: Indicators and Applications. J. Hydrometeorol. 12, 66-83. https://doi.org/10.1175/2010JHM1307.1

Stegehuis, A.I., Vautard, R., Ciais, P., Teuling, A.J., Jung, M., Yiou, P., 2013. Summer temperatures in Europe and land heat fluxes in observation-based data and regional climate model simulations. Clim. Dyn. 41, 455-477. https://doi.org/10.1007/s00382012-1559-x

Tang, X., Li, H., Desai, A.R., Nagy, Z., Luo, J., Kolb, T.E., Olioso, A., Xu, X., Yao, L., Kutsch, W., Pilegaard, K., Köstner, B., Ammann, C., 2014. How is water-use efficiency of terrestrial ecosystems distributed and changing on Earth? Sci. Rep. 4, 7483.

Tang, X., Li, H., Xu, X., Luo, J., Li, X., Ding, Z., Xie, J., 2016. Potential of MODIS data to track the variability in ecosystem water-use efficiency of temperate deciduous forests. Ecol. Eng. 91, 381-391. https://doi.org/10.1016/j.ecoleng.2016.02.022

Teuling, A.J., Loon, A.F. Van, Seneviratne, S.I., Lehner, I., Aubinet, M., Heinesch, B., Bernhofer, C., Grünwald, T., Prasse, H., Spank, U., 2015a. Evapotranspiration ampli fi es European summer drought 40, 2071-2075. https://doi.org/10.1002/grl.50495

Teuling, A.J., Loon, A.F. Van, Seneviratne, S.I., Lehner, I., Aubinet, M., Heinesch, B., Bernhofer, C., Grünwald, T., Prasse, H., Spank, U., 2015b. Evapotranspiration ampli fi es European summer drought. Geophys. Res. Lett. 40, 2071-2075. https://doi.org/10.1002/grl.50495

Teuling, A.J., Seneviratne, S.I., Stöckli, R., Reichstein, M., Moors, E., Ciais, P., Luyssaert, S., van den Hurk, B., Ammann, C., Bernhofer, C., Dellwik, E., Gianelle, D., Gielen, B., Grünwald, T., Klumpp, K., Montagnani, L., Moureaux, C., Sottocornola, M., Wohlfahrt, G., 2010. Contrasting response of European forest and grassland energy exchange to heatwaves. Nat. Geosci. 3, 722.

Turner, D.P., Ritts, W.D., Cohen, W.B., Gower, S.T., Running, S.W., Zhao, M., Costa, M.H., Kirschbaum, A.A., Ham, J.M., Saleska, S.R., Ahl, D.E., 2006. Evaluation of MODIS NPP and GPP products across multiple biomes. Remote Sens. Environ. 102, 282-292. https://doi.org/https://doi.org/10.1016/j.rse.2006.02.017

Tallaksen, L.M., Madsen, H., Clausen, B., (1997). On the definition and modelling of streamflow drought duration and deficit volume. Hydrol. Sci. J. 42, 15-33. https://doi.org/10.1080/02626669709492003

Thomas, A.C., Reager, J.T., Famiglietti, J.S., Rodell, M., (2014). A GRACE-based water storage deficit approach for hydrological drought characterization. Geophys. Res. Lett. 41, 1537-1545. https://doi.org/10.1002/2014GL059323 
Velpuri, N.M., Senay, G.B., Singh, R.K., Bohms, S., Verdin, J.P., 2013. A comprehensive evaluation of two MODIS evapotranspiration products over the conterminous United States: Using point and gridded FLUXNET and water balance ET. Remote Sens. Environ. 139, 35-49. https://doi.org/https://doi.org/10.1016/j.rse.2013.07.013

Vereecken, H., Huisman, J.A., Bogena, H., Vanderborght, J., Vrugt, J.A., Hopmans, J.W., 2008. On the value of soil moisture measurements in vadose zone hydrology: A review. Water Resour. Res. 44. https://doi.org/doi:10.1029/2008WR006829

Vicente-Serrano, S.M., Gouveia, C., Camarero, J.J., Beguerl’lia, S., Trigo, R., LópezMoreno, J.I., Azorl'lin-Molina, C., Pasho, E., Lorenzo-Lacruz, J., Revuelto, J., Morán-Tejeda, E., Sanchez-Lorenzo, A., 2013. Response of vegetation to drought time-scales across global land biomes. Proc. Natl. Acad. Sci. 110, 52-57. https://doi.org/10.1073/pnas.1207068110

Van Loon, A.F., Laaha, G., (2015). Hydrological drought severity explained by climate and catchment characteristics. J. Hydrol. 526, 3-14. https://doi.org/10.1016/j.jhydrol.2014.10.059

Van Loon, A.F., Van Lanen, H.A.J., (2012). A process-based typology of hydrological drought. Hydrol. Earth Syst. Sci. 16, 1915. https://doi.org/10.5194/hess-16-19152012

Van Vliet, M.T.H., Zwolsman, J.J.G., (2008). Impact of summer droughts on the water quality of the Meuse river. J. Hydrol. 353, 1-17. https://doi.org/10.1016/j.jhydrol.2008.01.001

Van Vliet, M. T. H., Franssen, W. H. P., Yearsley, J. R., Ludwig, F., Haddeland, I., Lettenmaier, D. P., \& Kabat, P. (2013). Global river discharge and water temperature under climate change. Global Environmental Change, 23(2), 450-464. http://doi.org/10.1016/j.gloenvcha.2012.11.002

Vicente-Serrano, S.M., Beguería, S., López-Moreno, J.I., (2010). A Multiscalar Drought Index Sensitive to Global Warming: The Standardized Precipitation Evapotranspiration Index. J. Clim. 23, 1696-1718. https://doi.org/10.1175/2009JCLI2909.1

Wang, H., Schubert, S., Koster, R., Ham, Y.-G., Suarez, M., 2014. On the Role of SST Forcing in the 2011 and 2012 Extreme U.S. Heat and Drought: A Study in Contrasts. J. Hydrometeorol. 15, 1255-1273. https://doi.org/10.1175/JHM-D-13069.1

Wagner, W., Scipal, K., Pathe, C., Gerten, D., Lucht, W., Rudolf, B., 2003. Evaluation of the agreement between the first global remotely sensed soil moisture data with model and precipitation data. J. Geophys. Res. Atmos. 108. https://doi.org/doi:10.1029/2003JD003663

Wilbers, G. J., Zwolsman, G., Klaver, G., \& Hendriks, A. J. (2009). Effects of a drought period on physico-chemical surface water quality in a regional catchment area. 
Journal of Environmental Monitoring, 11(6), 1298-1302.

http://doi.org/10.1039/b816109g

Wolf, S., Keenan, T.F., Fisher, J.B., Baldocchi, D.D., Desai, A.R., Richardson, A.D., Scott, R.L., Law, B.E., Litvak, M.E., Brunsell, N.A., Peters, W., van der LaanLuijkx, I.T., 2016. Warm spring reduced carbon cycle impact of the 2012 US summer drought. Proc. Natl. Acad. Sci. 113, 5880-5885. https://doi.org/10.1073/pnas.1519620113

Wong, G., Van Lanen, H.A.J., Torfs, P., (2013). Probabilistic analysis of hydrological drought characteristics using meteorological drought. Hydrol. Sci. J. 58, 253-270. https://doi.org/10.1080/02626667.2012.753147

Wood, E.F., Lettenmaier, D., Liang, X., Nijssen, B., Wetzel, S.W., 1997. HYDROLOGICAL MODELING OF CONTINENTAL-SCALE BASINS. Annu. Rev. Earth Planet. Sci. 25, 279-300. https://doi.org/10.1146/annurev.earth.25.1.279

Wu, J., Xingwei Chen, Lu Gao, Huaxia Yao, Ying Chen, and Meibing Liu, "Response of Hydrological Drought to Meteorological Drought under the Influence of Large Reservoir," Advances in Meteorology, vol. 2016, Article ID 2197142, 11 pages, 2016. https://doi.org/10.1155/2016/2197142.

Xia, Y., Mitchell, K., Ek, M., Cosgrove, B., Sheffield, J., Luo, L., Alonge, C., Wei, H., Meng, J., Livneh, B., Duan, Q., Lohmann, D., 2012. Continental-scale water and energy flux analysis and validation for North American Land Data Assimilation System project phase 2 (NLDAS-2): 2. Validation of model-simulated streamflow. J. Geophys. Res. Atmos. 117. https://doi.org/doi:10.1029/2011JD016051

Xiao, J., Zhuang, Q., Law, B.E., Chen, J., Baldocchi, D.D., Cook, D.R., Oren, R., Richardson, A.D., Wharton, S., Ma, S., Martin, T.A., Verma, S.B., Suyker, A.E., Scott, R.L., Monson, R.K., Litvak, M., Hollinger, D.Y., Sun, G., Davis, K.J., Bolstad, P. V, Burns, S.P., Curtis, P.S., Drake, B.G., Falk, M., Fischer, M.L., Foster, D.R., Gu, L., Hadley, J.L., Katul, G.G., Matamala, R., Mcnulty, S., Meyers, T.P., Munger, J.W., Noormets, A., Oechel, W.C., Tha, K., Paw, U., Peter, H., Starr, G., Torn, M.S., Wofsy, S.C., 2010. Remote Sensing of Environment A continuous measure of gross primary production for the conterminous United States derived from MODIS and AmeriFlux data. Remote Sens. Environ. 114, 576-591. https://doi.org/10.1016/j.rse.2009.10.013

Xiao, J., Zhuang, Q., Baldocchi, D.D., Law, B.E., Richardson, A.D., Chen, J., Oren, R., Starr, G., Noormets, A., Ma, S., Verma, S.B., Wharton, S., Wofsy, S.C., Bolstad, P.V., Burns, S.P., Cook, D.R., Curtis, P.S., Drake, B.G., Falk, M., Fischer, M.L., Foster, D.R., Gu, L., Hadley, J.L., Hollinger, D.Y., Katul, G.G., Litvak, M., Martin, T.A., Matamala, R., McNulty, S., Meyers, T.P., Monson, R.K., Munger, J.W., Oechel, W.C., Paw, U.K.T., Schmid, H.P., Scott, R.L., Su, G., Suyker, A.E., Torn, M.S., 2008. Estimation of net ecosystem carbon exchange for the conterminous United States by combining MODIS and AmeriFlux data. Agric. For. Meteorol. 148, $1827-1847$. 
Xiao, J., Zhuang, Q., Law, B.E., Baldocchi, D.D., Chen, J., Richardson, A.D., Melillog, J.M., Davish, K.J., Hollingeri, D.Y., Wharton, S., Orenk, R., Noormets, R., Fischerm, M.L., Verman, S.B., Cooko, D.R., Sun, G., McNulty, S., Wofsy, S.C., Bolstad, P.V., Burns, S.P., Curtis, P.S., Drake, B.G., Falk, M., Fosterv, D.R., Gu, L., Hadley, J.L., Katul, G.G., Litvaky, M., Ma, S., Martin, T.A., Matamala, R., Meyers, T.P., Monsons, R.K., 2011. Assessing net ecosystem carbon exchange of U.S. terrestrial ecosystems by integrating eddy covariance flux measurements and satellite observations. Agric. For. Meteorol. 151, 60-69.

$\mathrm{Xu}, \mathrm{X} ., \mathrm{Li}, \mathrm{J} .$, Tolson, B.A., 2014. Progress in integrating remote sensing data and hydrologic modeling. Prog. Phys. Geogr. Earth Environ. 38, 464-498. https://doi.org/10.1177/0309133314536583

Xue, B.-L., Guo, Q., Otto, A., Xiao, J., Tao, S., Li, L., 2015. Global patterns, trends, and drivers of water use efficiency from 2000 to 2013. Ecosphere 6, art174. https://doi.org/doi:10.1890/ES14-00416.1

Yan, H., Moradkhani, H., Zarekarizi, M., 2017. A probabilistic drought forecasting framework: A combined dynamical and statistical approach. J. Hydrol. 548, $291-$ 304. https://doi.org/https://doi.org/10.1016/j.jhydrol.2017.03.004

Ylla, I., Sanpera-Calbet, I., Vázquez, E., Romaní, A.M., Muñoz, I., Butturini, A., Sabater, S., (2010). Organic matter availability during pre-and post-drought periods in a Mediterranean stream. Hydrobiologia 657, 217-232. https://doi.org/10.1007/s10750010-0193-z.

Yu, Z., Wang, J., Liu, S., Rentch, J.S., Sun, P., Lu, C., (2017). Global gross primary productivity and water use efficiency changes under drought stress Global gross primary productivity and water use efficiency changes under drought stress. Environ. Res. Lett. 12. https://doi.org/10.1088/1748-9326/aa5258

Yan, H., Zarekarizi, M., Moradkhani, H., 2018. Toward improving drought monitoring using the remotely sensed soil moisture assimilation: A parallel particle filtering framework. Remote Sens. Environ. 216, 456-471. https://doi.org/https://doi.org/10.1016/j.rse.2018.07.017

Yang, F., Ichii, K., White, M.A., Hashimoto, H., 2007. Developing a continental-scale measure of gross primary production by combining MODIS and AmeriFlux data through Support Vector Machine approach. https://doi.org/10.1016/j.rse.2007.02.016

Yang, Y., Guan, H., Batelaan, O., Mcvicar, T.R., Long, D., Piao, S., Liang, W., Liu, B., Jin, Z., Simmons, C.T., 2016. Contrasting responses of water use efficiency to drought across global terrestrial ecosystems. Nat. Publ. Gr. 1-8. https://doi.org/10.1038/srep23284

Yu, Z., Wang, J., Liu, S., Rentch, J.S., Sun, P., Lu, C., 2017. Global gross primary productivity and water use efficiency changes under drought stress Global gross primary productivity and water use efficiency changes under drought stress. 
Environ. Res. Lett. 12. https://doi.org/10.1088/1748-9326/aa5258

Zargar, A., Sadiq, R., Naser, B., Khan, F.I., 2011. A review of drought indices. Environ. Rev. 19, 333-349. https://doi.org/10.1139/a11-013

Zhang, X., Moran, M.S., Zhao, X., Liu, S., Zhou, T., Ponce-campos, G.E., Liu, F., 2014. Remote Sensing of Environment Impact of prolonged drought on rainfall use ef fi ciency using MODIS data across China in the early 21st century. Remote Sens. Environ. 150, 188-197. https://doi.org/10.1016/j.rse.2014.05.003

ZIELIŃSKI, P., Gorniak, A., Piekarski, M.K., (2009). The effect of hydrological drought on chemical quality of water and dissolved organic carbon concentrations in lowland rivers. Pol. J. Ecol 57 No.2 pp.217-227 ref.28.

Zhao, M., Heinsch, F.A., Nemani, R.R., Running, S.W., 2005. Improvements of the MODIS terrestrial gross and net primary production global data set. Remote Sens. Environ. 95, 164-176. https://doi.org/https://doi.org/10.1016/j.rse.2004.12.011

Zhao, M., Running, S.W., 2010. Drought-Induced Reduction in Global Terrestrial Net Primary Production from 2000 Through 2009. Science (80-. ). 329, 940-943. https://doi.org/10.1126/science.1192666

Zscheischler, J., Mahecha, M.D., von Buttlar, J., Harmeling, S., Jung, M., Rammig, A., Randerson, J.T., Schölkopf, B., Seneviratne, S.I., Tomelleri, E., Zaehle, S., Reichstein, M., 2014. A few extreme events dominate global interannual variability in gross primary production. Environ. Res. Lett. 9, 35001. 